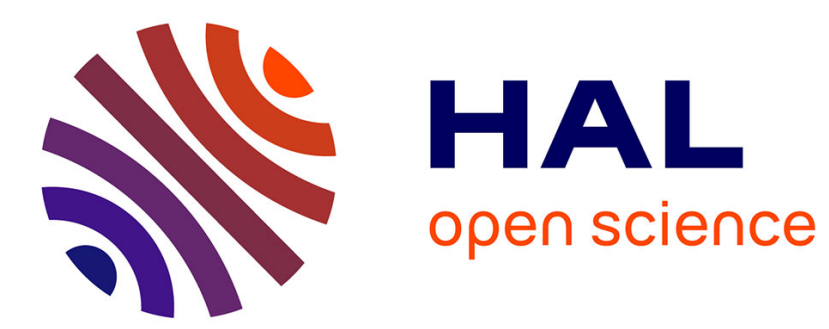

\title{
Le tumulus I de Colmar-Riedwihr (Haut-Rhin)
}

Charles Bonnet, Suzanne Plouin, François Lambach

\section{To cite this version:}

Charles Bonnet, Suzanne Plouin, François Lambach. Le tumulus I de Colmar-Riedwihr (HautRhin). Gallia - Fouilles et monuments archéologiques en France métropolitaine, 1991, 48, pp.13-57. 10.3406/galia.1991.2916 . hal-01912677

\section{HAL Id: hal-01912677 https://hal.science/hal-01912677}

Submitted on 19 Jan 2020

HAL is a multi-disciplinary open access archive for the deposit and dissemination of scientific research documents, whether they are published or not. The documents may come from teaching and research institutions in France or abroad, or from public or private research centers.
L'archive ouverte pluridisciplinaire HAL, est destinée au dépôt et à la diffusion de documents scientifiques de niveau recherche, publiés ou non, émanant des établissements d'enseignement et de recherche français ou étrangers, des laboratoires publics ou privés.

\section{(이) $\$$}

Distributed under a Creative Commons Attribution - NonCommercial - NoDerivatives $\mid 4.0$ 


\title{
Le tumulus I de Colmar-Riedwihr (Haut-Rhin)
}

\author{
par Charles BONNET*, Suzanne PLOUIN** et François LAMBACH
}

III Le tertre de Riedwihr I appartient à un groupe de deux tertres situés à l'extrémité sud du ried CentreA. ace, sur le ban de la ville de Colmar, au nord du village de Riedwihr en bordure du CD 45. Il s'agit d'un g1..ild tertre d'environ $40 \mathrm{~m}$ de diamètre, très bas $(55 \mathrm{~cm})$, édifié sur un substrat de graviers à l'aide de la terre (r:irileuse noirâtre environnante. A l'intérieur de l'aire délimitée par un fossé circulaire ouvert à l'est - sud-est, le tertre a fourni les restes de 28 sépultures disposées tangentiellement au fossé ainsi que de nombreux restes hựnains remaniés. Édifić vraiscmblablement dès le Bronze moyen, mais utilisé essentiellement à la période hălstattienne, le tertre a livré une riche tombe centrale avec poignard à antennes.

Riedwihr I belongs to a cluster of two barrows localised at the southern limit of the "ried Centre-Alsace" on the territory of the city of Colmar, north of the village of Riedwihr, along the CD 45. It is a large barrow of about 40 meters of diameter, very flat $(55 \mathrm{~cm})$ edificated on the gravel made with the clay from the surrounding ground. In the area limited by a circular ditch open in the east-south-east, the barrow has revealed the remains of 28 burial grounds ordered around the ditch and many displaced human remains. This barrow was probably edificated in the middle Bronze Age, and was especially used in the Hallstatt period. A rich midland burrial contening a dagger has been discovered in this mound.

Mots clés : tertre, Hallstatt, poignard à antennes, sépulture, fossé, organisation interne, cercueil, rite funéraire, anthropologie de terrain.

* Professeur honoraire à l'École normale.

** Chargé des collections archéologiques au musée d'Unterlinden de Colmar, Conservateur du musée gallo-romain de Biesheim.

*** Docteur en médecine, URA 376 du C.NRS, Laboratoire d'anthropologie, Université de Bordeaux I. 


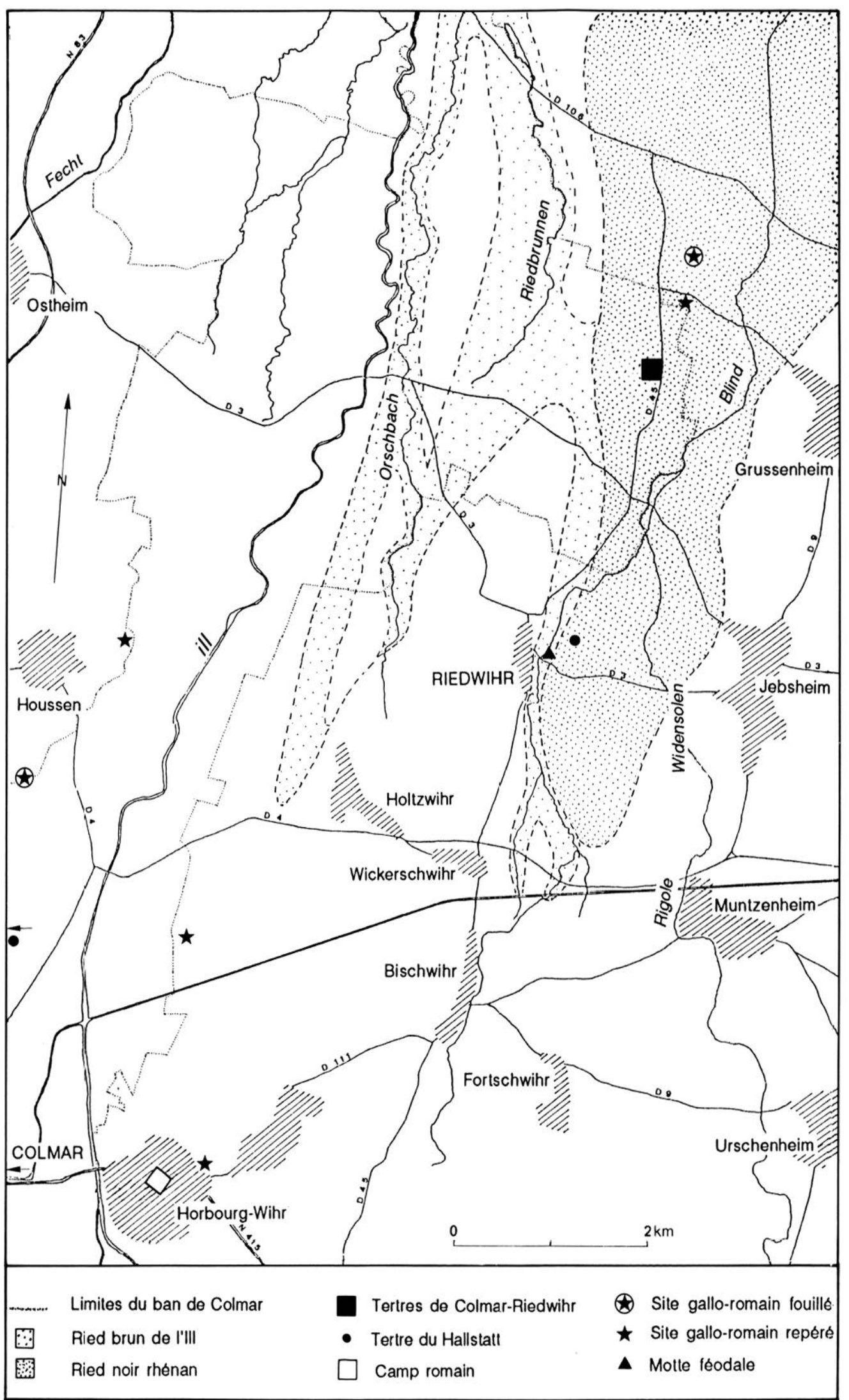

Fig. 1 - Plan de situation et environnement de la nécropole. 
A $3 \mathrm{~km}$ à vol d'oiseau au nord de Riedwihr, au bord de la route départementale 45 reliant le village à Illhaeusern, se trouvent deux tertres (fig. 1). Nous les avons appelés Colmar-Riedwihr, bien qu'ils soient éloignés de $15 \mathrm{~km}$ de la ville, car ils se trouvent encore à l'intérieur de son ban qui s'étend fort loin vers le nord. Ces tertres, menacés d'arasement, ont été fouillés de 1984 à 1989 par l'équipe archéologique de Colmar ${ }^{1}$.

\section{LA NÉCROPOLE ET SON ENVIRONNEMENT}

\section{Le Ried}

La localité de Riedwihr est située à l'extrémité sud du Ried Centre-Alsace. Il s'agit d'une portion de la plaine située entre l'Ill et le Rhin, qui s'étend vers le nord jusqu'au-delà d'Erstein. C'est une zone de subsidence, où la surface du sol est très proche de la nappe phréatique. Lors des pluies d'automne et surtout lors de la fonte des neiges au printemps, le Ried subit des inondations prolongées plus ou moins étendues. Les rapports entre le sol et la nappe souterraine ainsi que l'origine variée des alluvions (IIl ou Rhin) ont entraîné la formation de divers types de sols, caractérisés par les termes de Ried noir, Ried gris et Ried brun. Les tertres sont implantés dans le Ried noir rhénan, où une couche plus ou moins épaisse d'un sol argilo-tourbeux de couleur noire repose sur un substrat formé de nappes de graviers de petit calibre. Ce substrat n'est pas tout à fait horizontal; il est marqué par des ondulations dues à la présence de berges fossiles d'anciens bras du Rhin.

\section{L'archéologie dans le Ried}

L'image archéologique habituelle du Ried est très contradictoire. Les inondations ont refoulé les habitats, aussi bien ceux du passé que ceux d'aujourd'hui, vers les bordures un peu surélevées et le sol jadis impropre aux cultures a longtemps fait du Ried une zone répulsive, même si elle n'est pas dénuée de ressources: élevage, pêche et surtout chasse (c'est encore aujourd'hui la région la plus giboyeuse d'Alsace). Aussi avait-on coutume d'écrire

1 . Nous tenons à remercier très vivement tous les bénévoles qui ont participé aux différentes campagnes de fouilles: $M^{\text {mes }}$ Besnehard, Blisch, Boesch, Lichtlé, Kœnig et Pernet, MM. Blisch, Boes, Boesch, Bourra, Bucher, Jeaneau, Piningre, Plouin et Wagner. Tous nos remerciements aussi à M. G. Bischoff et aux èlèves-maîtres de l'École normale de Colmar, ainsi qu'à Agnès Fontaine qui a effectué le dessin du poignard en fer. que le Ried sépare, à la façon d'un no man's land la Haute Alsace de la Basse Alsace, qu'il n'a été occupé que très tardivement (à partir du milieu de l'Age du Fer seulement) et que l'établissement de tertres funéraires n'était motivé que par le désir de ne pas encombrer les bonnes terres. Ajoutons que la permanence des prairies et l'absence de constructions expliquent la rareté des découvertes fortuites en dehors de celles faites dans les tertres bien visibles dans le paysage.

Le Ried se singularise en effet par une étonnante densité en tertres funéraires. Soit isolés, soit le plus souvent groupés, ils se situent le long de deux cours d'eau, l'un presque en prolongement de l'autre: la Zembs au nord de Sélestat, la Blind au sud de cette ville. Alimentés par des résurgences de l'Ill, ces cours d'eau doivent être considérés comme d'anciens bras de l'Ill, voire comme son ancien cours. Dans la mesure où ces rivières devaient être plus favorables à la navigation que le Rhin, on peut affirmer que toutes les nécropoles tumulaires s'implantaient le long d'une importante voie de communication.

Les fouilles anciennes ont èté peu nombreuses et les seuls objets recueillis consistent en pièces tardives, bracelets à tampons sphériques caractéristiques du Hallstatt $\mathrm{D}$ régional ou torques à médaillons de La Tène ancienne. C'est grâce à de telles pièces qu'on a voulu prouver le peuplement tardif $d u$ Ried.

Quelques fouilles récentes renouvellent la physionomie archćologique du Ried. Près d'Obenheim, plusieurs tertres attestent une occupation du secteur dès le Bronze moyen (Pétry, 1984 et fouilles M. Lasserre, inédites). Pour les Ages du Fer, d'importants compléments ont été apportés par les tumulus de Mussig (Plouin et alii, 1986) et d'Herbsheim (Lasserre, Legendre, 1987).

\section{La carte archéologique des environs de Riedwihr (fig. 1)}

Hormis les sites gallo-romains de Horbourg et le tertre hallstattien situé au nord de Colmar (Bonnet, 1972; Plouin, 1987), la partie méridionale du Ried est pratiquement déserte : mentionnons une motte féodale à côté d'un ancien gué sur la Blind (immédiatement à l'est de Riedwihr, non fouillée), des implantations gallo-romaines au nord-ouest de Grussenheim (Bonnet, Lambach, Plouin, 1983) et l'extrémité sud de l'alignement de tertres longeant la Blind. Deux bracelets de bronze à décor géométrique étiquetés "Jebsheim" sont conservés au Musée de 


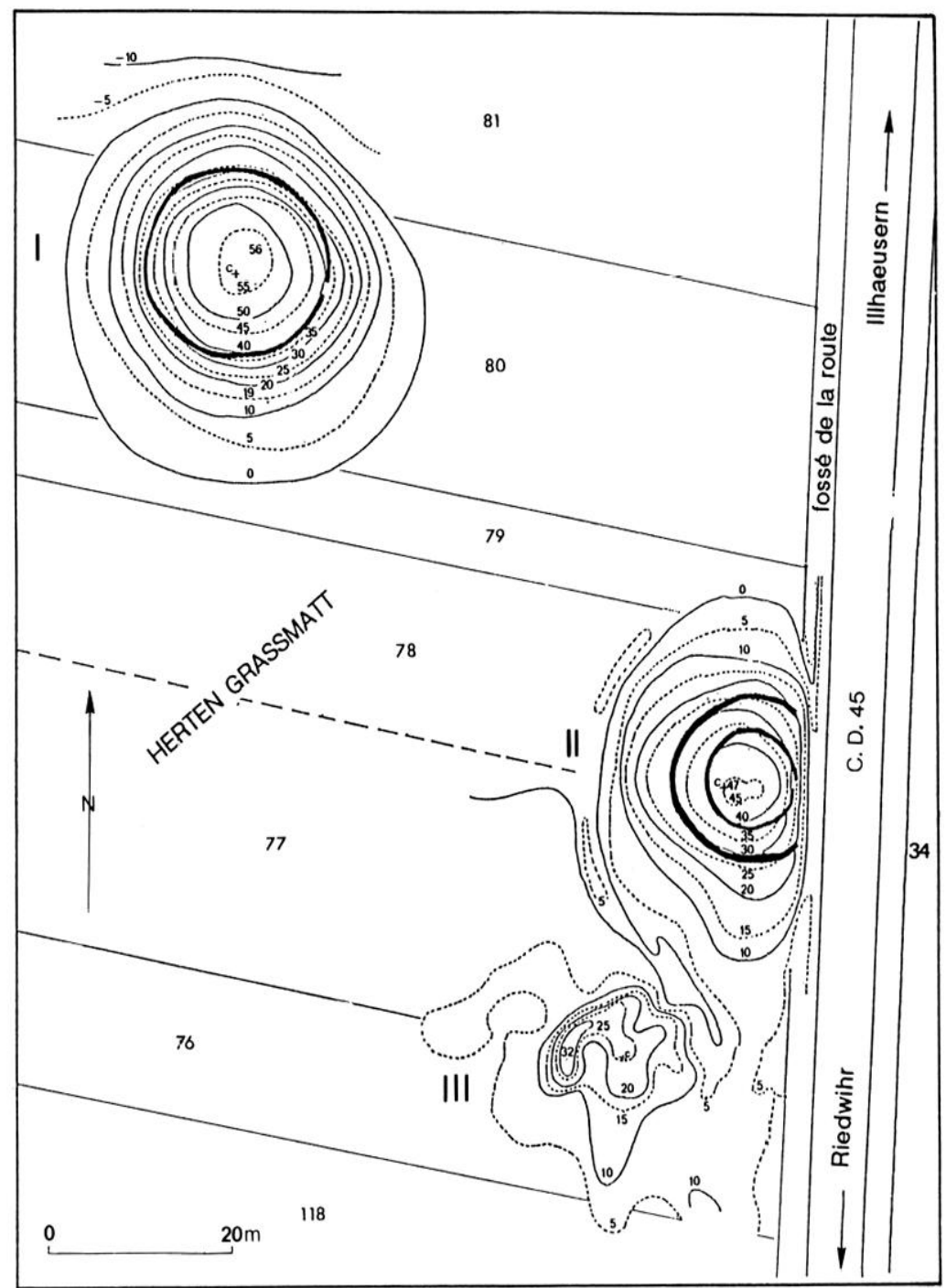

Fig. $2-$

Plan de la nécropole (altitude $179 \mathrm{~m}$ ).

Colmar. Malgré l'absence de toute publication, il est possible qu'ils proviennent d'un tertre fouillé anciennement dans le bois de Jebsheim, à l'est de Riedwihr.

\section{La nécropole de Riedwihr (fig. 2)}

Dans une lettre de 1847, mentionnée par A. W. Naue (1905, p. 389), le maire de Riedwihr signalait l'existence de "trois tumulus dans les prés sur la Blind, au canton Hoerten nommé Hoevel». Un quatrième aurait déjà été nivelé et "il s'y trouvait des ossements d'un homme de grande taille". Il s'agit là des tertres de Riedwihr; en effet, si le secteur est dénommé "Herten Grassmatt", sur le cadastre actuel, il portait le nom de "Grusenhubel" (Hubel $=$ Hoevel $=$ butte) sur le cadastre napoléonien (1815).
La nécropole actuelle se compose de deux tertres, espacés de $75 \mathrm{~m}$ de centre à centre. Leurs hauteurs sont très faibles ( 55 et $45 \mathrm{~cm}$ ), leurs pentes très douces et leurs diamètres difficiles à fixer avec précision. La troisième butte, mentionnée comme tertre au siècle dernier et encore visible actuellement, correspond en fait à une accumulation de terre pour laquelle nous n'avons pas d'explication, mais qui ne peut être que récente. Grâce à un vaste décapage, nous avons constaté que cette butte, située à $50 \mathrm{~m}$ environ de la route, recouvrait un chemin longeant un fossé se dirigeant vers le nord et passant à proximité du tertre II. Des fossés plus petits, confluant dans le grand fossé, permettent de conclure à un ancien système de drainage : en effet la carte allemande antérieure à 1914 (Messtischblatt de Guémar, $50000^{\mathrm{e}}$ ) présente des structures similaires, affectant de façon localisée certains endroits du Ried. 


\section{LE TERTRE I :}

\section{DÉCOUVERTES ET STRUCTURES INTERNES}

A l'intérieur d'un espace délimité par un fossé circulaire, le tertre a livré les restes d'au moins 34 sujets (sous forme de tombes en place mais aussi de nombreux ossements humains isolés correspondant à des tombes remaniées), quelques poteries isolées, ainsi qu'une fosse contenant des vestiges organiques et des ossements animaux. Dans le fossé même, se trouvaient des tessons et deux vases. La couche superficielle enfin contenait de nombreux vestiges médiévaux et modernes.

\section{Le tertre (fig. 3)}

Sous le tertre, le substrat de gravier est irrégulier. Tandis qu'au nord, il reste à peu près horizontal, vers le sud il s'abaisse brusquement pour remonter ensuite en pente douce, la dépression étant comblée par des niveaux argileux. Nous sommes en présence

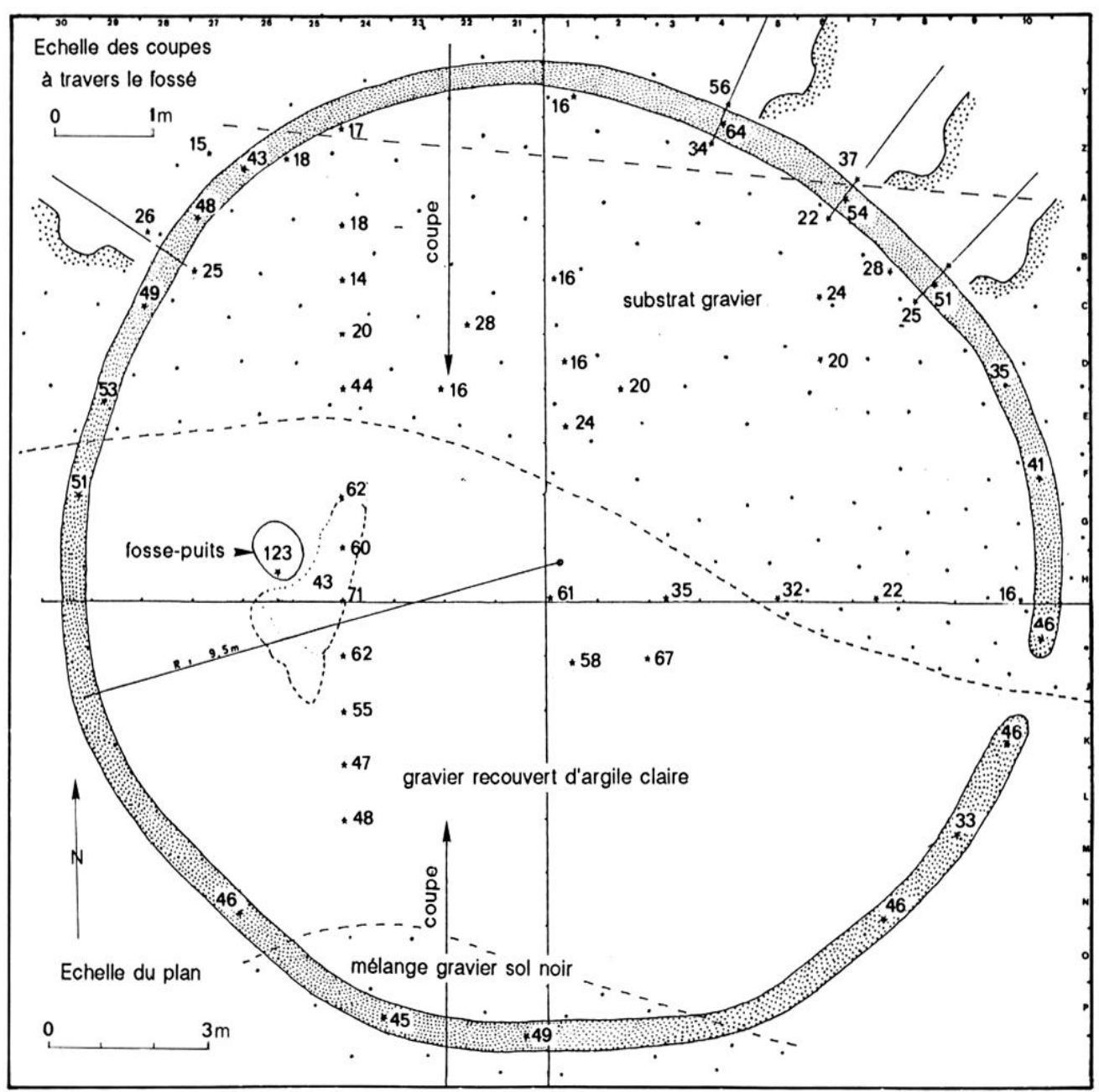

Fig. 3 -

Structure du tertre et coupes.

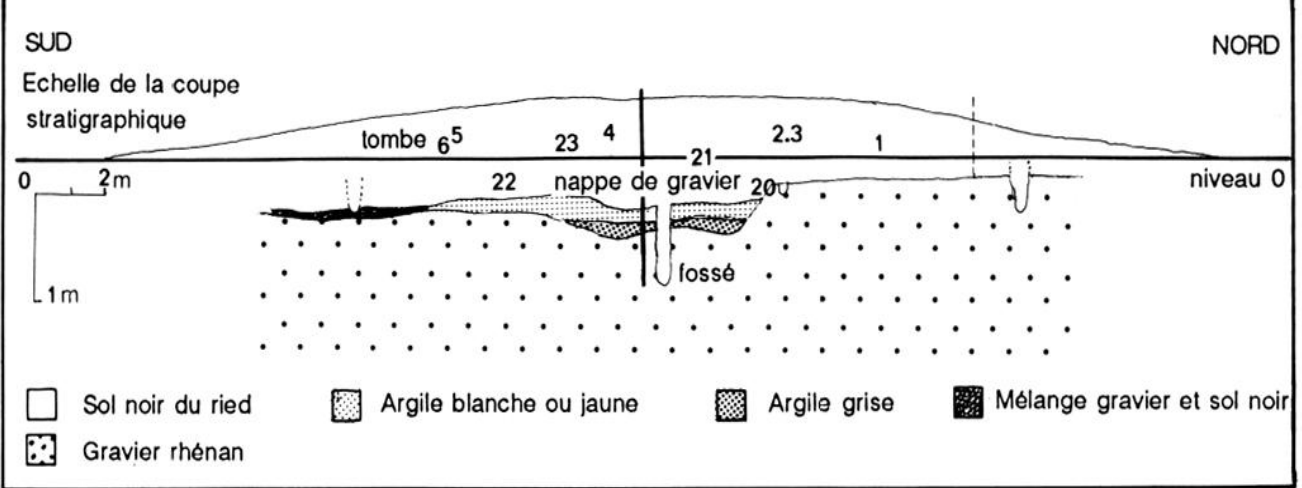


d'un ancien lit de cours d'eau, à profil dissymétrique typique d'une berge à tracé concave vers le nord. Tout autour du tertre, sauf du côté nord, l'épaisseur de sol noir était plus importante qu'ailleurs : aussi le tertre a-t-il été édifié quasi exclusivement avec ce matériau et avec très peu de graviers. La masse du tertre est donc homogène, ce qui ne permet pas la mise en évidence de fosses ou d'une éventuelle stratigraphie; seules les structures entamant le substrat seront apparentes.

\section{Le fossé (fig. 3)}

\section{Description}

Interrompu à l'est/sud-est, sur une largeur de $1,15 \mathrm{~m}$, par une "porte» (fig. 4), le fossé ne dessine pas un cercle parfait, car son diamètre varie entre $17,50 \mathrm{~m}$ et $19 \mathrm{~m}$. En outre, la courbure de son tracé est irrégulière : en plusieurs endroits, il est constitué de tronçons juxtaposés, dont le caractère rectiligne est particulièrement net le long de son bord interne.

Ce fossé, amplement recouvert par le tertre très étalé, n'est visible que dans sa partie profonde. Dans la moitié nord, il apparaît sous la forme d'un ruban noir bordé de gravier gris; du côté sud, il n'a été perceptible que grâce à des différences de matériaux et de teintes, et ceci près du fond seulement. Il présente un profil en $\mathrm{U}$, avec un fond plat et des versants abrupts, particulièrement nets du côté interne. Sans être régulière, sa profondeur oscille autour de $50 \mathrm{~cm}$ sous le niveau zéro ${ }^{2}$; sa largeur, à peu près constante, varie entre 50 et $55 \mathrm{~cm}$.

Le fossé est daté par deux céramiques hallstattiennes, déposées sur le fond, dans le secteur ouest.

\section{Évolution des recherches sur les structures circulaires}

En 1930, l'ouvrage de A. E. van Giffen sur les tumulus de Hollande fournit la première impulsion aux recherches sur la présence de fossés circulaires autour des sépultures. Les observations s'étendent rapidement à l'Allemagne du Nord, mais les cartes de répartition (Stieren, 1935; Hoffmann, 1940a) associent généralement les différents types de structures (cercles de pierres, cercles de poteaux, fossés) sans distinction de périodes, depuis le Néolithique jusqu'à l'époque mérovingienne. Dans une seconde étape,

2 Le niveau zéro correspond à un niveau moyen du sol actuel en dehors du tertre.

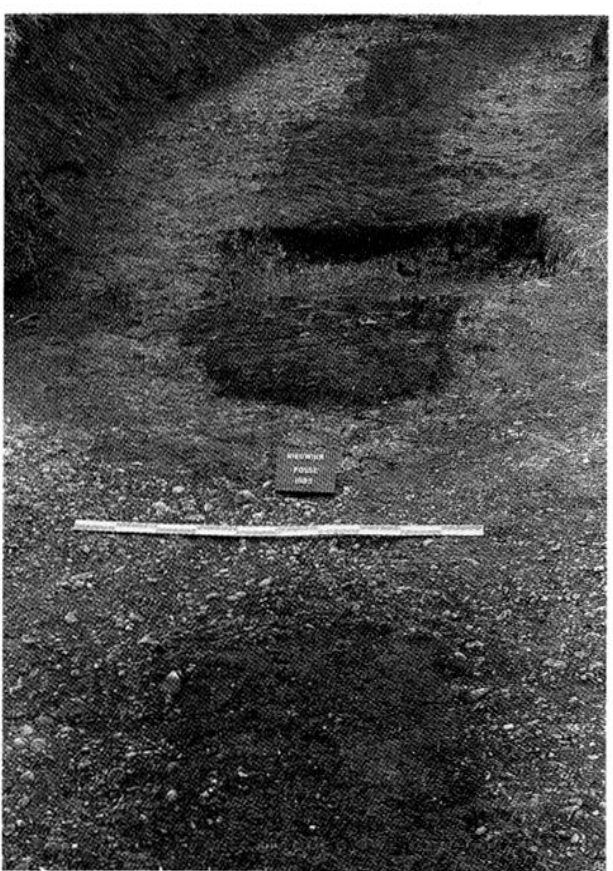

Fig. 4 - Vue de la "porte" du fossé.

H. Hoffmann (1940b) distingue ces différents types et leur datation mais son inventaire ne dépasse pas, vers le sud, la région du confluent Rhin-Main. Pour la période hallstattienne, il ne cite que deux tertres à palissade : Huttenheim près de Karlsruhe et Koberstadt (Hoffmann, 1940b, carte 2, nos 23 et 25), où il signale également un tertre à fossé (Hoffmann, 1940b, carte 4, no 28). J. Röder complète cette liste en 1941 pour le Palatinat rhénąn (Hunsruck-Eifel Kultur).

En 1951, la découverte d'un fossé autour du tertre 5 d'Asperg dans le Wurtemberg provoque l'étonnement, car les structures circulaires étaient alors considérées comme un phénomène nordique, caractérisant surtout l'Allemagne septentrionale et les Pays-Bas. Cette découverte incite II. Schermer (1952) à reprendre la documentation concernant les fossés et palissades d'Allemagne méridionale. Si le sud de la Rhénanie, la Hesse et le Palatinat rhénan constituent toujours les régions les mieux documentées de sa carte de répartition, quatre structures sont néanmoins répertoriées en Bavière et deux dans le Wurtemberg (mais parmi elles, celle de singen doit être supprimée car elle est médiévale).

\section{Recherches récentes}

Depuis ces travaux, les découvertes de fossés circulaires (palissadés ou non) se sont multipliées en Europe tempérée, grâce aux prospections aériennes et surtout grâce à la multiplication de fouilles exten- 
sives, débordant enfin plus largement la zone centrale des tumulus. L'augmentation considérable des données a incité récemment $J$. Rehmet (1987) à refaire l'inventaire des fossés circulaires d'Allemagne du Sud-Ouest, inventaire néanmoins limité aux découvertes déjà publiées. Il recense 24 sites hallstattiens dans le Bade-Wurtemberg, 14 en Bavière, 15 dans le Palatinat rhénan et 5 en Hesse du Sud (Rehmet, 1987, fig. 1 et liste p. 82-87). S'il exclut les cercles de pierres et de poteaux de ses propos, il y intègre les fossés palissadés.

Les diagrammes réalisés par $\mathrm{J}$. Rehmet sur les diamètres et les largeurs des fossés circulaires prouvent la grande variabilité de ces paramètres; il semble cependant que la moyenne s'établisse entre 8 et $16 \mathrm{~m}$ de diamètre, 0,20 et $1 \mathrm{~m}$ de largeur. Si des traces de palissades (en poteaux ou en planches) sont fréquentes dans les fossés de petit diamètre, elles ne semblent pas exister dans les fossés de grande taille. Ces différences de structure pourraient suggérer éventuellement une différence de fonction.

\section{Le fossé de Riedwihr et les autres découvertes régionales}

Par ses mesures, le fossé de Riedwihr I s'intègre bien dans les séries les plus fréquentes d'Allemagne du Sud-Ouest mais il se singularise par la présence d'une "porte", car la plupart des fossés bien observés cités par J. Rehmet sont fermés. Il est néanmoins nécessaire d'émettre quelques réserves sur cette particularité, car l'observation de "porte» a pu souvent échapper aux recherches en raison de mauvaises conditions géologiques ou de fouilles incomplètes.

Dans la vallée du Rhin supérieur, les fossés circulaires répertoriés sur la rive droite du Rhin sont encore rares. Parmi les trois seuls cas signalés par J. Rehmet, un seul, situé à Dattingen dans la région de Breisach, a été fouillé récemment par R. Dehn (1985), les deux autres ont été observés uniquement par prospection aérienne.

En Alsace, l'inventaire établi après la découverte d'un fossé palissadé du Ha C à Mussig (Plouin et alii, 1986, p. 19) avait permis de dénombrer 18 fossés bien datés; parmi eux, cinq appartiennent à la fin du Bronze final, sept autres sont hallstattiens (Réguisheim, Sainte-Croix-en-Plaine ...). La fouille récente des tertres de Riedwihr II et de Herbsheim, Nordhouse 2B et Nordhouse 5 (Bas-Rhin) a permis de mettre en évidence la présence systématique de fossés et ceci dès le Bronze final IIIb. Il semble donc que l'on puisse considérer les fossés circulaires comme un élément constant du rituel funéraire.

\section{La fosse ou «puits» (fig. 5)}

\section{Description}

Dans la partie ouest de l'enclos circulaire (carré $\mathrm{H}$ 26), à l'écart des sépultures, se trouvait une fosse très profonde $(1,23 \mathrm{~m}$ sous le niveau 0$)$, de section ovale au niveau du substrat où elle a été repérée $(1,10$ sur $0,75 \mathrm{~m})$.

Cette fosse s'enfonce largement dans la nappe phréatique et ainsi contient de l'eau quel que soit le niveau de la nappe. Il s'agit très certainement d'un "puits" nécessaire à un rituel lié au tertre, ce qui implique une fosse ouverte et accessible en permanence. La partie inférieure, remplie d'argile noire mélangée aux graviers du substrat, a livré une incisive de porc et une trentaine de fragments osseux. Ces ossements, bien groupés dans la moitié ouest de

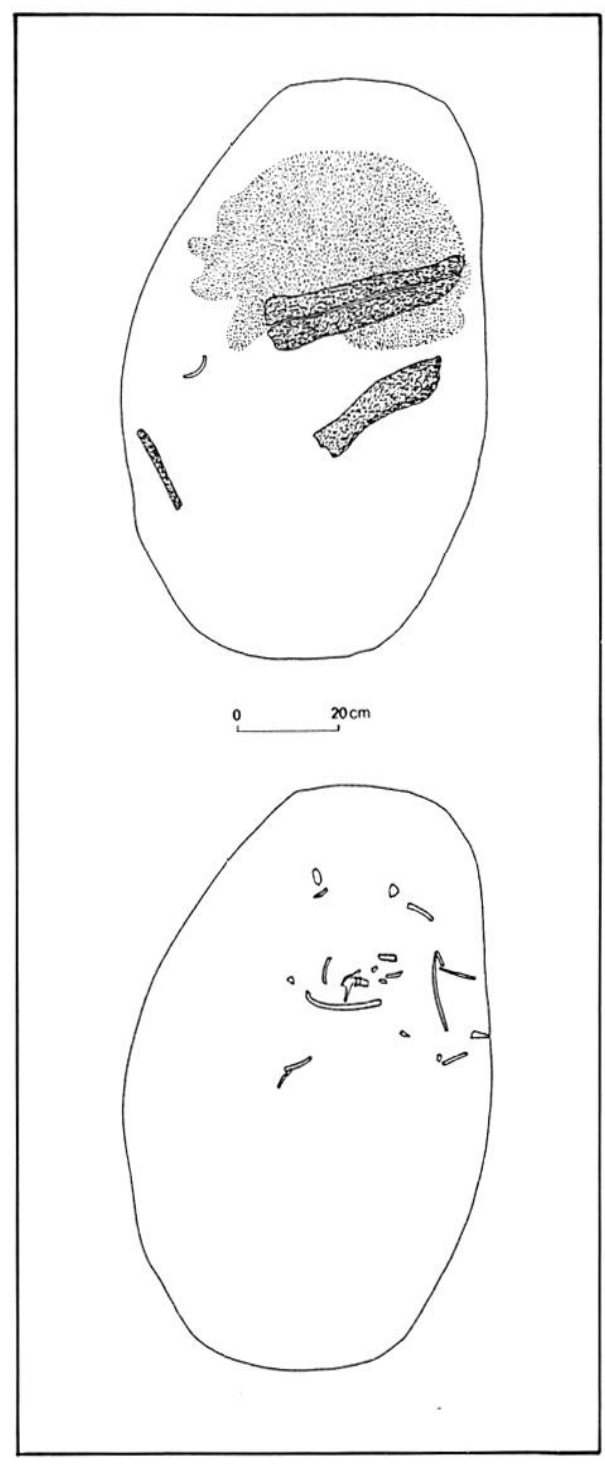

Fig. 5 - Plans de la fosse en H26. 
la fosse, sans connexion anatomique, appartiennent à une jeune brebis (fig. 5 , en bas) (cf. annexe I, p. 52). La partie supérieure (environ $40 \mathrm{~cm}$ ) présente un remplissage constitué d'argile noirâtre, de débris végétaux, de trois fragments de bois et d'une fine couche d'écorce tapissant toute la moitié ouest de la fosse (fig. 5, en haut), la moitié orientale restant à nouveau stérile.

Aux alentours de la fosse, une nappe de graviers s'étalait en une couche mince au niveau -10 . Ces graviers proviennent du creusement de la fosse et la base horizontale de la nappe démontre que ce creusement s'est effectué en terrain plat, c'est-à-dire avant l'édification du tertre hallstattien.

\section{Comparaisons}

Ce type de structure doit appartenir à un rituel funéraire complexe, dont les modalités sont difficiles à cerner. Les très rares losses comparables et contemporaines proviennent de Huttenheim en Bade-Wurtemberg (Nellissen, 1984) et de Grosseibstadt en Franconie (Kossack, 1970). La fosse de Huttenheim, située sous un tumulus de $70 \mathrm{~cm}$ de hauteur, se trouve à l'extérieur d'un enclos palissadé d'environ $8 \mathrm{~m}$ de diamètre entourant une tombe centrale féminine datée du Hallstatt D par une épingle à col de cygne; la position surélevée de cette tombe, située à $40 \mathrm{~cm}$ sous le sommet du tertre peut être rapprochée de celle de la tombe centrale 4 de Riedwihr. Cette fosse, comme celle de Riedwihr, contenait des fragments de bois qui devaient en tapisser le fond ainsi que des débris végétaux assimilés à un fumier. Comme elle atteignait la nappe phréatique, elle a été considérée comme un puits. La fosse de Grosseibstadt est située à l'intérieur d'un fossé circulaire de $23 \mathrm{~m}$ de diamètre entourant une tombe centrale bien datée du début du Hallstatt D par un poignard à antennes en fer. Comme la fosse de Riedwihr, elle a livré les restes d'un animal sous forme d'innombrables éclats osseux.

On peut rapprocher ces deux fosses d'une structure plus ancienne datant du Bronze final, mais néanmoins comparable : à Rheinsheim dans le Wurtemberg, H. E. Nellissen (1984) signale la présence d'une fosse circulaire très profonde $(2,30 \mathrm{~m})$ contenant du bois, à proximité de plusieurs longues fosses rectangulaires à incinération, tapissées de galets, sans doute de caractère cultuel. Reprenant les hypothèses de W. Kimmig, H. E. Nellissen considère ce site comme un emplacement sacré ou "téménos", et la fosse circulaire comme une bouche ou "bothros" mettant en communication monde des morts et monde des vivants.
Nous sommes tentés d'attribuer une fonction rituelle identique à l'enclos circulaire de Riedwihr I, entourant le tertre et le puits. Cette fonction trouvera en Europe tempérée une expression bien plus spectaculaire avec les puits très profonds inclus dans les enclos quadrangulaires de type "Viereckschantze" de la fin de la période celtique (tabl. I, p. 50).

\section{LA DESCRIPTION DES TOMBES}

(tabl. I I, p. 50)

Depuis les tombes superficielles situées juste sous la surface actuelle du tertre jusqu'aux sépultures situées à près de $1 \mathrm{~m}$ de profondeur, tous les niveaux coexistent. Les tombes ont été réparties en quatre groupes selon leur niveau, chacun correspondant à une tranche de $15 \mathrm{~cm}$ d'épaisseur (fig. 6).

\section{Tombe 1 (fig. 7)}

Sépulture superficielle (niveau +7 ) partiellement remaniée d'un adulte (ou d'un grand adolescent) de sexe indéterminé, orientée tête à l'ouest. Les quelques os qui nous sont parvenus laissent supposer que le sujet reposait en décubitus dorsal.

Aucun mobilier.

\section{Tombe 2 (fig. 9)}

Sépulture superficielle (niveau $+16 \mathrm{~cm}$ ) partiellement remaniée d'un adulte de sexe indéterminé, orientée tête à l'ouest, reposant sans doute en décubitus dorsal.

Il n'est pas certain que le petit fragment de tige de bronze retrouvé au contact de la symphyse mandibulaire (axe de ressort de fibule) appartienne à cette sépulture, car toute la zone aux alentours est remaniée.

\section{Tombe 3 (fig. 9)}

Sépulture (niveau + 16) dont la moitié supérieure est entièrement remaniée d'un adulte peutêtre de sexe masculin, orientée tête à l'est.

Aucun mobilier.

\section{Tombe 4 (fig. 7)}

Sépulture centrale du tertre, mais aussi l'une des plus superficielles (niveau +19 ); orientée tête à l'est, elle appartient à un adulte de sexe et d'âge indéterminés. Les humérus apparaissent par leur face antérieure, le droit reposant sur la face antérieure du gauche. Les avants-bras sont étendus sur les bras et superposés. La position des membres inférieurs est tout à fait paradoxale. Alors que le fémur gauche apparait par sa face antéro-interne et que le droit se présente par sa face antérieure, les tibias 


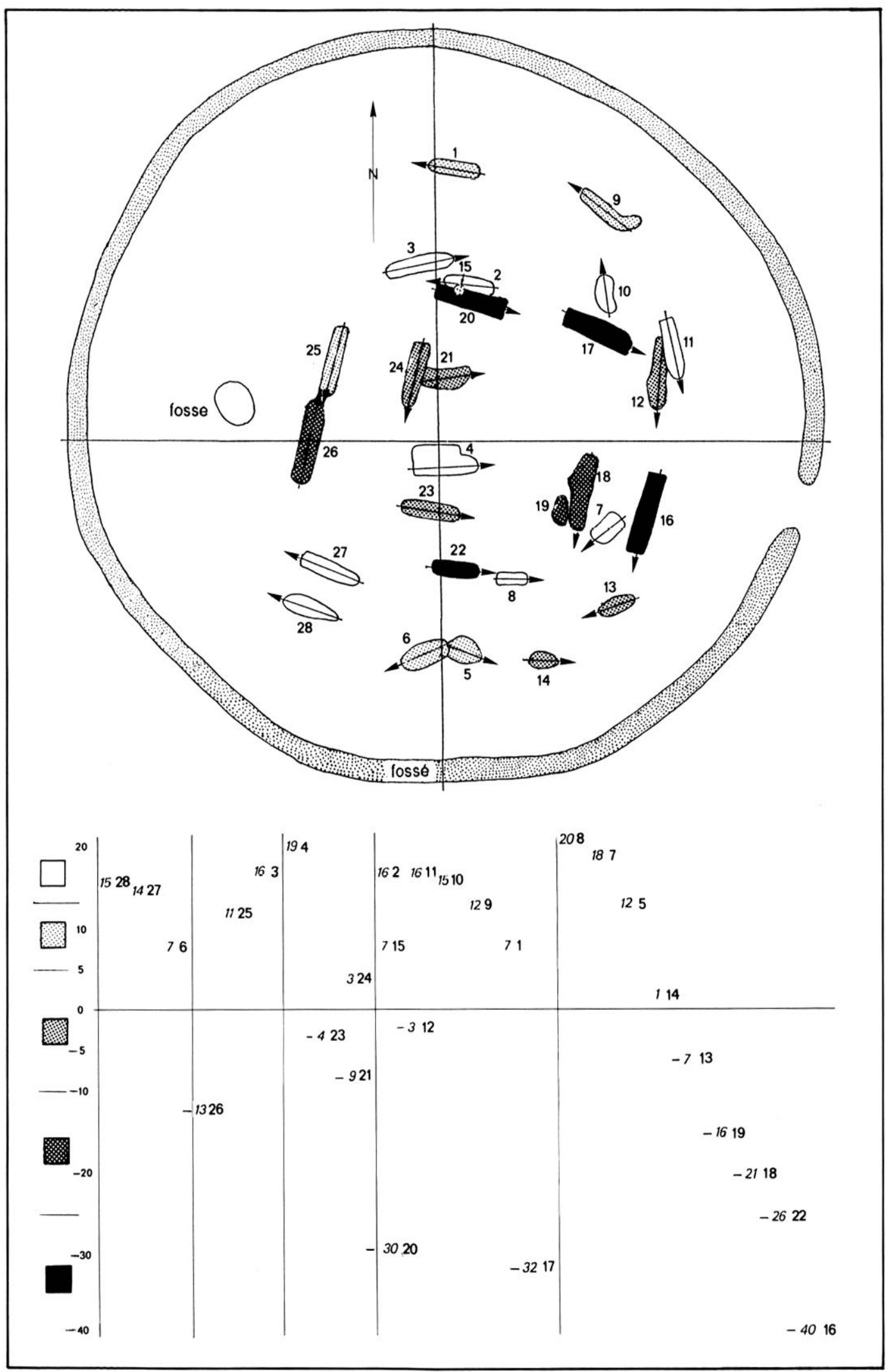

Fig. 6 - Orientation et niveau des tombes. Le premier groupe $(+20$ à +5$)$ est le plus riche avec plus de la moitié des sépultures $(14$ tombes soit $54 \%$ ). Le deuxième groupe $(+5 \grave{a}-10)$ comprend 6 sépultures $(23 \%)$, le troisième $(-10$ à -25$)$ seulement $2(8 \%)$, le dernier $(-25$ à -40$)$ en contient $4(15 \%)$. Nous avons ensuite subdivisé le premier groupe en deux parties pour mettre en évidence les tombes les plus superficielles. 
22

CH. BONNET, S. PLOUIN, FR. LAMBACH
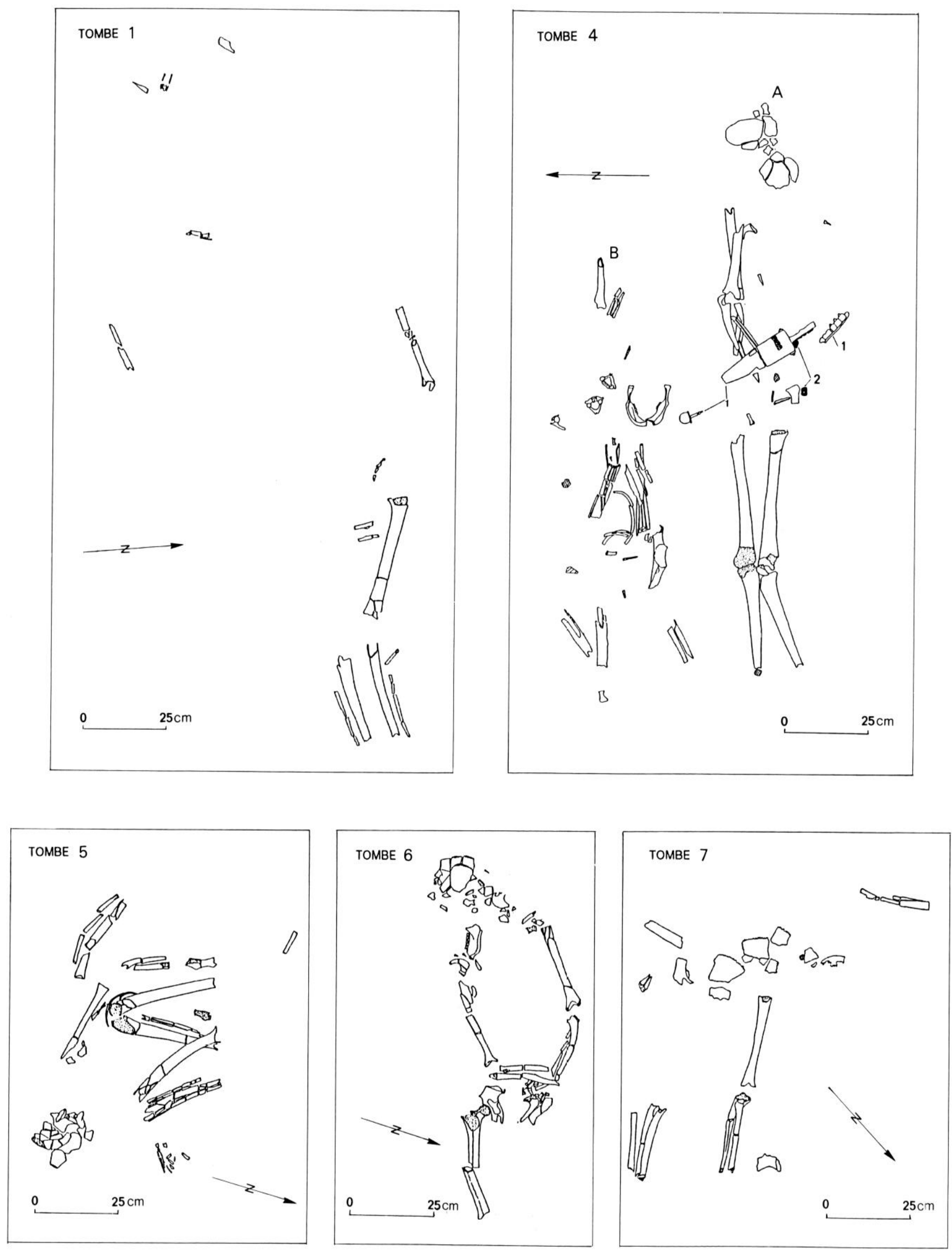

Fig. 7 - Plans does tombs 1.4 à 7 . 


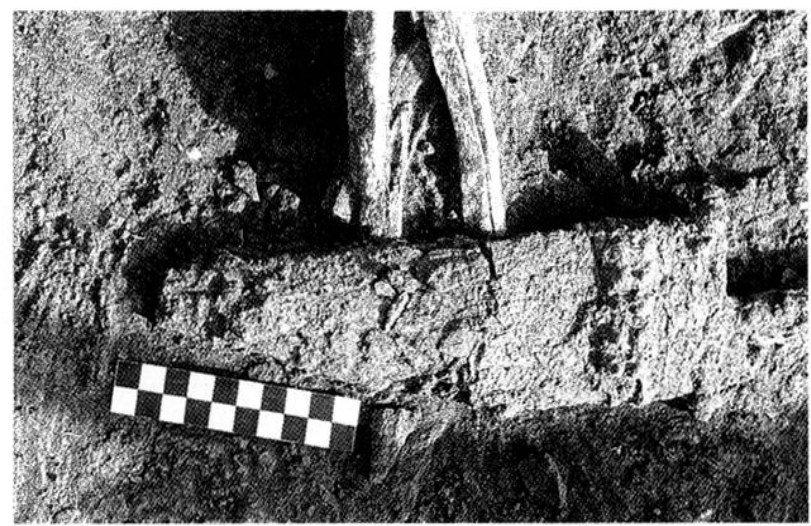

Fig. 8 - Tombe 4 : poignard in silu.

apparaissent par leur face interne, leur bord antérieur en contact, la patella droite étant en stricte connexion anatomique. Tout se passe comme si un des membres inférieurs avait "basculé" par-dessus l'aulre tout en restant en parfaite connexion anatomique. Les cuisses sont ètendues sur le bassin, la jambe gauche est en extension sur la cuisse et la droite est légèrement fléchie.

La tombe 4 a livré un poignard reposant sur les avants-bras du sujet et des fragments de plaque de ceinture retrouvés en partie sous la soie du poignard (fig. 8).

Cette sépulture a visiblement perturbé au moins une tombe antérieure d'adulte (tombe $4 \mathrm{~B}$ ), dont les restes dispersés, mélangés à des fragments de faune, ont été retrouvés au nord du squelette, au même niveau que lui. Ces restes comprennent entre autres deux fragments de diaphyses tibiales gauches distinctes posant le problème de l'existence éventuelle d'un deuxième sujet à cet endroit.

La position du défunt n'est pas interprétable de manière logique. Seule une explication complexe avec déplacement en bloc (c'est-à-dire en connexion anatomique stricte) d'un membre inférieur pardessus l'autre peut rendre compte de la position de la moitié inférieure du corps. On peut imaginer, mais sous toutes réserves, que la position du sujet (primitivement en décubitus dorsal) pourrait résulter de la fracture longitudinale d'un cercueil monoxyle (tronc d'arbre évidé par exemple). A la suite de cette fracture, les deux moitiés se seraient rapprochées sous la poussée des sédiments, entraînant la superposition des membres supérieurs et le déplacement de l'un des membres inférieurs par-dessus l'autre pour l'amener du côté opposé.

\section{Tombe 5 (fig. 7)}

Sépulture superficielle (niveau +12 ) orientée tête au sud-est. Le sujet, vraisemblablement de sexe féminin, d'âge indéterminé, reposait en position fortement contractée, pratiquement assis sur le côté droit, le tronc rabattu sur les membres inférieurs.

Aucun mobilier.

Il s'agit d'une sépulture primaire comme en témoigne la parfaite connexion anatomique des restes humains conservés. Leur disposition (coxal droit vertical, patella droite en connexion anatomique parfaite) milite pour une sépulture en pleine terre, avec colmatage immédiat de la tombe.

\section{Tombe 6 (fig. 7)}

Sépulture superficielle (niveau +7 ), orientée tête au sud-ouest, d'un adulte de sexe et d'âge indéterminés, couché sur le ventre.

Aucun mobilier.

\section{Tombe 7 (fig. 7)}

Sépulture superficielle (niveau +18 ), en grande partie remaniée, d'un adulte de sexe indéterminé (peut-être masculin?) orientée tête au sud-ouest.

Le crâne, sensiblement en position anatomique, est incomplet et fortement fragmenté. Le membre supérieur droit est en parfaite connexion anatomique; l'humérus droit apparaît par sa face antérieure, l'avant-bras est étendu sur le bras et en pronation. Le reste de la sépulture a été remanié; le tiers supérieur de la diaphyse fémorale gauche, brisée en deux fragments, a été retrouvé à la droite du crâne et au même niveau que lui ; mais surtout, les os du membre supérieur gauche ont été intentionnellement regroupés en fagot, "sensiblement en position anatomique", les os de l'avant-bras reposant au contact de la face postérieure de l'humérus correspondant dont l'extrémité inférieure regarde vers le crâne.

Il s'agit à l'évidence d'une sépulture primaire comme en témoigne la parfaite connexion anatomique des fragments crâniens conservés et du membre supérieur droit. La présence, au même niveau que la sépulture, des trois os regroupés en fagot du membre supérieur gauche, du tiers supérieur de la diaphyse fémorale et d'un autre fragment diaphysaire à proximité du crâne (et sans le remanier) ainsi que la présence d'un fragment d'os coxal à quelques centimètres à l'ouest de l'avant-bras droit sont autant d'éléments qui militent pour un remaniement précoce d'une sépulture non encore colmatée ou partiellement colmatée.

Aucun mobilier.

Tombe 8 (fig. 10)

Tombe superficielle (niveau +20 ) représentée seulement par le membre inférieur droit en 


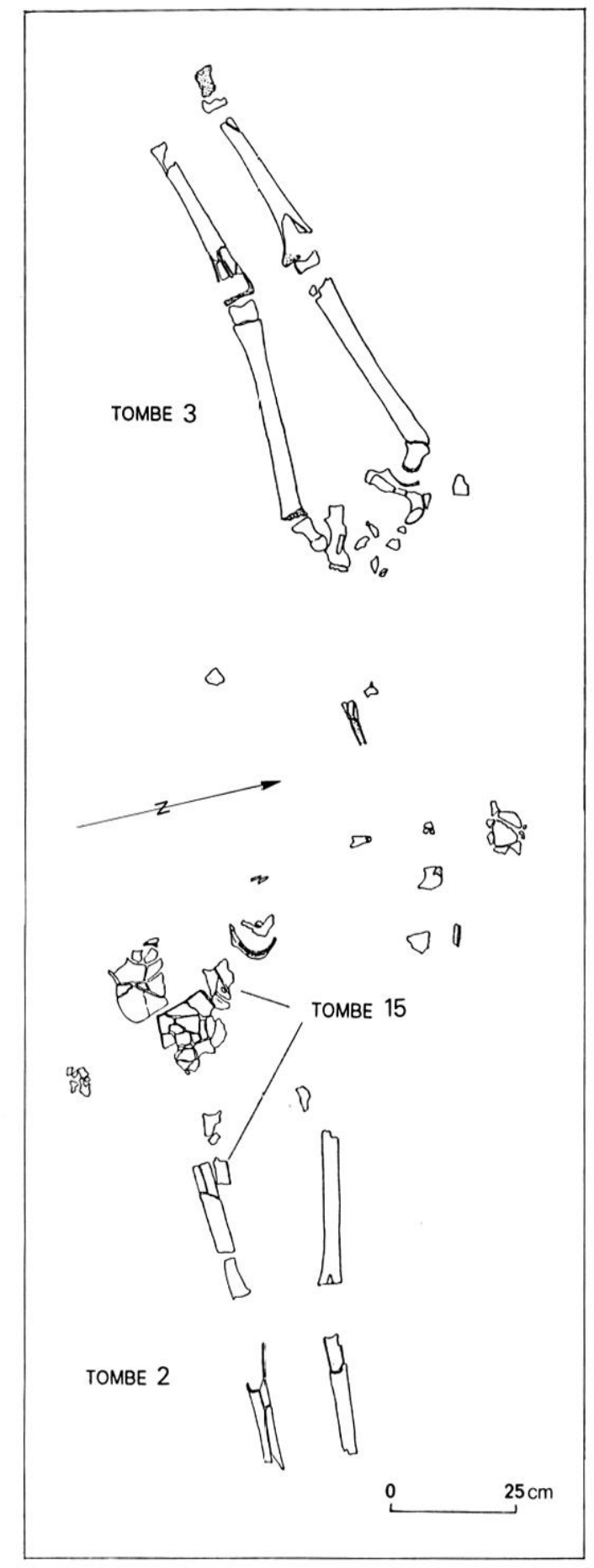

Fig. 9 - Plans des tombes 2, 3 et 15 .

connexion anatomique d'un adulte ou d'un grand adolescent. Nous sommes vraisemblablement en présence d'une sépulture primaire en partie remaniée et orientée tête à l'ouest.

Aucun mobilier. L'extrémité inférieure d'un fémur de porc a été retrouvée au même niveau, à une dizaine de centimètres au sud-est du tibia.

\section{Tombe 9 (fig. 10)}

Tombe superficielle (niveau +12 ) primaire orientée tête au nord-ouest, d'un adulte de sexe indéterminé, couché sur le côté droit. La présence de deux petits tessons atypiques dans cette sépulture est peut-être fortuite.

Aucun autre mobilier n'est à signaler.

Tombe 10 (fig. 10)

Sépulture primaire fortement remaniée d'un adulte de sexe indéterminé, orientée tête au nord (niveau +15 ). Seule une partie de la moitié inférieure de la tombe est conservée.

Aucun mobilier.

\section{Tombe 11 (fig. 10)}

Plus récente que la tombe 12 qu'elle recouvre en partie sans la remanier, cette sépulture superficielle (niveau +16 ), orientée tête au sud-est, est celle d'un adulte de sexe indéterminé reposant en décubitus dorsal.

Cette sépulture n'a livré aucun mobilier, mais un tesson était mêlé aux fragments crâniens.

A $60 \mathrm{~cm}$ à l'ouest de la sépulture et au même niveau, se trouvaient le radius et l'ulna droits d'un même sujet, reposant l'un sur l'autre et n'appartenant ni à la tombe 11 ni à la tombe 12 .

\section{Tombe 12 (fig. 10)}

Tombe d'un adulte de sexe masculin, orientée tête au sud (niveau -3), dont l'âge au décès était compris entre 51 et 76 ans, reposant en décubitus dorsal.

Le mobilier funéraire comprend un rasoir (fig. 21, $\mathrm{n}^{\circ} 6$ ) situé entre les cuisses, au contact du tiers moyen du fémur gauche, et cinq pointes de flèches retrouvées regroupées au niveau de l'abdomen (fig. 21, nos 1 à 5).

\section{Tombe 13 (fig. 10)}

Tombe mal conservée (niveau -7), orientée tête au sud-ouest, d'un enfant âgé d'environ 6 à 7 ans reposant en décubitus dorsal.

Deux poteries étaient placées aux pieds de l'enfant (fig. $22, \mathrm{n}^{\text {os }} 10$ et 11 ).

\section{Tombe 14 (fig. 11)}

Sépulture très incomplète d'un enfant àgé d'environ 6 à 8 ans (niveau +1$)$, orientée tête à l'est.

Aucun mobilier.

\section{Tombe 15 (fig. 9)}

Il ne s'agit pas en fait d'une véritable sépulture, mais d'une calotte crànienne isolée retrouvée au niveau +7 entre les tombes 2 et 20 . 

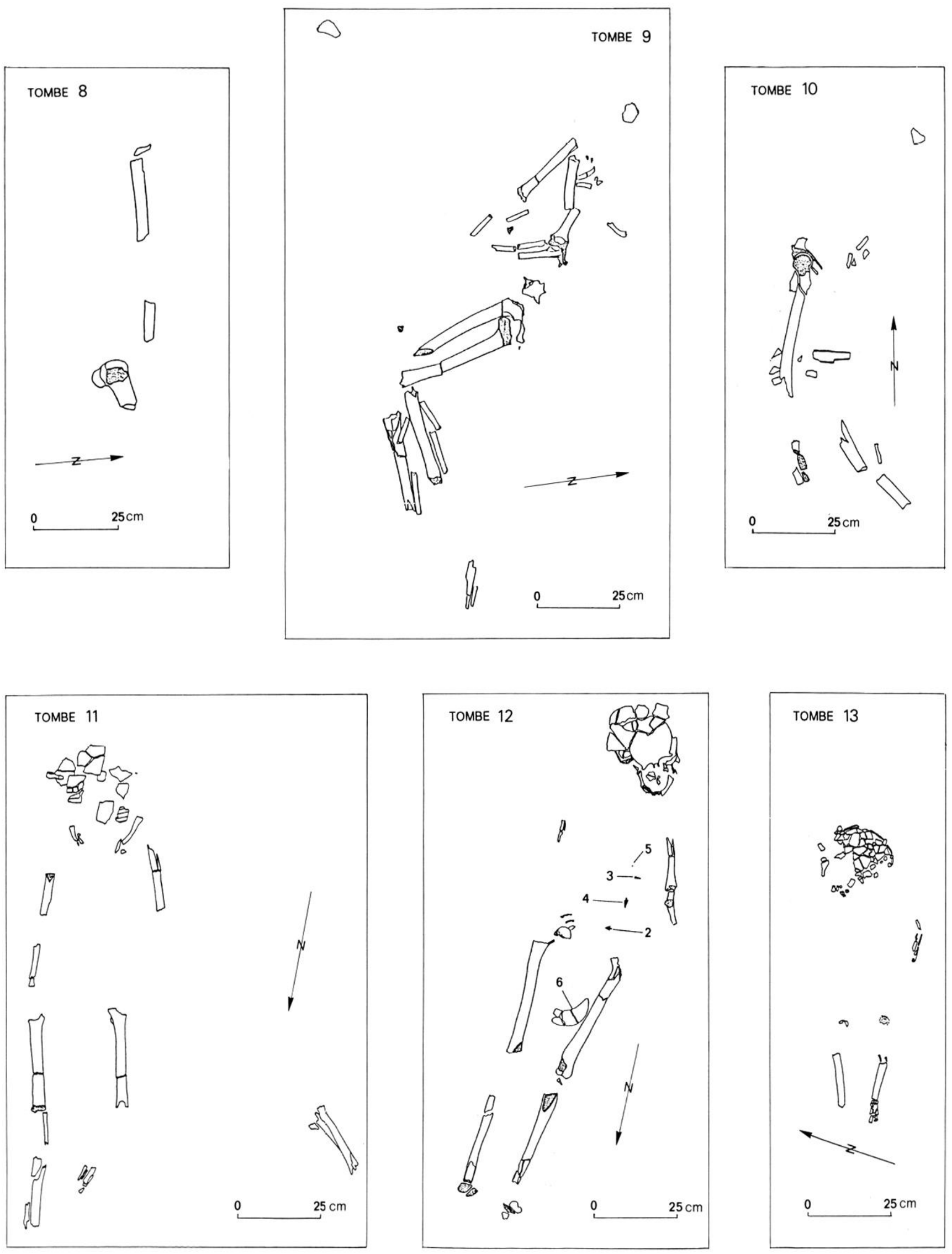

Fig. 10 - Plans des tombes 8 à 13 . 


\section{Tombe 16 (fig. 11)}

Sépulture en fosse (niveau - 40), orientée tête au sud-ouest, appartenant à un adulte de grande taille de sexe masculin, reposant en décubitus dorsal, dont l'âge au décès était compris entre 46 et 71 ans.

Un bracelet en fer ornait le poignet gauche (fig. 11B, bf). Une urne, posée au-dessus du squelette, au niveau du coude et de la moitié inférieure du bras gauche, avait été vraisemblablement déposée au-dessus du cercueil (fig. 11A, no 12).

Le défunt reposait sur une planche en bois partiellement conservée (fig. 12), surtout visible le long du bord gauche du sujet sous forme d'une mince pellicule de 2 à $3 \mathrm{~mm}$ d'épaisseur. La longueur de la planche était d'environ $205 \mathrm{~cm}$, pour une largeur d'environ $50 \mathrm{~cm}$. Quelques centimètres au-dessus du fond de la fosse, dans la paroi latérale ouest, des fragments ligneux sont apparus sur environ $10 \mathrm{~cm}$ de longueur, à la hauteur du tiers inférieur du fémur gauche. La décarnisation s'est effectuée dans un espace vide comme en témoigne la mise à plat du bassin et la bascule post-mortem de la main droite vers le dehors. La planche en bois retrouvée sous le squelette et le reste d'un fragment de montant latéral témoignent de l'existence d'un cercueil en bois en planches équarries, à fond plat ou presque plat.

La fosse, à parois verticales, est visible dès le niveau - 14. Elle est dissymétrique, avec un bord est presque rectiligne et un bord ouest largement ovalisé. De grande taille $(205 \mathrm{~cm}$ pour $67 \mathrm{~cm}$ de largeur maximale), elle est remplie par la terre argileuse noire du tertre et s'enfonce de $26 \mathrm{~cm}$ dans le substrat jaune. Dans sa moitié sud où cela a pu être mis en évidence (mais vraisemblablement sur tout son pourtour), la fosse était bordée par une collerette régulière en terre jaune du substrat, de 15 à $25 \mathrm{~cm}$ de largeur pour une hauteur d'environ $10 \mathrm{~cm}$, qui rejoignait en pente douce les bords de la fosse du côté interne alors que sa limite externe était verticale. Cet aspect s'explique par un double effet de paroi qui confirme encore l'existence d'un cercueil, la paroi externe correspondant aux limites de la fosse de creusement, la paroi interne aux montants latéraux du cercueil.

\section{Tombe 17 (fig. 11 et 13)}

Sépulture orientée tête au sud-est (niveau - 32), d'une jeune femme dont l'âge au décès était vraisemblablement compris entre 20 et 48 ans. Elle reposait en décubitus dorsal, la tête en nette rotation gauche (fig. 13).

Le mobilier comprend deux boucles d'oreille en bronze (fig. 21, $\mathrm{n}^{\circ} 8$ ) composées chacune de deux annelets et d'un pendentif en tôle creuse estampée, et deux bracelets en lignite bien conservés, le gauche situé au niveau du coude, le droit retrouvé à la partie haute de l'avant-bras (fig. 21, $\mathrm{n}^{\text {os }} 7$ et 9 ).

Sous le squelette, des fibres ligneuses, orientées selon le grand axe de la sépulture, sont bien visibles en arrière du crâne et le long du bord sud de la tombe, sous forme d'une mince pellicule horizontale de quelques millimètres d'épaisseur. Ces traces ligneuses ainsi que la mise à plat du bassin qui témoigne d'un processus de décarnisation en espace vide prouvent l'existence d'un cercueil dont les dimensions approximatives sont de $0,63 \mathrm{~m}$ de large pour une longueur légèrement supérieure à $2 \mathrm{~m}$.

\section{Tombe 18 (fig. 11)}

Sépulture profonde (niveau -21 ), orientée tête au sud-ouest, d'un adulte de sexe indéterminé (peutêtre féminin), dont l'âge au décès était vraisemblablement inférieur à 50 ans.

Le sujet repose en décubitus dorsal, le crâne en légère rotation gauche. Le sujet portait deux bracelets en lignite; une agrafe de ceinture en fer reposait sur la partie gauche de l'abdomen (fig. $21, n^{\text {os }} 10$ à $12)$.

De part et d'autre du crâne se trouvaient les restes d'une planche en bois dont l'extrémité supérieure, bien visible, se situait à environ $20 \mathrm{~cm}$ en arrière du crâne. La mise à plat du coxal gauche, due à une décarnisation en espace vide, confirme la présence d'un cercueil en bois.

\section{Tombe 19}

Il ne reste de cette sépulture que les deux tiers inférieurs d'un radius gauche et la portion médiane de la diaphyse d'une ulna droite, immatures. Ces ossements, retrouvés épars (niveau - 16) à l'ouest de la tombe 18, appartiennent à un enfant âgé d'environ 6 à 10 ans. Le tiers inférieur de l'ulna droite est verdi.

Trois fragments de bronze appartenant à deux bracelets différents étaient associés à ces ossements (fig. 21, $\mathrm{n}^{\mathrm{0}}$ 13).

\section{Tombe 20 (fig. 14)}

Sépulture (niveau - 30) orientée tête au sud-est, avec les restes de trois individus : un adulte de sexe masculin âgé d'environ 20 à 25 ans et deux enfants âgés d'environ 1 à 2 ans et 5 à 7 ans.

Les restes des enfants sont extrêmement mal conservés et seule l'étude des germes dentaires a permis de les distinguer. Ils ne sont représentés que par quelques fragments crâniens qui recouvraient l'ex- 


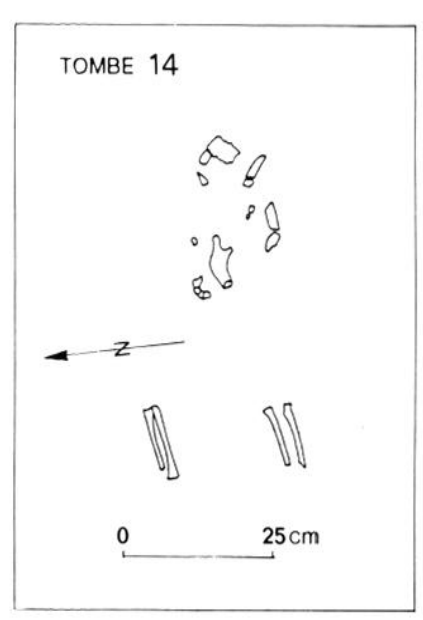

TOMBE 17

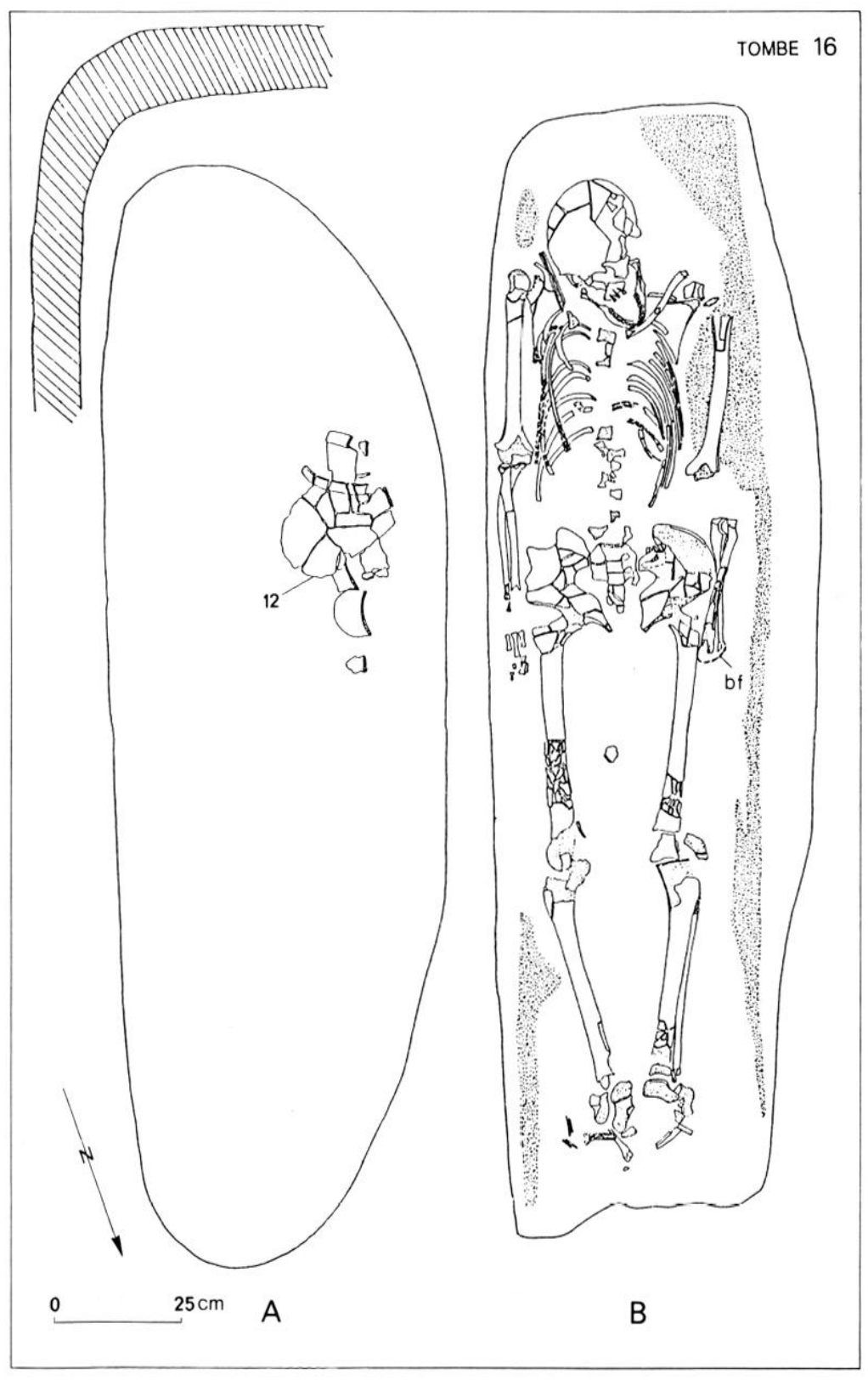

Fig. 11 - Plans des tombes 14,16 à 18 .

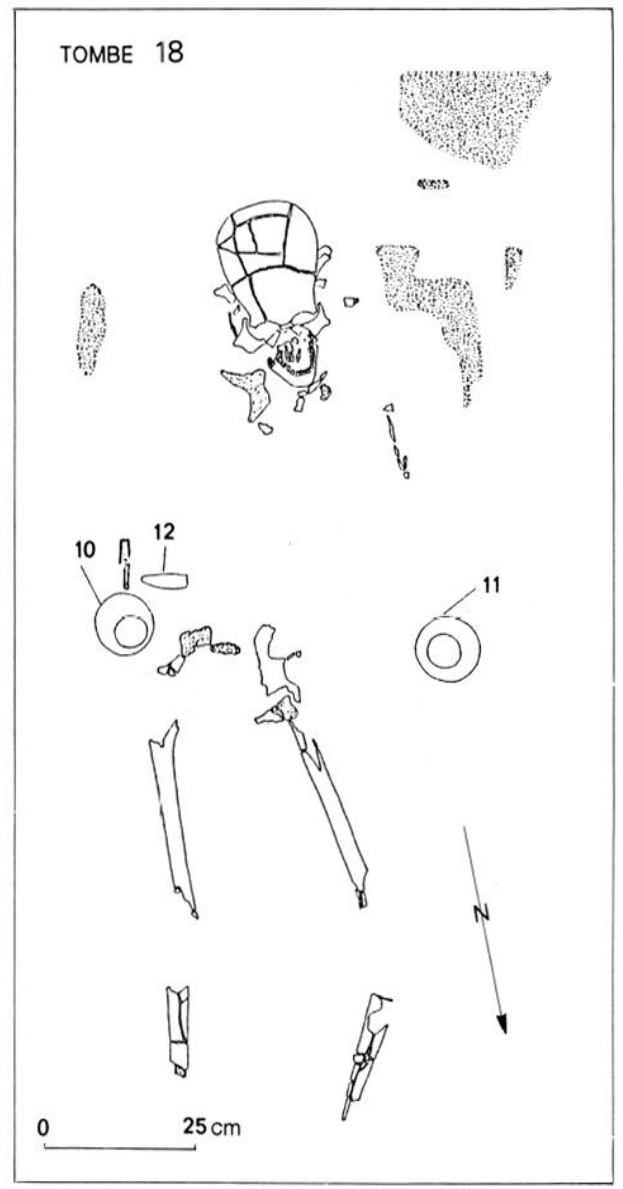


trémité supérieure de l'humérus droit de l'adulte et par quelques esquilles d'os longs retrouvés à hauteur de son poignet.

Autour de cette sépulture ont été retrouvés des éléments appartenant à une tombe d'adulte plus ancienne : ces éléments sont représentés au niveau - 15 par un fémur gauche et une diaphyse tibiale droite (visibles par leur faces internes) qui bordaient respectivement le bord nord et l'extrémité ouest de la fosse. La disposition de ces os est à l'évidence intentionnelle. Les autres éléments de cette tombe d'adulte plus ancienne ont été retrouvés au niveau -30 , c'est-à-dire au niveau de la tombe 20 . Il s'agit d'une patella gauche (visible par sa face postérieure) située au contact du tiers inférieur de l'humérus gauche de la tombe 20, d'un fémur droit (symétrique du précédent situé au niveau - 15) visible également

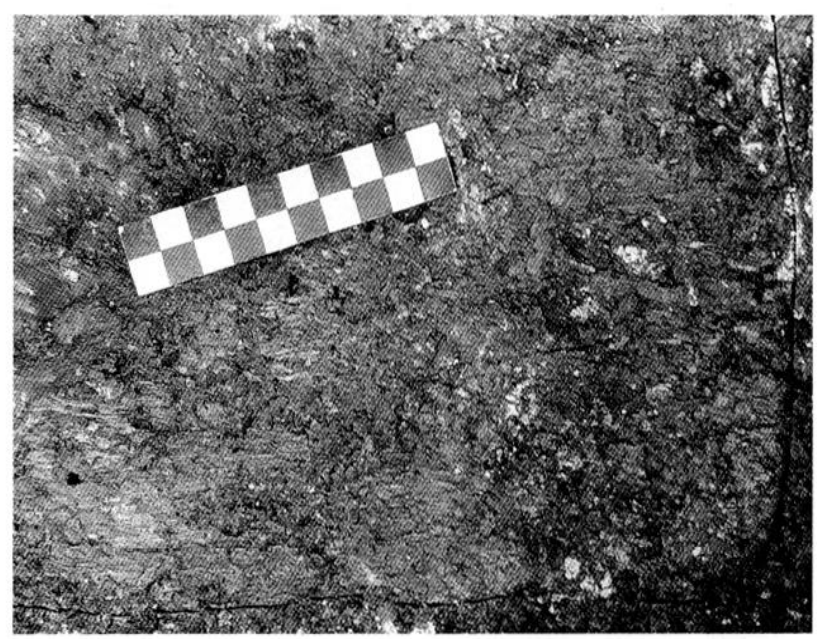

Fig. 12 - Tombe 16 : bois du cercueil. par sa face postérieure et déposé le long du bord sud de la tombe, enfin d'une diaphyse de fibula retrouvée entre le fémur droit remanié et le tibia gauche de la tombe 20 , sous les tessons de céramique.

La mise à plat complète du bassin témoigne d'un processus de décarnisation en espace vide. Malgré l'absence de traces ligneuses, il existait donc vraisemblablement aussi un cercueil en bois. Cette hypothèse est étayée par la mise en évidence d'un effet de paroi le long du bord sud de la tombe, suggéré par la disposition des restes humains (membres supérieur et inférieur gauches de l'adulte, disposition de la clavicule parallèle au grand axe de la sépulture) mais surtout matérialisé par la position des tessons de céramique bordant la tombe.

Le mobilier comprend une grande urne haute (fig. $22, \mathrm{n}^{0} 8$ ), qui malgré quelques lacunes a pu être reconstituée entièrement et des fragments d'une petite urne graphitée extérieurement (fig. 22, $n^{\circ} 9$ ). La plupart de ces tessons ont été retrouvés au niveau - 15, qui est également celui de quelques os humains isolés signalés précédemment : cela indique l'existence d'une assez vaste surface horizontale dans laquelle la fosse a été creusée jusqu'au niveau -30 . Un certain nombre de tessons de la grande urne ont glissé jusqu'au niveau du squelette. Leur disposition, bien alignés parallèlement à la tombe et pour la plupart positionnés verticalement, prouve qu'ils sont tombés dans l'intervalle étroit, mais encore libre, entre la paroi sud de la fosse et un obstacle vertical qui ne peut être que le cercueil. La poterie a donc été déposée sur le rebord de la fosse, accolée au montant latéral du cercueil. Elle a dû être brisée soit par les premiers jets de terre lors du recouvrement de la tombe, soit d'une façon délibérée par un geste rituel.

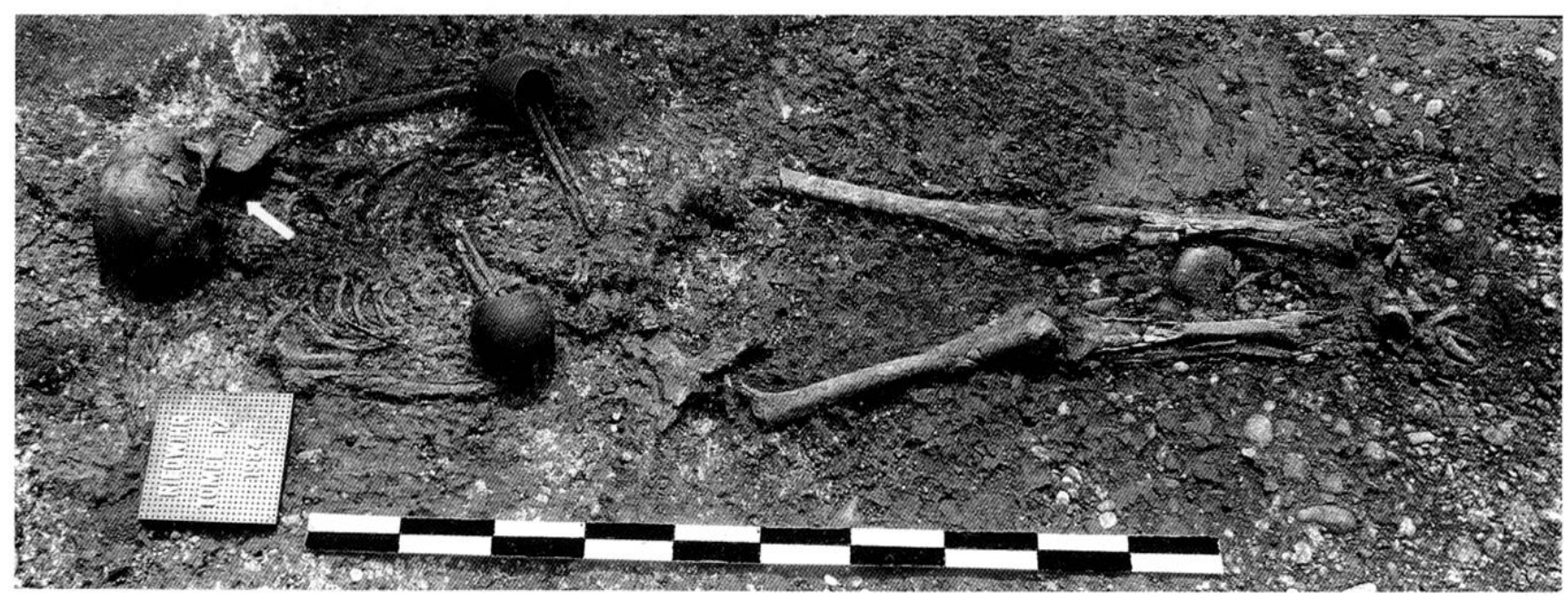

Fig. 13 - Vue de la tombe 17. 


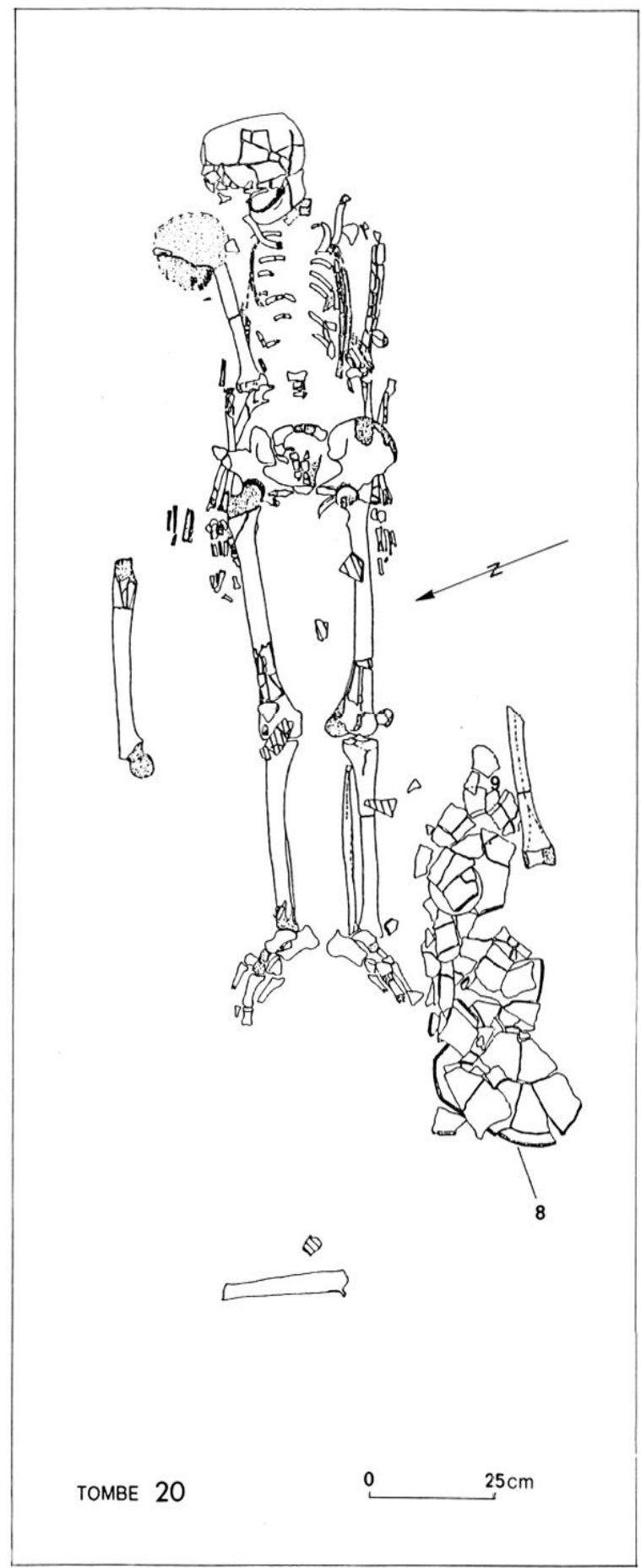

Fig. 14 - Plan de la tombe 20.

\section{Tombe 21 (fig. 15)}

Sépulture orientée tête à l'est (niveau - 9), d'un adulte de sexe et d'âge indèterminés, reposant en décubitus dorsal.

Cette tombe a livré six céramiques complètes (fig. 16 et $22, n^{\text {os }} 1$ à 6 ). Deux coupelles superposées (fig. $15, n^{\text {os }} 3$ et 4 ) se trouvaient entre les jambes, légèrement au-dessus des chevilles; deux autres coupelles superposées (fig. $15, n^{\text {os }}$ I et 2 ) étaient déposées à côté d'une petite urne (fig. $15, \mathrm{n}^{\circ} 6$ ) qui renfermait une cinquième coupelle (fig. $15, \mathrm{n}^{0} 5$ ) et recouvrait en partie le pied gauche du défunt. Enfin de nombreux tessons de céramique grossière (fig. $15, n^{0} 7$ ) étaient répandus au niveau de la partie supérieure droite du corps. Il est intéressant de constater que dans les deux cas de coupelles superposées, c'est la plus petite qui se trouvait sous la plus grande.

\section{Tombe 22 (fig. 15)}

Sépulture orientée tête à l'est (niveau - 26) d'un enfant âgé d'environ 6 à 7 ans, reposant en décubitus dorsal, la tête en nette rotation droite.

Un peu en dessous de l'épaule droite, sur la face antérieure de la scapula et de l'humérus, se trouvait une grande fibule à navicelle (fig. $21, \mathrm{n}^{\circ} 14$ ).

Un gros galet a été retrouvé entre les jambes, à la hauteur des chevilles. Des traces de bois, mises en évidence au niveau du tiers inférieur de l'humérus droit, correspondent à la présence d'un cercueil, confirmée par la mise à plat du bassin.

Tombe 23 (fig. 15)

Sépulture orientée tête sensiblement à l'est (niveau -4), d'une femme dont l'âge au décès était compris entre 20 et 48 ans, reposant en décubitus dorsal.

Aucun mobilier.

\section{Tombe 24 (fig. 15)}

Sépulture d'un adulte de sexe masculin, orientée tête au sud-ouest (niveau +3 ), dont l'âge au décès était compris entre 45 et 75 ans.

Un petit anneau en bronze a été retrouvé au contact de la face endocrânienne du pariétal droit (fig. 21, $\mathrm{n}^{\circ} 15$ ).

Cette sépulture recouvre partiellement les céramiques de la tombe 21 ; elle est donc postérieure à cette dernière.

\section{Tombe 25 (fig. 15)}

Sépulture orientée tête au sud-ouest (niveau +11), mal conservée et en partie remaniée, d'un adulte de sexe et d'âge indéterminés reposant en décubitus dorsal.

Aucun mobilier.

\section{Tombe 26 (fig. 15)}

Tombe orientée sensiblement tête au nord-est, (niveau - 13) d'un adulte de sexe et d'âge indéterminés reposant en décubitus dorsal. 

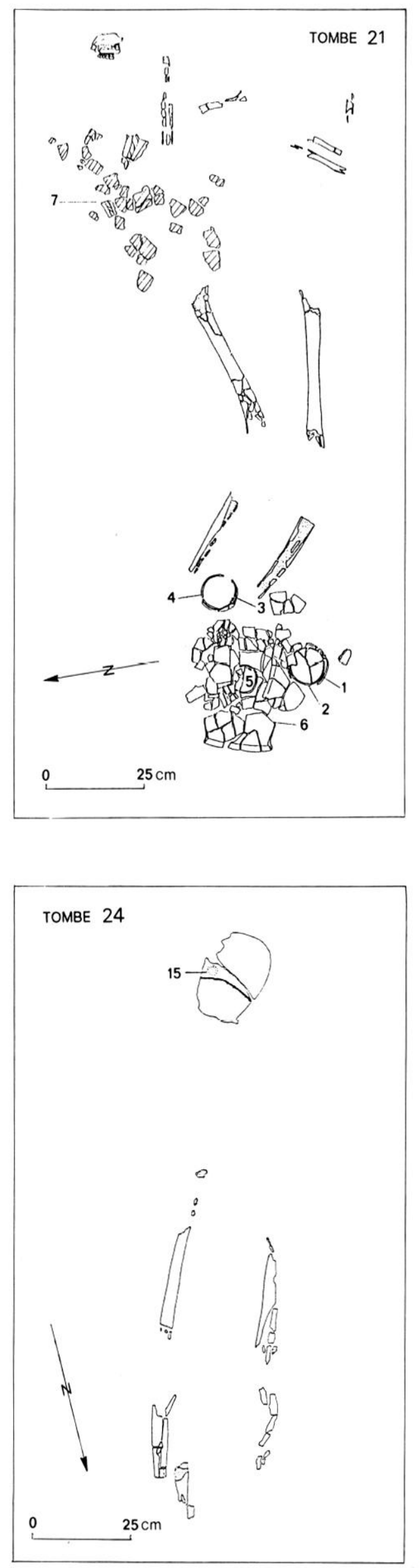

Fig. 15 - Plans des tombes 21 à 26 .
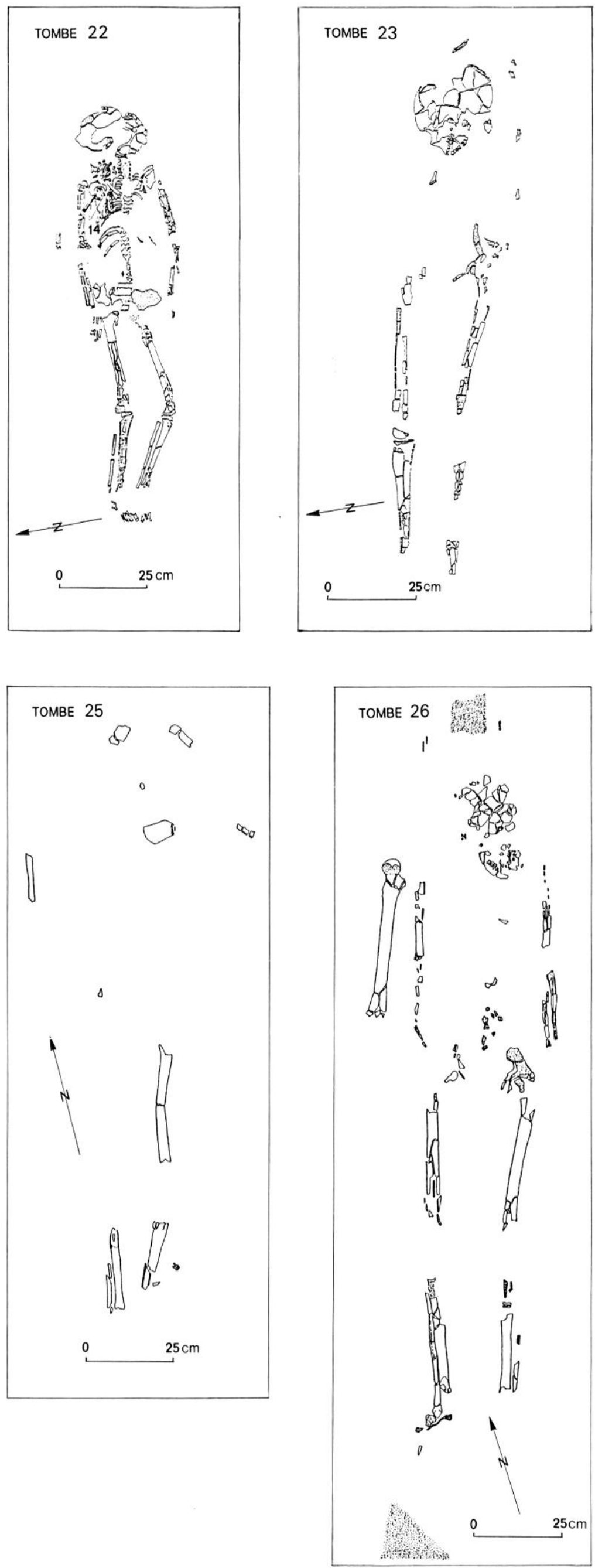
Aucun mobilier.

Un fémur gauche isolé, appartenant à un sujet adulte, a été découvert à environ $10 \mathrm{~cm}$ au-dessus du niveau de la tombe, à l'ouest du membre supérieur droit.

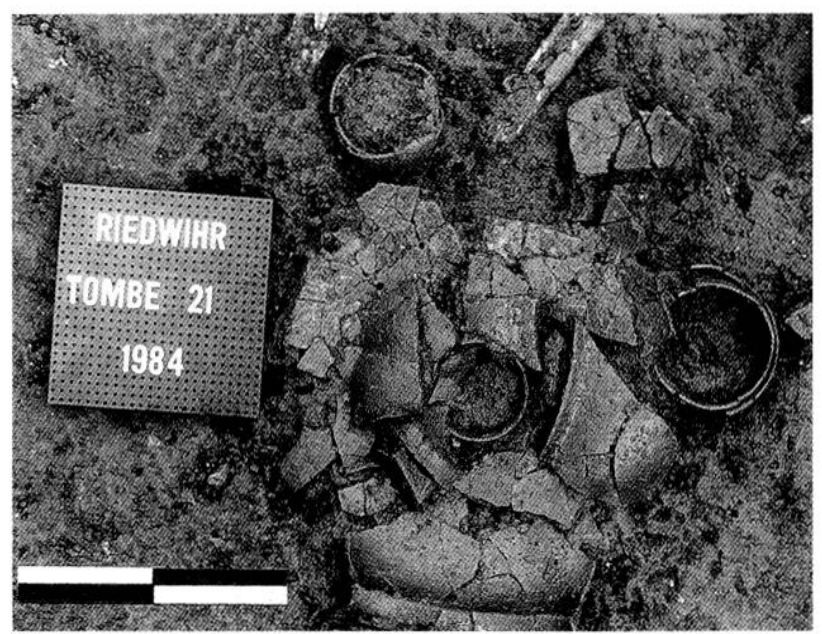

Fig. $16-$ Vue de la tombe 21 .
Des traces ligneuses, visibles aux deux extrémités de la sépulture, prouvent l'existence d'un cercueil en bois.

\section{Tombe 27 (fig. 17)}

Sépulture d'un adulte de sexe et d'âge indéterminés (niveau +14 ) orientée tête au nord-ouest, reposant en décubitus dorsal.

Aucun mobilier.

La diaphyse tibiale gauche d'un adulte a été trouvée $7 \mathrm{~cm}$ au-dessus du talus gauche de cette tombe.

\section{Tombe 28 (fig. 17)}

Sépulture très remaniée d'un adulte de sexe et d'âge indéterminés, orientée tête au nord-ouest (niveau +15 ).

Un bracelet de bronze a été trouvé à $20 \mathrm{~cm}$ à l'est du tibia droit (fig. $21, \mathrm{n}^{\circ} 17$ ).
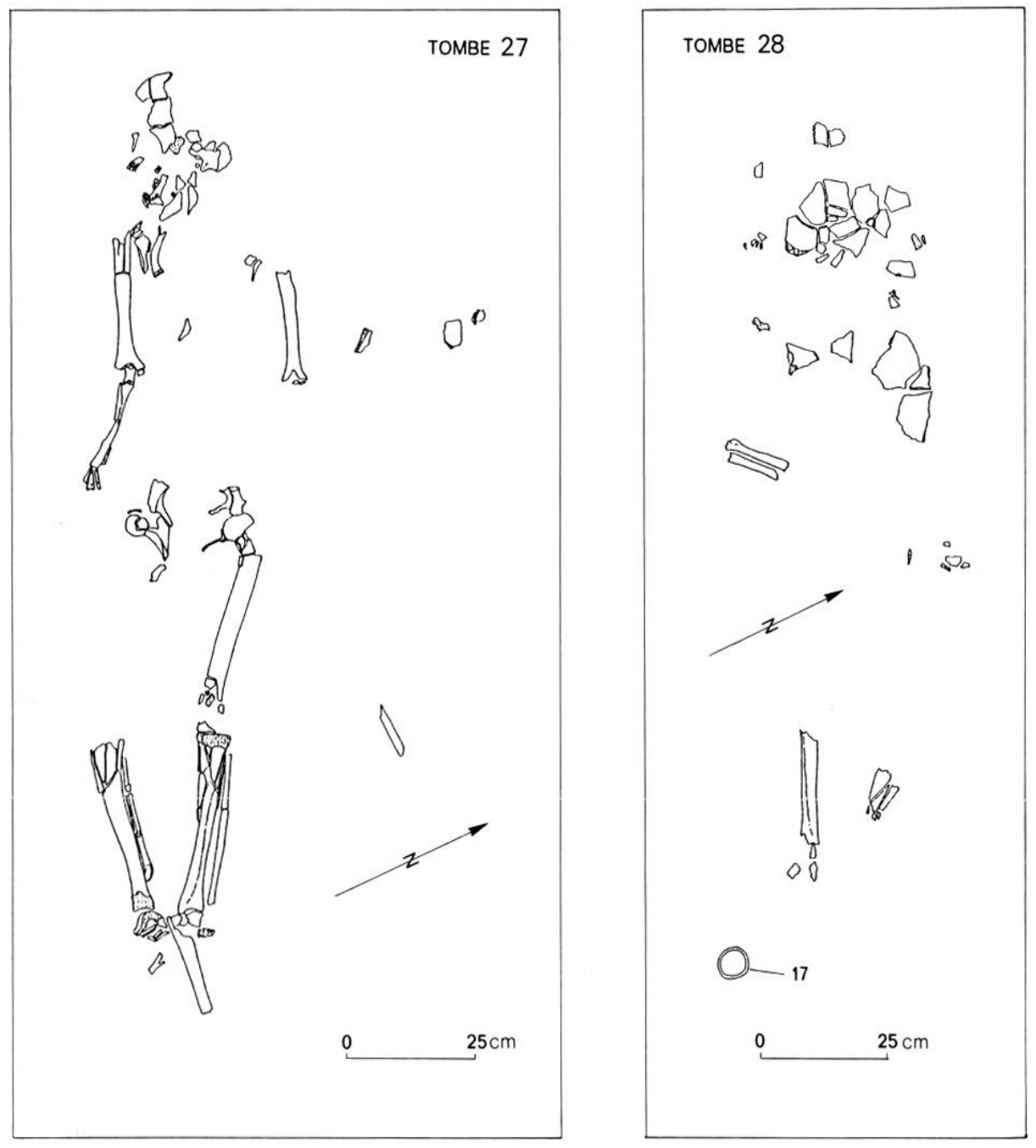
Les restes humains dispersés

(tabl. III, p. 51 et fig. 18)

Particulièrement nombreux, ces restes humains sont répartis sur presque toute la surface du tertre, à l'exception de son tiers ouest, et à toutes les profondeurs.

\section{Les restes humains des tombes incomplètes}

Les résultats de cette recherche sont décevants, en partie à cause de la mauvaise conservation des restes humains, mais surtout parce que la grande majorité d'entre eux appartient vraisemblablement à des sépultures distinctes remaniées.

Néanmoins deux résultats semblent acquis. Le fragment d'occipital de G21 appartient au crâne de la tombe 24, située à proximité immédiate. La diaphyse tibiale gauche de E4 est très certainement symétrique de celle de la tombe 10 proche.
Les autres résultats ne sont malheureusement pas assurés. Ainsi les fragments crâniens de $\mathrm{I} 2$ et $\mathrm{I} 3$ pourraient appartenir à l'un des deux sujets de la tombe 4 (même niveau et même situation). Les diaphyses fémorales droites de N1, de DE6, et la diaphyse humérale gauche de D5 pourraient appartenir respectivement aux tombes 6 et 10 .

\section{Les restes humains des tombes remaniées}

Nous avons regroupé les restes humains symétriques ou géographiquement proches et de niveau sensiblement comparable, pour tenter de reconstituer d'éventuelles tombes remaniées.

En GH2, le fragment de mandibule isolée n'appartient pas à celle de la tombe 21 ; il existe donc très certainement là les restes d'une tombe d'adulte remaniée. Cette tombe est représentée en outre par

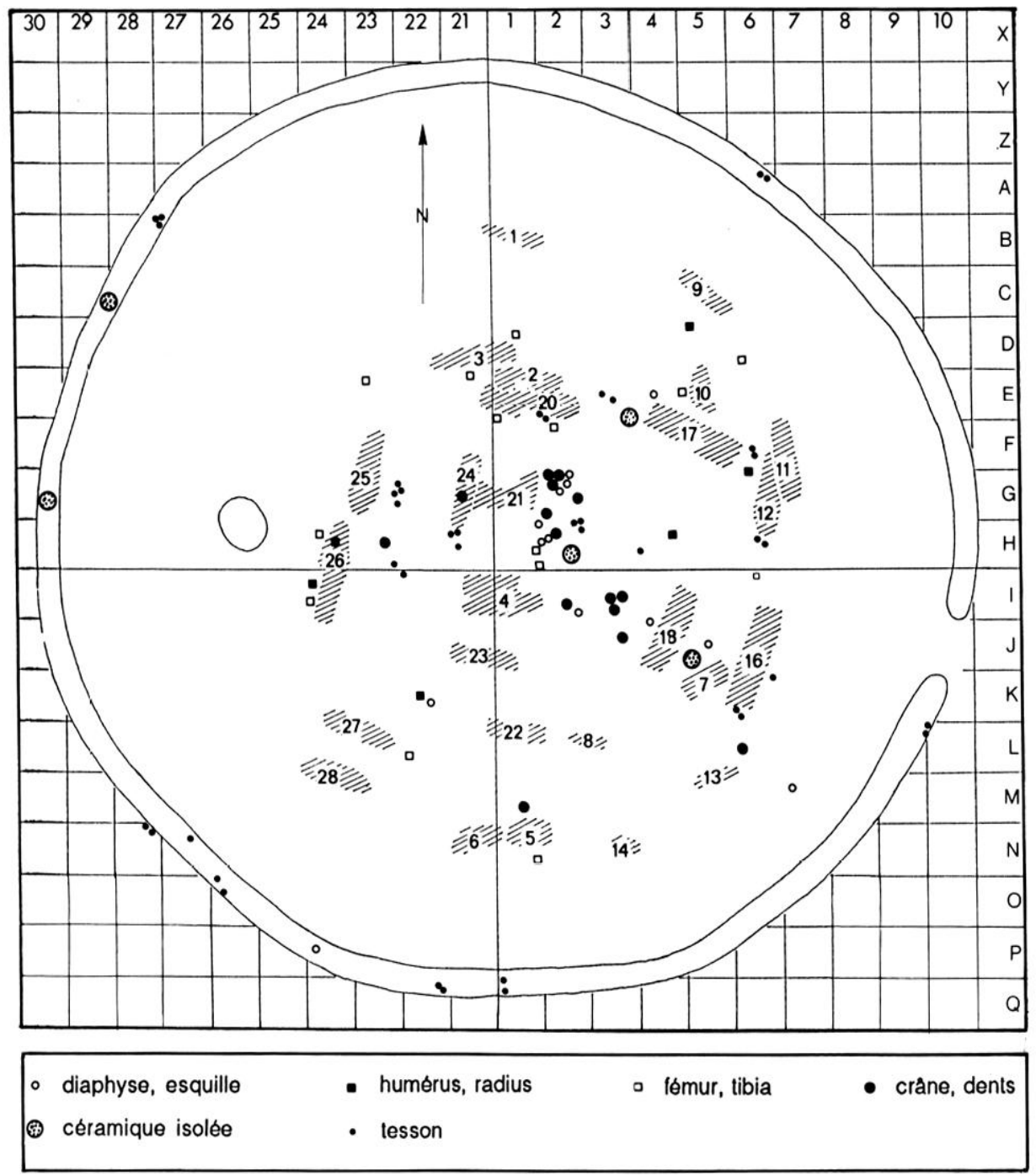

Fig. 18 - Répartition des céramiques et des restes humains isolés. 
plusieurs fragments crâniens et par quelques petits fragments diaphysaires.

Les dents isolées de Ml appartiennent à une tombe d'enfant dont l'âge au décès est compris entre 2 et 4 ans. Il s'agit sans doute d'une tombe remaniée, mais la mauvaise conservation des os d'enfant ne permet pas d'exclure formellement l'existence d'une tombe en place dont seuls les restes dentaires nous seraient parvenus.

Les humérus symétriques de HI24 et I24, le fémur gauche de H24 et le tibia gauche de I25 appartiennent vraisemblablement au même adulte.

Un autre sujet (adulte ou adolescent) pourrait être représenté par la diaphyse tibiale gauche de L22 qui reposait sur le pied de la tombe 27 et par la diaphyse humérale gauche de K22.

Rappelons aussi les restes humains isolés autour de la tombe 20 , représentés par les deux fémurs symétriques de E1 et D1, le tibia droit de D21, la fibula de E1 et la patella gauche de E2 .

Enfin les diaphyses humérales gauche de $\mathrm{H} 4$ et droite de I6, l'ulna et le radius droits de E6 et la diaphyse fémorale de DE23 ne semblent faire partie d'aucune sépulture intacte ou remaniée. Malgré leur isolement, ils appartiennent sans doute aussi à une ou plusieurs sépultures distinctes remaniées.

En définitive, sans tenir compte des os rigoureusement isolés ci-dessus, les données qui précèdent militent pour l'existence d'un minimum de cinq tombes supplémentaires remaniées.

\section{LE MOBILIER : ÉTUDE ET DATATION}

Le poignard de la tombe 4 (fig. 19)

\section{Étude typologique}

Le poignard en fer, d'une longueur totale de $42,7 \mathrm{~cm}$, est une pièce exceptionnelle à la fois par sa rareté et par son état de conservation. Lame et fourreau sont malheureusement trop oxydés pour qu'il soit possible de les séparer.

La lame à double tranchant possède une largeur de $7 \mathrm{~cm}$. Sa longueur $(27 \mathrm{~cm})$ a été révélée par la radiographie effectuée lors de la restauration du poignard au Musée du Fer de Jarville. La garde rectiligne est décorée de fines stries transversales à
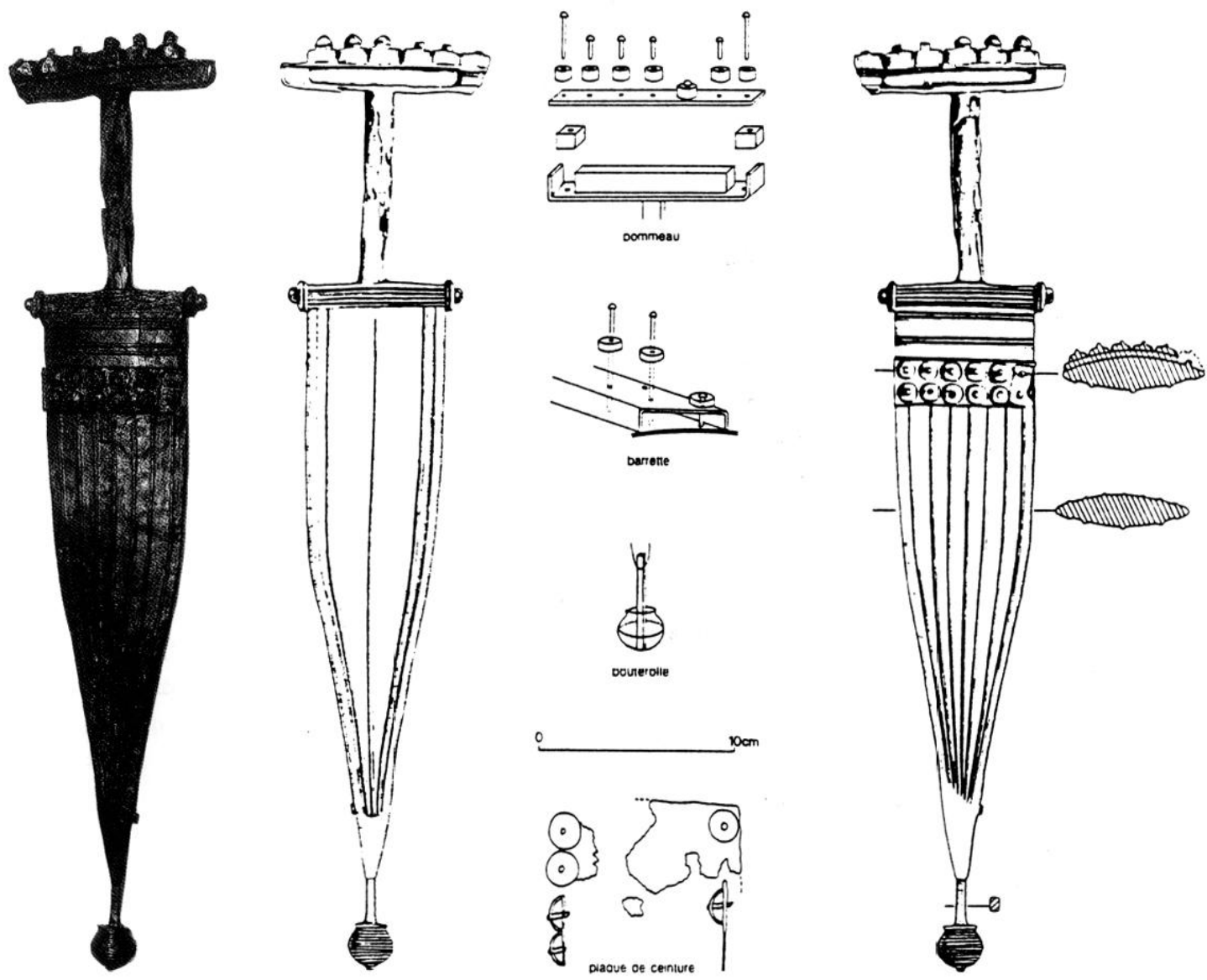

Fig. 19 - Tombe 4 : poignard et plaque de ceinture. 
l'avant et d'une bossette rappelant celles du pommeau sur les faces latérales. La poignée est composée d'une soie quadrangulaire longue de $8,6 \mathrm{~cm}$, qui devait servir d'axe à des éléments en matière périssable et d'un pommeau transversal rectiligne orné de sept bossettes rivetées (une d'elles a disparu).

Le fourreau, constitué de deux tôles de fer décorées de longs filets verticaux obtenus par martelage, porte sur la face antérieure une plaquette décorative rapportée, ornée de deux rangées de six petites bossettes, rappelant le décor du pommeau. L'extrémité du fourreau se termine par une bouterolle sphérique creuse, formée de deux hémisphères réunies par brasure ; cette bouterolle porte un décor de larges cannelures horizontales.

Le poignard de Riedwihr appartient à la catégorie des poignards à antennes, dont il existe un très grand nombre de variantes. Dès 1927, J. Déchelette cffcctuc une première ètude typologique de ces armes. Cette étude a été reprise récemment par S. Sievers (1982b) dans un inventaire exhaustif de tous les exemplaires connus dans le domaine hallstattien nord-alpin. A coté des poignards munis de véritables antennes (droites ou arquées), généralement terminées par des protubérances plus ou moins sphériques ou des disques, S. Sievers distingue deux types possédant des fourreaux ornés de filets verticaux, technologiquement et typologiquement semblables. Le premier est caractérisé par des antennes atrophiées, très courtes, repliées et plaquées sur le pommeau (type Etting); pour le second, les antennes ont totalement disparu et sont remplacées par une longue barre transversale quadrangulaire, sur laquelle deux plaquettes rectangulaires sont fixées à l'aide de longs rivets décorés (type Estavayer). Le nombre de ces rivets est variable selon les modèles (neuf sur l'exemplaire éponyme, sept à Riedwihr). De cette complication du pommeau découle l'appellation de "poignard à pommeau évolué " (entwickeller Knauf).

Parmi les vingt-quatre poignards à antennes évoluées répertoriés par $\mathrm{S}$. Sievers, douze appartiennent avec certitude à la variante Etting et sept à la variante Estavayer. En l'absence d'éléments déterminants du pommeau, les cinq autres trouvailles, auxquelles il faut ajouter une découverte récente à Uttendorf en Autriche (Egg, 1985b), ne peuvent être classées avec certitude à l'intérieur d'une variante précise.

Par son état exceptionnel, le poignard de Riedwihr appartient, avec ceux d'Estavayer et de Wolfegg, aux rares poignards à antennes évoluées encore pratiquement intacts à l'heure actuelle.

\section{Attribution culturelle et chronologique}

Si les poignards de type Estavayer sont largement dispersés sur tout le sud de l'Europe tempérée, de l'Autriche à l'Alsace, la carte de répartition prouve l'existence d'une concentration dans le sud du Wurtemberg (fig. 20). La variante Etting est, elle aussi, plus abondamment représentée dans cette même région que l'on peut donc concevoir comme centre de diffusion des différents poignards à antennes évoluées.

La datation des poignards de type Estavayer est difficile à déterminer, à cause de la rareté des associations pertinentes : cinq exemplaires en effet proviennent de découvertes anciennes $\left(\mathrm{xIX}^{\mathrm{e}} \mathrm{s}\right.$. et du début $\mathrm{xx}^{\mathrm{e}} \mathrm{s}$.), pour lesquelles la documentation est incertaine. Le poignard d'Estavayer a été trouvé dans le lac de Neuenburg en Suisse, sans contexte. Seul l'exemplaire de Wolfegg dans le Wurtemberg, découvert en 1962, est bien daté; provenant d'une tombe double, il était associé à une pointe de lance en fer et à une fibule serpentiforme de type S4, attribuée à la fin du Hallstatt D1 (Mansfeld, 1973). Les poignards de type Etting, qui possèdent la même attribution culturelle et présentent un schéma technologiquement très proche, appartiennent très certainement aussi à cette première phase du Ha D.

Ln argument d'ordre stylistique permet de conforter cette attribution à la fin du Hallstatt D1. La bouterolle cannelée de l'extrémité du fourreau s'apparente très fortement aux cabochons hémisphériques qui bordent la caisse du char de la célèbre tombe princière de Hochdorf (Der Keltenfürst von Hochdorf, 1985, p. 156), bien datée de la transition D1-D2. La ressemblance entre ces deux éléments décoratifs, élaborés du reste dans la même zone géographique, indique très certainement leur contemporanéité.

\section{Implications sociales}

Cette arme prestigieuse constitue un important témoignage de la maîtrise à laquelle étaient parvenus les artisans celtes vers 550 avant notre ère. La mise en forme et l'ornementation prouvent que la métallurgie du fer, particulièrement complexe, était alors parfaitement maîtrisée et avait atteint là une apogée.

Les prouesses techniques dont témoignent ces poignards en fer et leur valeur intrinsèque impliquent leur caractère de biens de prestige, à l'évidence réservés à une élite. Ces biens de prestige doivent sans doute être interprétés comme des signes d'identification sociale. Insigne de pouvoir et de 


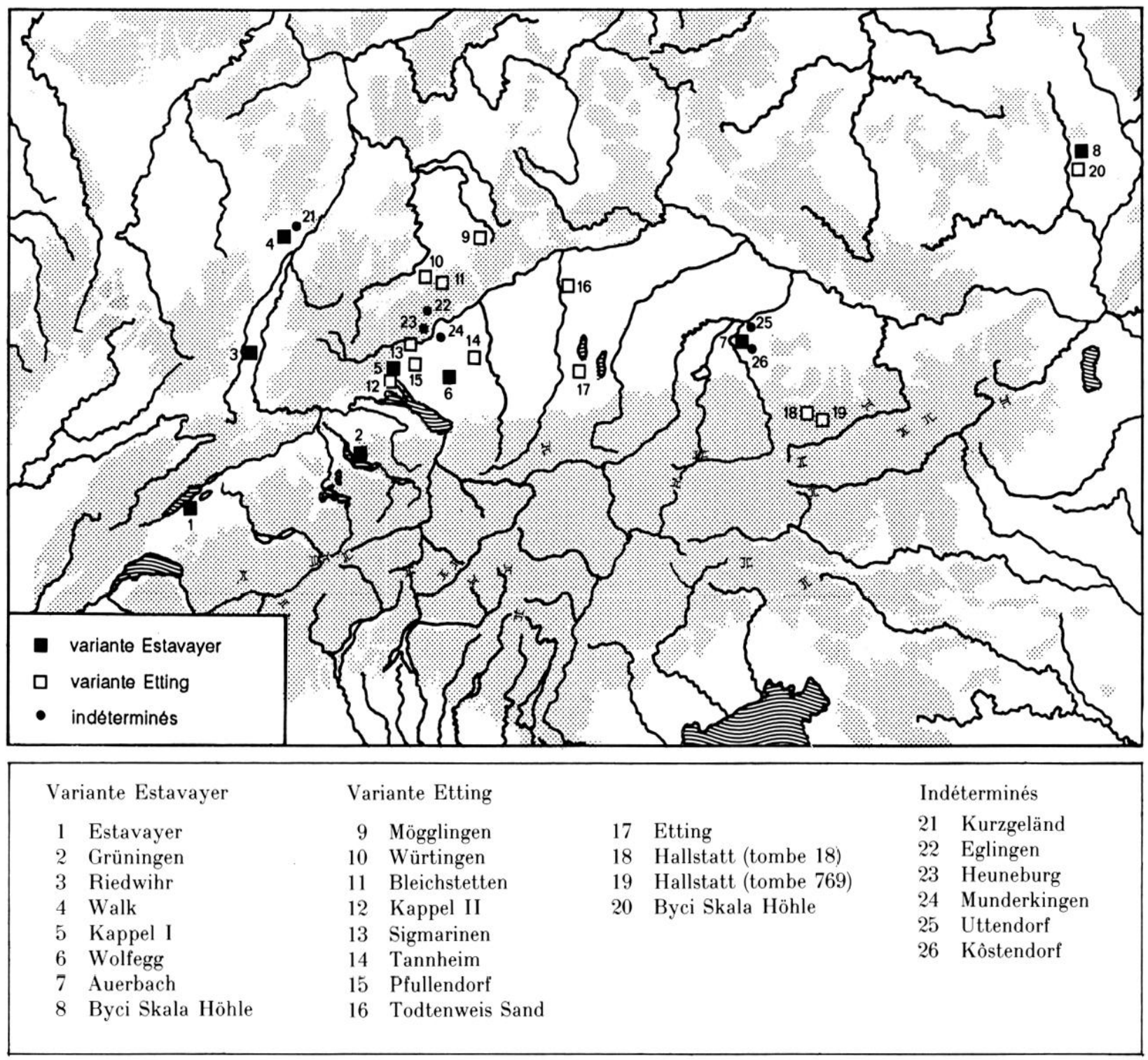

Fig. 20 - Carte de répartition des poignards à antennes évolués.

puissance plutôt qu'arme réelle, le poignard de Riedwihr suggère une tombe de type aristocratique.

\section{Les autres objets en fer}

\section{Le rasoir de la tombe 12 (fig. $21, n^{\circ} 6$ )}

Malgré ses extrémités tronquées, ce rasoir en forme de croissant possède une longueur de $9 \mathrm{~cm}$, ce qui en fait un exemplaire de grande taille.

Parmi les nombreux types de rasoir en bronze, une forme en croissant appelée type Ins (Jockenhövel, 1971, no 581) apparaît au cours du Hallstatt C, en Suisse occidentale. Ce modèle est rapidement remplacé par une variante en fer, dont la datation précoce est attestée dans quelques tertres de Suisse et du Wurtemberg (Schwab, 1984, p. 74; Aufder- mauer, 1963). Ainsi à Mauenheim, tumulus $\mathrm{Jl}$, dans une incinération, un rasoir en fer est associé avec des urnes à épaulement et col tronconique et avec des urnes basses à décor gravé et estampé, caractéristiques du Ha C.

Considérés par H. Parzinger (1986a) comme un des fossiles-directeurs du $\mathrm{Ha} \mathrm{Dl}$, les rasoirs en croissant sont particulièrement fréquents en Allemagne du Sud-Ouest, en Suisse et dans la France de l'Est, alors que plus au nord, ils restent rares (la Hesse du Sud n'en a livré que quatre exemplaires [Schumacher, 1974, p. 53]). Les neuf rasoirs en fer du Magdalenenberg (Spindler, 1971-1980) prouvent la variété des modèles durant une même phase, car leur longueur oscille entre 7,5 et $11,5 \mathrm{~cm}$. Leur largeur aussi est très variable, alors qu'ils sont à peu près contemporains. 
Associés à un mobilier funéraire stéréotypé (fibule à navicelle, fibule à arc cintré, urne à haut col tronconique, poignard, pointes de lance et pointes de flèches), les rasoirs sont présumés appartenir à l'équipement masculin. A Riedwihr, ce fait est confirmé par l'analyse anthropologique, comme il l'a été pour les tombes à rasoir 51, 80, 108 et 119 du Magdalenenberg (Gallay, 1977, p. 105). Si la position des rasoirs dans la tombe est très variable (au-dessus de la tête, au niveau de l'épaule, entre les jambes ou aux pieds), la signification éventuelle de ces variantes nous échappe pour l'instant. Les fragments textiles conservés par les oxydes métalliques, visibles sur les deux faces du rasoir et sur plusieurs épaisseurs, prouvent qu'il était entouré de tissu, selon une coutume hallstattienne attestee pour de nombreux types d'objets (Masurel, 1984). Les fibres sont malheureusement trop mal conservées pour permettre une étude du tissage.

\section{Les pointes de flèche (fig. 21, nos 1 à 5)}

La tombe 12 contenait aussi quatre petites pointes de flèche en fer martelé, de tailles variables, et un fragment de fer pouvant appartenir à une cinquième pointe. L'armature triangulaire est prolongée par des ailerons plus ou moins longs. Le pédoncule, plus épais, a été forgé sur l'armature; son extrémité inférieure s'aplatit en languette destinée à être insérée dans une hampe en bois.

Même si l'orientation des pointes diverge, leur nombre élevé et leur situation bien regroupée suggèrent l'hypothèse d'un carquois en matière périssable, dont l'existence est parfois bien attestée par des traces tangibles: tombe VI du Hohmichele (Riek, Hundt, 1956), tombe princière de Hochdorf (Keltenfürst von Hochdorf, fig. 83 et 158).

Dans son étude sur les armes hallstattiennes du Bade-Wurtemberg, S. Sievers répertorie 119 pointes de flèche réparties sur seize sites seulement $(1982 b$, p. 94). La relative rareté de ce type d'objet permet de supposer qu'il s'agissait certainement davantage d'un symbole social que d'un objet utilitaire. Les pointes de flèches en fer sont généralement associées à d'autres armes : couteau, poignard ou pointe de lance. Leur apparition avec un rasoir est plus rare. Cette association existe néanmoins dans deux tombes du Wurtemberg, à Heidenheim-Schnaitheim et à Tübingen (Zürn, 1987, pl. 107 et 426).

La datation des pointes de flèche trouvées en Europe tempérée est homogène. Celles des deux tombes citées précédemment sont datées du Ha D1 par des épingles à col de cygne et par une fibule serpentiforme de type $\mathrm{S} 4$. Cette datation est valable pour la grande majorité des pièces d'Allemagne du Sud-Ouest, même si quelques rares associations se situent un peu plus tard, à la transition Ha D1/ Ha D2. En Alsace, dix pointes de flèche de grande taille proviennent d'un tertre de Mussig (Hatt, 19401946). Elles sont aussi datées du $\mathrm{Ha} \mathrm{Dl}$ par leur association avec une boucle d'oreille en or et deux fibules serpentiformes à disque d'arrêt de type $\mathrm{S} 1$.

Les pointes de flèche de Riedwihr confirment donc l'importance de la tombe 12 et son attribution au Ha D1.

\section{Le bracelet en fer de la tombe 16}

Ce bracelet, porté au poignet gauche, possédait une tige massive de section ronde, mais les quelques fragments conservés ne permettent pas de définir précisément sa forme. D'après les exemplaires du Wurtemberg, il existe des modèles fermés comme ceux de la tombe 6 de Hirschlanden (Zürn, 1970, pl. 30B) mais aussi des modèles ouverts, à tampons plus ou moins volumineux tels ceux de Deisslingen (Oeftiger, 1984b, fig. 4) et de Feldkirch-Hartheim (Badische Fundberichte, 1940).

L'existence de bracelets en fer est largement attestée dans le domaine hallstattien nord-alpin : Wurtemberg, Bade (Nellissen, 1975), région du RhinMain (Polenz, 1973), Bavière (Torbrugge, 1979), mais la précarité de leur conservation complique leur étude et ne permet pas actuellement de définir une évolution interne ou l'existence de types régionaux.

S. Sievers (1982b, p. 97) signale qu'en BadeWurtemberg, la présence d'un seul bracelet, porté au poignet gauche, caractérise une tombe masculine. Cette constatation est confirmée ici par l'analyse anthropologique.

\section{L'agrafe en fer de la tombe 18 (fig. 21, no 12)}

L'interprétation du petit objet en fer trouvé sur l'abdomen de la femme de la tombe 18 est délicate. Il s'agit sans doute d'une agrafe de ceinture, dont le type est bien connu en Suisse au Ha Dl (Drack, 1968-1969).

\section{Les objets hallstattiens en bronze}

\section{Le fragment de fibule de la tombe 2}

Un petit fragment de bronze $(12 \mathrm{~mm}$ de long, $1 \mathrm{~mm}$ de diamètre) appartient à un axe de ressort de fibule, sur lequel subsistent encore deux spires. Ce type de ressort n'apparaît qu'à partir du Ha D2. 


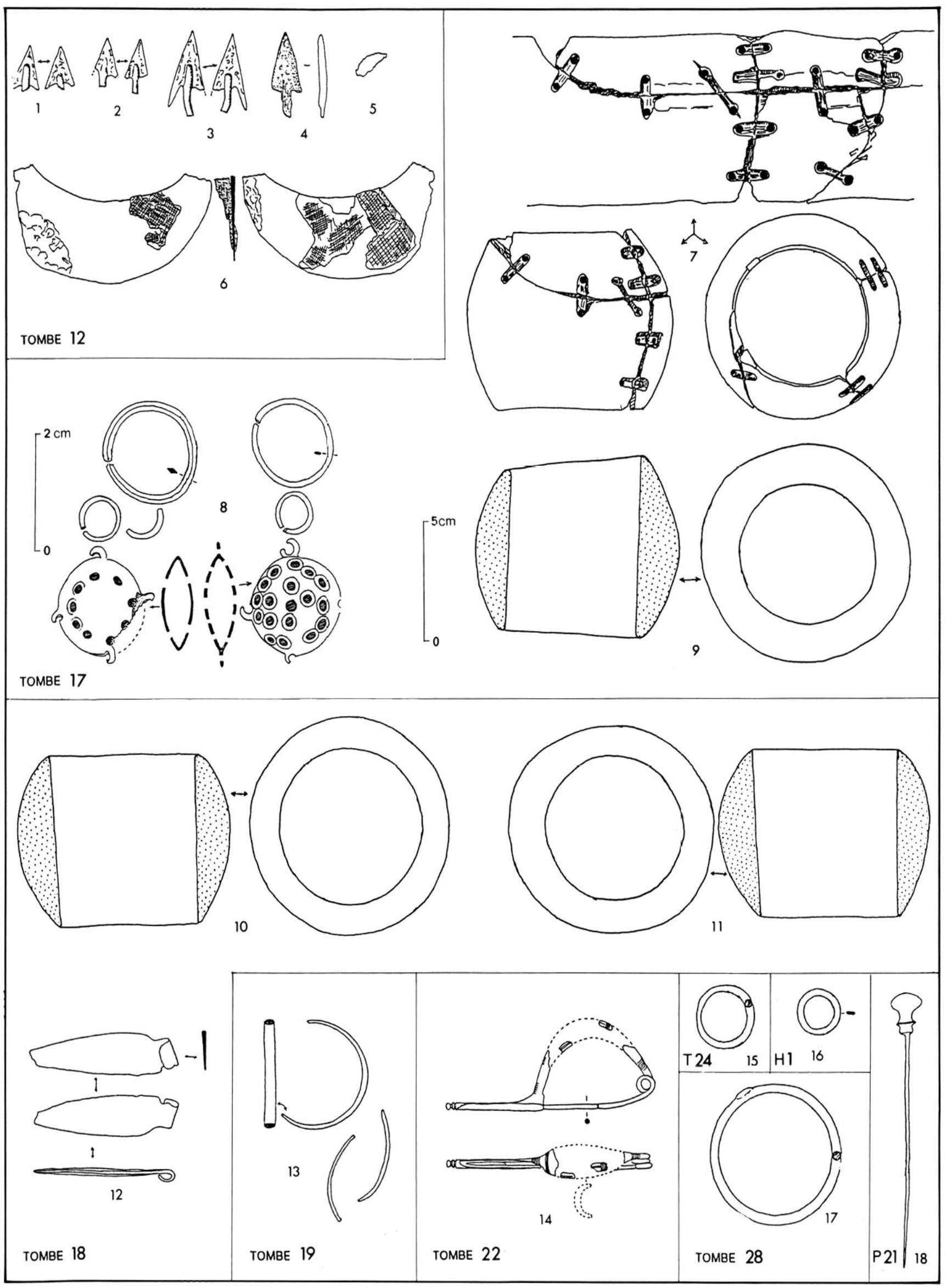

Fig. 21 - Tombes 12,17 à 19, 22, 24 et $28:$ mobilier; H1, P21 : objets isolés. 


\section{La plaque de ceinture de la tombe 4 (fig. 19)}

Les deux fragments trouvés sous le poignard correspondent à une extrémité de plaque de ceinture en bronze lisse, ornée de gros cabochons hémisphériques en tôle, fixés par rivetage. Ces caractéristiques permettent de classer la plaque parmi le type "Inneringen", connu à travers vingl-neuf exemplaires, très largement dispersés sur l'ensemble du domaine hallstattien nord-alpin, depuis le Jura français jusqu'à Hallstatt en Autriche, avec une concentration relativement forte dans le sud du pays de Bade et du Wurtemberg (Kilian-Dirlmeier, 1972, p. 17).

Une quinzaine de plaques de type Inneringen proviennent d'ensembles clos, mais leur datation n'est pas homogène car elles couvrent le $\mathrm{Ha} \mathrm{Dl}$ et le Ha D2. En Alsace, les trois plaques de type Inneringen, type cantonné jusqu'à présent en forêt de Haguenau (Schaeffer, 1930, fig. 136x, 122, 50v) appartiennent à la même fourchette chronologique. La plaque de Maegstub c, 8, I, accompagnée de deux fibules à navicelle (très proches de celle de la tombe 22) appartient au Ha D1. Celle de Maegstub c, 1, II, de taille nettement supérieure aux deux autres, appartient à une tombe riche datée de la fin du $\mathrm{Ha}$ D1 (phase 2 de H. Parzinger, 1988), par un torque à 6 anneaux de suspension, deux bracelets massifs fermés, deux bracelets composés de 143 et 79 perles de lignite, deux anneaux de jambe massifs ouverts, et une poterie dont la panse est couverte de petits mamelons. Enfin la plaque de Kurzgeländ 3, III est associée à deux grandes fibules de type particulier (un arc en fer surmonté d'une calotte en bronze); ces fibules sont datées par I. Kilian-Dirlmeier (1972) du Ha D2, mais elles appartiennent vraisemblablement au début de cette phase. Pour la tombe 4 de Riedwihr, l'association de cette plaque avec le poignard en fer confirme une datation à la fin du Ha Dl.

Comme les plaques de type Inneringen sont assez souvent associées à des armes, surtout en Bavière, I. Kilian-Dirlmeier considère qu'elles font sans doute partie de l'équipement masculin. H. Parzinger (1986a) leur attribue cette même fonction dans la région de Stuttgart. Il est difficile d'étendre ces conclusions aux trouvailles alsaciennes. A Riedwihr, l'association avec un poignard tendrait à confirmer cette fonction, mais le mobilier de Maegstub c, 1, II, avec ses nombreuses parures correspond plutôt au costume féminin.

\section{Les boucles d'oreilles de la tombe 17 (fig. 21, no 8)}

Les deux boucles d'oreilles forment une parure composite, associant un anneau massif ouvert de sec- tion losangique, deux annelets ouverts et deux pendeloques formées chacune de deux calottes accolées, de $1,8 \mathrm{~cm}$ de diamètre et $0,7 \mathrm{~cm}$ de hauteur. Réalisées en tôle très fine, elles présentent quatre œillets sur leur pourtour et sont ornées d'une série de perforations, disposées assez irrégulièrement et entourées d'une strie.

Nous ne connaissons jusqu'à présent aucun parallèle exact à ce type de parure, mais il est évident que l'extrême finesse de la tôle de bronze entraîne des problèmes de conservation, expliquant sans aucun doute la rareté apparente de ces boucles d'oreilles. Seules certaines pendeloques creuses du Magdalenenberg (t. 16) et de Maegstub, 4, I, formées de deux hémisphères accolés pourraient évoquer un type plus ou moins proche, du moins techniquement. Mais elles ne sont pourvues que d'une seule bélière, terminant une tige qui traverse la pendeloque et leur système d'accrochage est donc beaucoup plus évident.

\section{La fibule à navicelle de la tombe 22 (fig. 21, no 14)}

Avec son arc semi-circulaire, la fibule à navicelle appartient au type K1 de Mansfeld (1973, p. 20). Elle possède un long porte-agrafe terminé par un très petit bouton mouluré et un ressort unilatéral formé de deux spires. L'arc, en tôle très fine, est très mal conservé, mais les quelques fragments restant permettent néanmoins de reconstituer le décor gravé. Il est composé de groupes de stries transversales alternant avec des zones lisses et encadrant unc zonc médiane qui comporte des stries sans doute longitudinales. D'après le schéma établi par G. Mansfeld, ces différents caractères classent la fibule de Riedwihr dans la catégorie $\mathrm{Kl}$ (arc), D (bouton), x (ressort), V5 (décor). Si les différenciations établies à partir de la forme de l'arc semblent peu pertinentes pour fixer datation ou région d'origine, les critères de sélection fondés sur la forme du ressort ( $\mathrm{x}=$ ressort unilatéral, $\mathrm{w}=$ disque d'arrêt, $\mathrm{y}$ et $\mathrm{z}=$ à petit ressort bilatéral) semblent plus pertinents pour séparer les types. Les ressorts $\mathrm{x}$ et $\mathrm{w}$ (ce dernier étant très rare) sont les plus précoces et concernent essentiellement l'Allemagne du Sud-Ouest, la Suisse, la France de l'Est; les ressorts y et $\mathrm{z}$ sont plus tardifs et géographiquement, ils sont surtout bien représentés en Bavière et dans le nord du Wurtemberg.

G. Mansfeld a répertorié 83 fibules à navicelle en Europe moyenne. Parmi elles, une cinquantaine possèdent un ressort unilatéral (type $\mathrm{x}$ ) analogue à celui de Riedwihr et sont particulièrement nombreuses dans la région du moyen Neckar et le sud du Wurtemberg. Les fibules à navicelle sont bien représen- 
tées en Alsace; la majorité provient du nord de la région, de la forêt de Haguenau (Konigsbruck, 17, II ; Kurzgeländ, 4, I ; Maegstub, 8, I ; Maegstub, 14, $\mathrm{V}$; Ohlungen $3, \mathrm{Xl}$ et 3 , XIV et peut-être Kurzgeländ, 88, III) ou des environs (Hatten-Eschenbusch, tumulus 2, tombes III et IV; Achenheim, fosse 32 ; Dingsheim); dans le sud de l'Alsace, le seul exemplaire connu jusqu'à la découverte de Riedwihr I était celui de l'habitat princier du Britzgyberg.

Si toutes les fibules à navicelle à ressort unilatéral de la Heuneburg et d'Allemagne du Sud-Ouest sont datées du Ha D1, une évolution semble perceptible dans la taille du bouton terminant le porteagrafe. A partir d'une forme assez volumineuse, le bouton diminue progressivement. Avec son bouton de type $\mathrm{D}$, la fibule à navicelle de Riedwihr se situerait dans la phase IIIb de la Heuneburg (Mansfeld, 1973, p. 69), c'est-à-dire vers la fin du Ha D1.

\section{L'anneau de la tombe 24 (fig. 21, no 15)}

Le petit anneau de bronze de $2,6 \mathrm{~cm}$ de diamètre était vraisemblablement accroché au cou à l'aide d'un cordon périssable, ce qui est suggéré par sa position au niveau de la tête. Ce type de pendeloque est bien connu régionalement durant tout le Hallstatt D, aussi bien à Haguenau, Kurzgeländ, tumulus 7, IV (Schaeffer, 1930, fig. 51g) que dans de nombreuses fouilles récentes inédites (Nordhouse, Wettolsheim).

\section{Le bracelet de la tombe 28 (fig. 21, no 17)}

Ce bracelet massif et fermé, de $\overline{0}, 2 \mathrm{~cm}$ de diamètre intérieur, est caractérisé par la présence d'une trace de coulée. Très fréquent au Magdalenenberg, dans le Wurtemberg du Nord ainsi qu'à Haguenau, ce type de bracelet apparaît au cours du Ha D1 (phase 2 de H. Parzinger, 1988), mais son utilisation se poursuit au Ha D2, et même encore au Ha D3 dans certaines régions comme le Palatinat rhénan (Engels, 1967). La position excentrée de la tombe 28 pourrait peut-être suggérer ici une datation au Ha D2.

\section{Les objets en bronze antérieurs au Hallstatt}

\section{Les fragments de bracelets de la tombe 19} (fig. 21, no 13)

Ces trois fragments, en bronze massif, appartiennent à deux bracelets différents. Les deux fragments peu recourbés ne peuvent être datés avec précision en l'absence de toute indication sur la nature des extrémités. Mais avec leur section très légèrement en D, dont nous ne connaissons pas d'équi- valent régional durant la période hallstattienne, ils pourraient appartenir à un bracelet spiralé du Bronze moyen. Le troisième fragment, plus épais et à section en $\mathrm{D}$ plus accentuée, rappelle un type de bracelet de la même période, dont les extrémités amincies auraient disparu.

L'attribution de la tombe 19 au Bronze moyen n'est pas aberrante, dans la mesure où l'occupation du site dès cette période est attestée par la tombe 5 du tertre voisin, datée par une cruche de type haguenovien et une épingle fusiforme.

\section{Épingle de type Wollmesheim (fig. 21, $n^{\circ}$ 18)}

Une petite épingle de $11,2 \mathrm{~cm}$ de longueur provient du carré $P 21$ (niveau 0 ). Avec sa tête volumineuse, grossièrement biconique, et ses deux fines collerettes de diamètre nettement inférieur à celui de la tête, elle appartient au type Wollmesheim, originaire de la région Rhin-Main et daté du Bronze final Ila, pour lequel W. Kubach (1977, pl. 104) distingue trois variantes. L'épingle de Riedwihr appartient au groupe I, assez largement diffusé en Suisse du NordOuest, Jura et Wurtemberg. Il s'agit du seul exemplaire de cette variante trouvé en Alsace, si l'on excepte une épingle du Musée d'Unterlinden à Colmar dont la provenance est inconnue (Zumstein, $\left.1966, \mathrm{n}^{\circ} 116 \mathrm{~b}\right)$. Les autres épingles de type Wollmesheim locales, provenant de deux tombes à incinération de Colmar et de Durrenentzen (Zumstein, 1966, $\mathrm{n}^{\text {os }} 62$ et 117), appartiennent à la variante III, caractérisée par une tête beaucoup plus globuleuse.

\section{Petit annelet en bronze (fig. 21, $n^{\circ} 16$ )}

Dans le carré $\mathrm{H} 1$, à $40 \mathrm{~cm}$ de profondeur, se trouvait un petit anneau de $2 \mathrm{~cm}$ de diamètre avec une section fortement aplatie. Sa patine différente de celle des autres objets hallstattiens du tertre permet de le considérer comme étranger à ce dernier. Par similitude avec des annelets trouvés au Hohlandsberg, il pourrait être attribué au Bronze final.

\section{Les bracelets en lignite}

\section{Les bracelets en lignite de la tombe 17}

Par leur taille, ces deux bracelets appartiennent au type "très haut" $(6,8$ à $10 \mathrm{~cm})$ de 0 . Rochna (1962). Le bracelet porté au bras droit (fig. 21, no 9 ), irrégulier, possède une hauteur variant de $7 \mathrm{~cm}$ à $7,8 \mathrm{~cm}$ et un diamètre intérieur de $6 \mathrm{~cm}$; le bracelet découvert au bras gauche (fig. 21, $n^{\circ} 7$ ) haut de $7,3 \mathrm{~cm}$ pour un diamètre de $5,7 \mathrm{~cm}$, particulièrement mal lissé à l'intérieur, présente une cassure et des perforations remplies d'une matière organique 
(ficelle?). Ces perforations correspondant à des réparations sont relativement fréquentes, ainsi qu'en témoignent d'autres découvertes locales à Eguisheim (Naue, 1905, p. 361) et à Seltz (Schneider, 1981).

$\mathrm{Si}$ le type "très haut" est particulièrement répandu en Suisse occidentale, il était rare en Allemagne du Sud-Ouest, jusqu'aux découvertes du Magdalenenberg à Villingen. Les seuls exemplaires semblables trouvés en Alsace proviennent d'Herrlisheim et de Maegstub et 0 . Rochna les isole car leur hauteur est supérieure à $8,5 \mathrm{~cm}$. Ils ne sont pas datés, car les premiers sont des trouvailles anciennes dont les circonstances sont inconnues (Naue, 1905, p. 373) et celui de Maegstub, tm 14, VII est isolé (Schaeffer, 1930, fig. 147).

Ces bracelets apparaissent à partir du début du $\mathrm{Ha}$ D1, ainsi que l'attestent les tombes 10,96 et 120 du Magdalenenberg. D'après 0 . Rochna, les bracelets trouvés en Suisse ne seraient pas antérieurs à la fin du Ha D1, et certains seraient même du Ha D2 ; mais les associations sont souvent douteuses et aucune trouvaille récente ne confirme une perduration au Ha D2.

\section{Les bracelets en lignite de la tombe 18 (fig. $21, n^{o s} 10$ et 11)}

Les deux bracelets en lignite appartiennent au type "haut" $(6$ à $6,7 \mathrm{~cm})$ de 0 . Rochna par leur hauteur de 6,1 et $6,7 \mathrm{~cm}$. Ce type formerait un petit groupe cohérent centré dans le sud du Jura souabe, entre la Bavière et le lac de Constance. Selon son invenlaire, les exemplaires plus occidentaux sont rares : deux bracelets en Suisse et deux bracelets en Alsace (Herrlisheim et Bischoffsheim). O. Rochna date ce groupe du Ha D2, sans preuve tangible. Le bracelet de Riedwihr, associé à une agrafe en fer bien datée du $\mathrm{Ha}$ D1, atteste l'apparition de ce type dès cette phase et pose peut-être le problème de la validité d'une séparation entre les groupes "très hauts" et "hauts».

\section{Les céramiques}

Le tertre de Colmar-Riedwihr I a fourni un nombre important de céramiques. Si certaines constituaient le mobilier de tombes, d'autres ont été trouvées sans contexte funéraire, ou alors étaient liées au fossé.

\section{Les poteries isolées}

Il s'agit de deux urnes hautes trouvées en E4 et J5 et d'une urne basse en $\mathrm{H} 2$ (fig. 23). Les tessons recueillis en $\mathrm{E} 4$ ont permis de remonter la moitié de l'urne, mais le reste avait disparu. C'est l'exempletype d'un vase incomplet provenant d'une tombe dispersée. En revanche, la poterie trouvée en $\mathbf{J 5}$ (à proximité de la tombe 18 , mais à un niveau nettement supérieur) est pratiquement complète. Les tessons de cette urne étaient étalés sur une surface en plan incliné (entre +9 et 0 ). Il paraît fort probable que ce vase a été placé sur le rebord de la fosse de la tombe 18 (niveau - 21), d'une façon assez semblable à ce qui a été observé pour la tombe 20. Dans cette hypothèse, il ne s'agirait plus d'une poterie isolée.

L'urne basse recueillie en $\mathrm{H} 2$ pose un problème différent. Écrasée sur place, elle a pu être intégralement reconstituée. Située presque au même niveau que la tombe 4 (niveau +20 ), elle se trouve cependant à 1,80 $\mathrm{m}$ du poignard, ce qui ne permet pas de l'attribuer à cette tombe. Comme aucune autre sépulture ne se trouve à proximité, il doit s'agir cette fois d'une poterie vraiment isolée, dont la finalité nous échappe.

\section{Les poteries des tombes (fig. 22)}

On a souvent considéré le passage du $\mathrm{Ha} \mathrm{C}$ au $\mathrm{Ha} \mathrm{D}$ comme une césure d'importance majeure, se traduisant par un changement des rites funéraires, lui-même reflet d'une transformation des structures sociales. $\mathrm{Au} \mathrm{Ha} \mathrm{C}$, les tertres contiennent une tombe centrale importante, quelquefois avec une longue épée de bronze ou de fer, d'autres fois avec une abondante céramique richement décorée (style AlbSalem). $\Lambda \mathrm{u} \mathrm{Ha} \mathrm{D,} \mathrm{les} \mathrm{tertres} \mathrm{contiennent} \mathrm{beaucoup}$ plus de tombes, le mobilier est presque exclusivement métallique et les rares céramiques possèdent souvent déjà des formes évoluées (Zürn, 1943).

Ces affirmations doivent être modulées à la lumière des découvertes récentes. Plus de la moitié des 120 tombes du Magdalenenberg ont livré des poteries et l'abondance des céramiques trouvées à Riedwihr s'intègre bien dans ce schéma. D'autre part, la majorité des formes se situe nettement dans la continuité du $\mathrm{Ha} \mathrm{C}$.

Les urnes hautes (tombe 16,20 et carré J5) dérivent des modèles antérieurs, avec des proportions plus trapues, une panse plus sphérique et. un diamètre du col plus large. L'urne de la tombe 20 (fig. 22, no 8 ) a encore un fond très étroit par rapport à son diamètre maximum. Il est intéressant de constater que l'urne de la tombe 16 (fig. 22 , no 12 ) reproduit exactement la forme et les dimensions de l'urne trouvée en $\mathbf{J 5}$ (fig. 23), supposée précédemment appartenir à la tombe 18. Ces deux sépultures, voisines et rigoureusement parallèles, auraient ainsi un lien supplémentaire. 


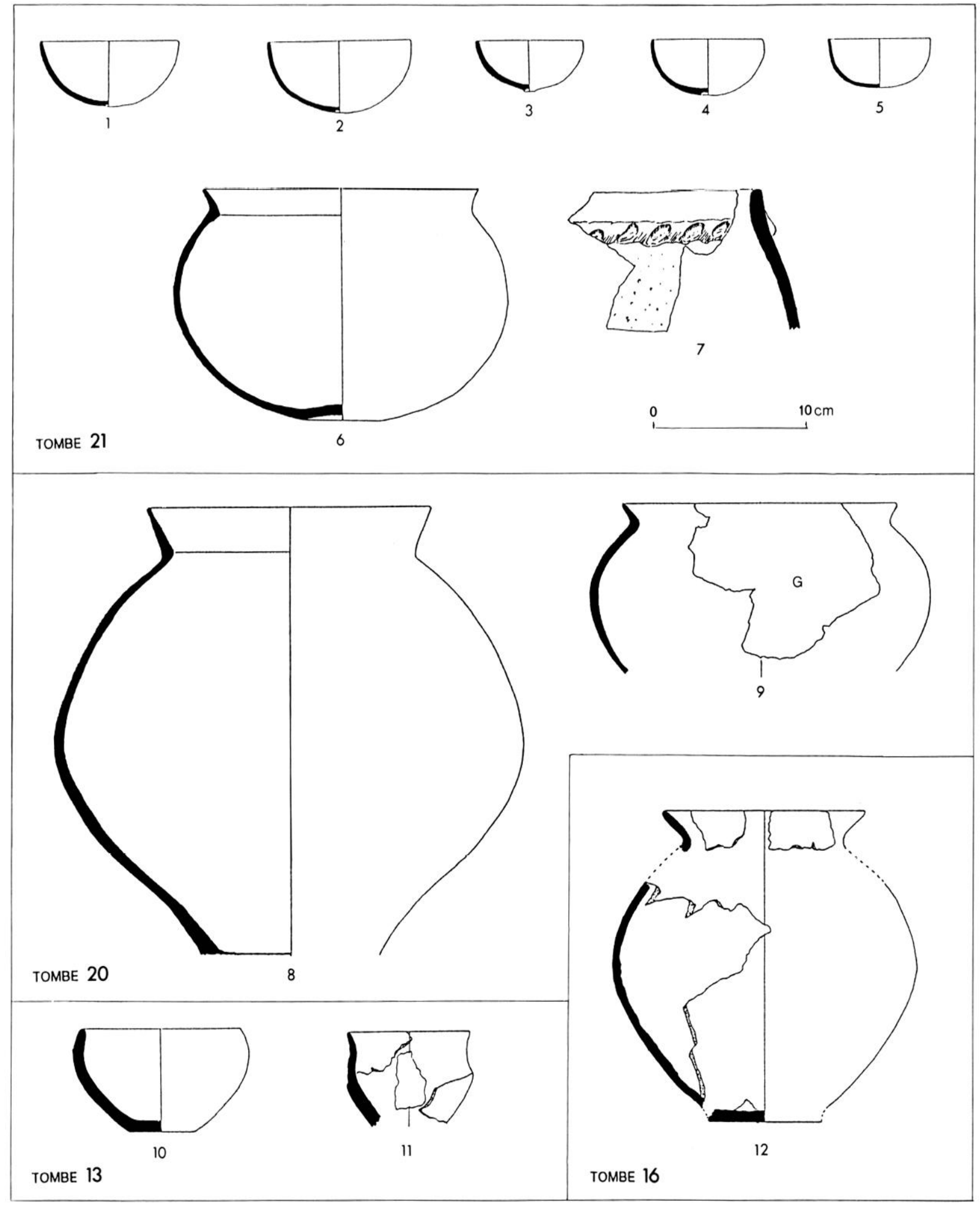

Fig. 22 - Tombes $13,16,20$ et 21 : mobilier céramique.

Les urnes basses (tombes 20 et 21 , fig. $22, n^{\text {os }} 9$ et 6) sont bien connues régionalement, aussi bien dans des sépultures que dans des habitats. Si les modèles les plus anciens apparaissent dès la fin du $\mathrm{Ha} \mathrm{C}$ à Appenwihr III avec une longue épée de fer
(Jehl, Bonnet, 1958), ils caractérisent surtout le Ha D1. Les urnes des tombes 5 et 6 de Colmar-Nord appartiennent à cette phase (Plouin, 1987). Constatons que les deux tombes concernées par ce type de poterie sont proches et presque parallèles, quoique 


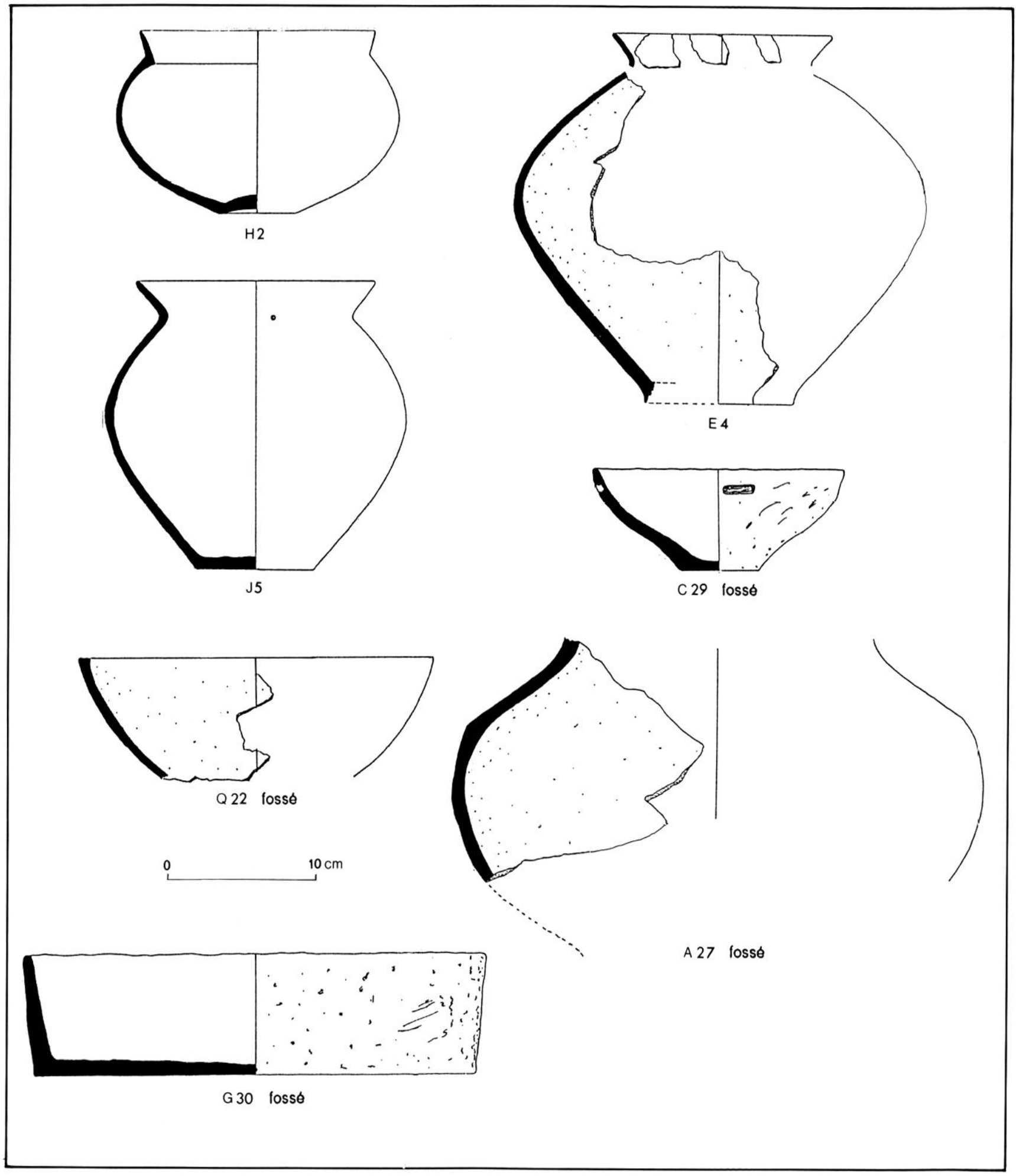

Fig. 23 - Mobilier céramique isolé.

situées à des niveaux différents. Ce schéma, reproduisant celui des tombes 16 et 18, permet peut-être de supposer une relation privilégiée entre les deux tombes.

La tombe 21 contenait également cinq coupelles (fig. $22, \mathrm{n}^{\text {os }} 1$ à 5 ) à fond arrondi, souligné pour quatre d'entre elles par une minuscule cupule qui n'est visible qu'extérieurement. Une seule des coupelles est graphitée $\left(n^{0} 1\right)$. Si les coupelles font fréquemment partie du mobilier funéraire hallstattien, 
elles sont difficiles à attribuer à une phase précise. Elles apparaissent localement dès le $\mathrm{Ha} \mathrm{C}$, par exemple dans la grande fosse du tertre VII d'Appenwihr, datée par une urne à épaulement et col tronconique peinte et graphitée (Bonnet, Plouin, Lambach, 1981). Elles existent encore au Ha Dl, dans certaines tombes de Sainte-Croix-en-Plaine, où elles sont associées à des bracelets à cannelures longitudinales (Plouin, Kœnig, 1990).

Cette mème tombe a livré aussi des fragments de céramique très grossière (fig. $22, \mathrm{n}^{0} 7$ ) appartenant vraisemblablement à un seul vase, caractérisée par un dégraissant composé de chamotte et de grains de quartz. Sous la lèvre, un cordon digité rapporté permet d'assimiler ce vase à une grande jarre à provisions, dont le type est bien connu dans les habitats du Hallstatt D (Colmar-Sud). La présence, dans une sépulture, de tessons appartenant à de la céramique grossière pose problème.

Les poteries placées aux pieds de l'enfant de la tombe 13 se distinguent des formes précédentes. Un petit bol (fig. 22, $\mathrm{n}^{\circ} 10$ ) en pâte épaisse à dégraissant très fin est caractérisé par un bord fortement rentrant. Quelques tessons appartiennent à un petit gobelet (fig. $22, \mathrm{n}^{\circ} 11$ ) en pâte bien lissée, à panse carénée et à col galbé terminé par une lèvre légèrement éversée. Si ce type de gobelet apparaît dès le Ha Dl (Magdalenenberg, t. 81), il perdure ensuite; une forme proche, à col cependant plus haut, a été récemment trouvée dans l'habitat de Geispolsheim (Bas-Rhin), bien daté du Hallstatt D2 (Kœnig, Legendre, 1989).

\section{Les céramiques du fossé}

Si des tessons isolés ont été retrouvés dans tout l'enclos circulaire, seul le secteur ouest (dont le rôle particulier a déjà été souligné) a livré deux céramiques, déposées sur le fond du fossé (C29 et G30).

La petite jatte découverte au niveau -35 , à fond plat extérieurement et en cuvette intérieurement, à profil sinueux, terminée par une lèvre arrondie, présente une finition très grossière. Sous la lèvre, à l'extérieur, une petite encoche horizontale et rectangulaire a été effectuée avant cuisson; s'agit-il d'une empreinte accidentelle? Si ce n'est pas le cas, sa destination reste problématique (fig. 23, C29).

L'ècuelle trouvée sur le fond du fossé, au niveau -40 , possède des parois presque verticales, terminées par une lèvre arrondie. La pâte, peu cuite, contient beaucoup de dégraissant composé de grains de quartz et de chamotte. Sur le fond est imprimée une intéressante empreinte de vannerie. Ce type de céramique, trop rare, ne permet pas de commentaire (fig. 23, G30).
Quelques tessons provenant de A27 (fig. 23) appartiennent à la partie médiane d'une urne (niveau - 34) dont les caractéristiques (large épaulement aplati se poursuivant par l'amorce d'un haut col tronconique) permettent d'envisager une datation assez tardive. Une urne de ce type était associée à Wintzenheim avec une fibule à timbale et ressort bilatéral du Ha D2 (Bonnet, Plouin, 1979, fig. 9).

Enfin, à proximité du bord externe du fossé (niveau - 11) se trouvaient deux tessons appartenant à une jatte à lèvre aplatie, bien lissée intérieurement et plus rugueuse extérieurement (fig. 23, Q22).

\section{LES RITES ET LES PRATIQUES FUNÉRAIRES}

Les données dont nous disposons actuellement pour l'Alsace sont extrêmement réduites, car la plupart des nécropoles sont installées sur des terrains acides, peu propices à la conservation des restes humains. Aussi, malgré le nombre important de fouilles de tumulus, spécialement au début du siècle en forêt de Haguenau, le nombre de tombes utilisables pour l'étude des rites est extrêmement faible. A Riedwihr, l'état des squelettes est loin d'être satisfaisant, surtout pour les tombes superficielles, mais il permet néanmoins quelques observations.

\section{L'orientation des tombes (fig. 6)}

Pour les tombes périphériques, la disposition tangentielle au fossé prédomine manifestement sur une éventuelle orientation selon les points cardinaux. Ce type d'organisation est très largement attesté dans le domaine hallstattien occidental depuis que les fouilles ne se bornent plus à la zone centrale des tertres. Si l'exemple du Magdalenenberg, où 127 tombes organisées sur plusieurs rangées encerclent la chambre funéraire centrale, est le plus connu (Spindler, 1971-1980), bien d'autres peuvent être cités, aussi bien en France de l'Est à Bresseysur-Tille (Ratel, 1977) qu'en Allemagne du SudOuest à Böblingen (Zürn, 1979) et à Deisslingen (Oeftiger, 1984b).

L'orientation selon les points cardinaux ne prend son sens que pour la tombe centralc. Pour tous les cas attestés en Allemagne du Sud-Ouest, les tombes centrales présumées masculines d'après la présence d'une arme, sont orientées tête au sud. La tombe centrale 4 de Riedwihr se démarque de cette coutume car elle est orientée tête à l'est.

\section{Les modes d'inhumation}

\section{Les cercueils en bois}

De nombreuses fouilles récentes ont prouvé 
l'existence de cercueils en bois en Alsace dès la période hallstattienne, à Colmar-Nord (Bonnet, 1972) et à Nordhouse.

A Riedwihr, des cercueils en bois sont attestés dans toutes les tombes profondes $(16,17,18,20,22$, 26). L'absence de traces de bois dans les sépultures superficielles ne permet cependant pas de conclure à l'absence de cercueil.

Dans deux cas (16 et 20), ces cercueils étaient visiblement constitués de planches assemblées; les largeurs des quatre autres sépultures permettent d'envisager le même type de cercueil. Celui de la tombe 16 mesurait environ $205 \mathrm{~cm}$ pour une largeur de $50 \mathrm{~cm}$ et celui de la tombe 17 environ $200 \mathrm{~cm}$ sur $63 \mathrm{~cm}$. Ils sont donc larges et relativement longs (c'est aussi le cas du cercueil de la tombe 18 dont la limite supérieure était située à plus de $20 \mathrm{~cm}$ en arrière du crâne).

Rappelons enfin la position du corps de la tombe 4 qui pourrait s'expliquer par l'existence d'un cercueil monoxyle. L'utilisation de ce type de cercueil, mentionnée déjà par R. Ratel (1977), est bien attestée par les fouilles récentes de Nordhouse (Plouin el alii, 1989).

\section{Les sépultures en pleine terre}

Une seule sépulture en pleine terre a pu être mise en évidence. Il s'agit de la tombe 5 , où le sujet est assis sur le côté droit. On peut supposer que, dans ce cas, le mode d'inhumation en pleine terre est lié à celte position très particulière. Si l'existence d'autres sépultures en plcine terre n'a pu être observée, la pauvreté des restes humains conservés et les multiples remaniements ne permettent pas de préciser, dans bon nombre de cas, le mode d'inhumation et engagent à une certaine réserve.

\section{Les types d'inhumation}

\section{Tombes en décubitus dorsal}

La position en décubitus dorsal, position la plus fréquente à l'époque hallstattienne dans tout le domaine nord-alpin, est largement prédominante à Riedwihr I, où elle est attestée dans dix-sept sépultures $(1,2,3,11,12,13,16,17,18,20,21,22,23,24$, $25,26,27)$. Les positions respectives des jambes et des bras sont plus variables, mais l'absence de constantes et la conservation partielle de nombreuses sépultures ne permettent pas d'interpréter ces positions.

\section{Autres types d'inhumation}

Parmi les neuf autres tombes en place, la posi- tion de cinq sujets reste indéterminée pour des raisons de conservation $(4,8,10,14,28)$.

Quatre sépultures s'individualisent très nettement. Le sujet de la tombe 9 repose sur le côté droit, position assez souvent attestée à l'époque hallstattienne et observée récemment dans une tombe de Werbach dans le Wurtemberg. A cette occasion, K. Wehrberger $(1984$, p. 164) a rappelé l'inventaire réalisé par L. Pauli en 1975, qu'il complète pour la vallée de la Tauber. Le sujet de la tombe 6 est couché sur le ventre, position également signalée déjà par L. Pauli (1975). La position du sujet de la tombe 5 , où la défunte est pratiquement assise sur le côté droit, le tronc rabattu sur les membres inférieurs, est tout à fait particulière et nous n'en connaissons pas d'équivalent. Enfin la tombe 7, avec le regroupement en fagot des os du membre supérieur gauche, est évoquée ci-dessous.

La signification de ces pratiques, impossible à appréhender pour l'instant, est sans doute très différente de celle de l'inhumation en décubitus dorsal, tout particulièrement pour les tombes 5 et 7 . Les sépultures évoquées ci-dessus sont toutes celles d'adultes, mais elles ne contenaient aucun mobilier funéraire et seul le sexe du sujet de la tombe 5 a pu être déterminé.

\section{L'inhumation triple (tombe 20)}

L'existence de tombes contenant plus d'un individu correspond à une pratique bien connue à la période hallstattienne dans tout le domaine nordalpin. Il s'agit le plus souvent d'inhumation double, associant deux adultes ou alors un adulte et un enfant. La tombe 20 de Riedwihr contenait un homme et deux très jeunes enfants; elle s'oppose à l'association classique femme-enfant, souvent citee, mais qu'il serait nécessaire de prouver par une analyse anthropologique.

\section{Les pratiques particulières}

Rappelons d'abord la disposition visiblement intentionnelle des grands os longs des membres inférieurs autour de la tombe 20 . On retrouve cette même disposition pour le fémur isolé trouvé en H24, le long de la tombe 26.

Le remaniement de la tombe 7 , d'après les données de l'anthropologie de terrain, a été effectué avant le colmatage complet de la sépulture, donc peu après son dépôt. Le caractère très superficiel de la tombe (niveau +12 ) et la pauvreté des restes humains conservés ne permettent aucune conclusion formelle. On ne peut cependant exclure un remanie- 
ment intentionnel, d'autant qu'il ne semble pas correspondre à la mise en place au voisinage d'une autre tombe contemporaine. Il est encore difficile d'apprécier les divers cas signalés en plusieurs endroits de l'Allemagne du Sud-Ouest, cas généralement désignés, malgré leur diversité, sous la dénomination globale de "sépultures en deux temps" (Zürn, 1987; Pauli, 1975; Torbrugge, 1979). Même si l'on élimine, surtout dans les fouilles anciennes, les cas douteux où l'observation a été trop hâtive et ceux entachés d'idées préconçues, il reste suffisamment d'exemples pour prouver l'authenticité de pratiques funéraires dont nous ne pouvons expliquer ni les modalités, ni la raison d'être.

\section{L'ORGANISATION INTERNE DU TERTRE (fig. 24)}

L'observation de l'agencement des tombes débouche sur un certain nombre de constatations qui semblent souvent contradictoires.

On peut d'une part souligner l'organisation rigoureuse des très nombreuses tombes hallstattiennes regroupées dans un espace restreint de $133 \mathrm{~m}^{2}$. Une seule tombe remanie visiblement une sépulture de la même époque (membre inférieur droit de la tombe 6 par la tombe 5). La disposition des tombes en couronnes, séparées par des intervalles à peu près réguliers, souligne que l'emplacement des sépultures était connu de tous et sans doute même visible.

D'autre part, il faut mettre l'accent sur le grand nombre de restes humains dispersés et de sépultures incomplètes (conservation différentielle mise à part) ou remaniées. Ces remaniements appartiennent soit à la couche superficielle, soit aux couches profondes et ne semblent pas occasionnés par les mêmes causes.

\section{Les remaniements superficiels}

Les tombes remaniées $(1,2,3,8,10,15,25,28)$ et la plupart des restes humains isolés (cf. tabl. III, p. 51) proviennent de la couche superficielle (jusqu'à $40 \mathrm{~cm}$ de profondeur). Pratiquement toutes les tombes superficielles de la zone centrale ont été perturbées, à l'exception de la tombe au poignard.

Nous expliquons ce fait par l'implantation à des époques récentes de pavillons de chasse installés au sommet du tertre, qui, malgré sa hauteur médiocre, restait à l'abri des inondations. En effet, jusqu'à $40 \mathrm{~cm}$ de profondeur, et uniquement dans la zone centrale, nous avons recueilli un abondant matériel non protohistorique. Il s'agit principalement de tessons de céramique, dont: le tiers se situe typologique- ment de la fin du $\mathrm{Xv}^{\mathrm{e}}$ au $\mathrm{Xvi}^{\mathrm{e}}$ s., le reste aux $\mathrm{Xvili}^{\mathrm{e}}$ et $\mathrm{XIX}^{\mathrm{e}} \mathrm{s}$. (la lacune au Xvir ${ }^{\mathrm{e}}$ s. est normale en Alsace, à cause de la guerre de 30 ans et de ses séquelles). Il existe aussi de nombreux objets en fer : couteaux, clous, hachoir, fers à cheval et surtout une dague du $\mathrm{xVIII}^{\mathrm{e}}-\mathrm{XIX}^{\mathrm{e}} \mathrm{s}$. de $70 \mathrm{~cm}$ de longueur, pliée deux fois à angle droit, comme si la lame avait été pliée de force autour d'un poteau vertical. Précisons qu'en bordure et en dehors du tertre, on ne trouve plus aucun vestige de cette époque.

Seule cette succession de constructions au même endroit peut expliquer à la fois les tombes remaniées et la protection de la tombe au poignard. L'idée de pavillon de chasse est confortée par l'examen de la carte allemande antérieure à 1914, montrant encore six emplacements semblables dans le Ried environnant (sur le tertre même, il n'en existe plus à cette époque).

\section{Les remaniements profonds et leur interprétation}

Les restes humains retrouwés dans les couches plus profondes ne peuvent pas être rattachés à l'explication précédente et posent un problème différent. Certains d'entre eux sont visiblement disposés de façon intentionnel le autour des tombes 20 et 26 et doivent appartenir à des tombes plus anciennes.

\section{Existence d'un tertre primitif}

En effet, sans être formels, plusieurs éléments militent pour l'existence d'un tertre antérieur à l'occupation hallstattienne :

- parmi les trois fragments de bronze associés aux quelques os remaniés de la tombe 19 , deux appartiennent très vraisemblablement à des bracelets du Bronze moyen. Ils prouvent donc une occupation du site dès; cette phase précoce;

- à l'ouest, la nappe ale gravier extraite de la fosse possède une limite orientale pratiquement rectiligne, démontrant l'existence d'un obstacle à cet endroit;

- la position de lla tombe 4 , à proximité du centre, l'importance de son mobilier (poignard) et sa contemporanéité avec les tombes profondes $(16,17$, 18,20 et 22) en font sans conteste ia sépulture centrale du tertre hallstattien. Mais sa' situation très superficielle est paradoxale car ce typ.e de sépulture est généralement situé au niveau du paléosol, parfois même dans une fosse plus ou moins profonde. On peut donc envisager qu'elle a été dépos'ée dans la partie supérieure d'un tertre préexistant.

Ces trois données suggèrent l'existerice d'un petit tertre daté du Bronze moyen, auquel on peut attribuer les restes humains des couches profondes. 
Fig. $24-$

Plan général du tumulus.

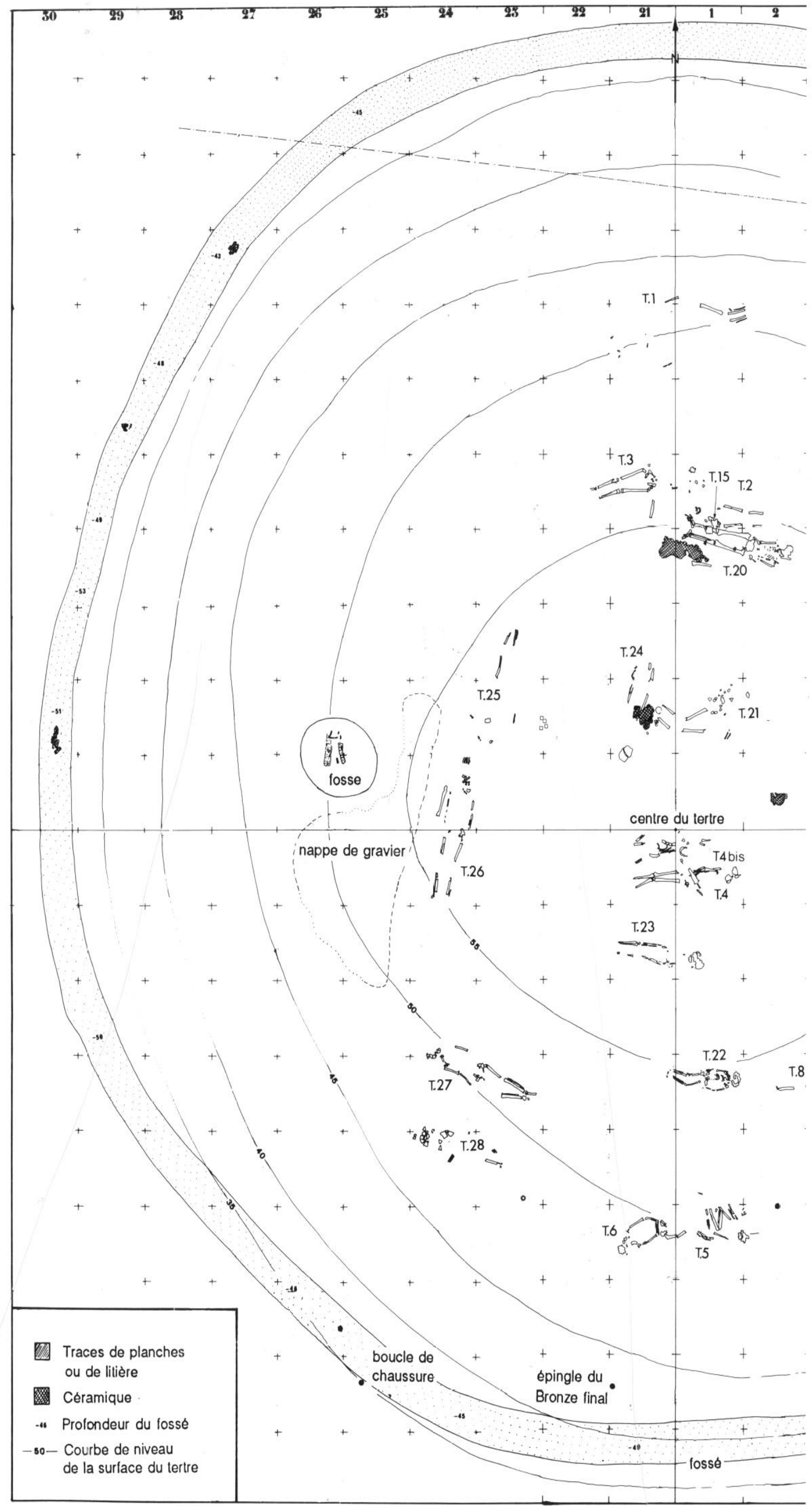




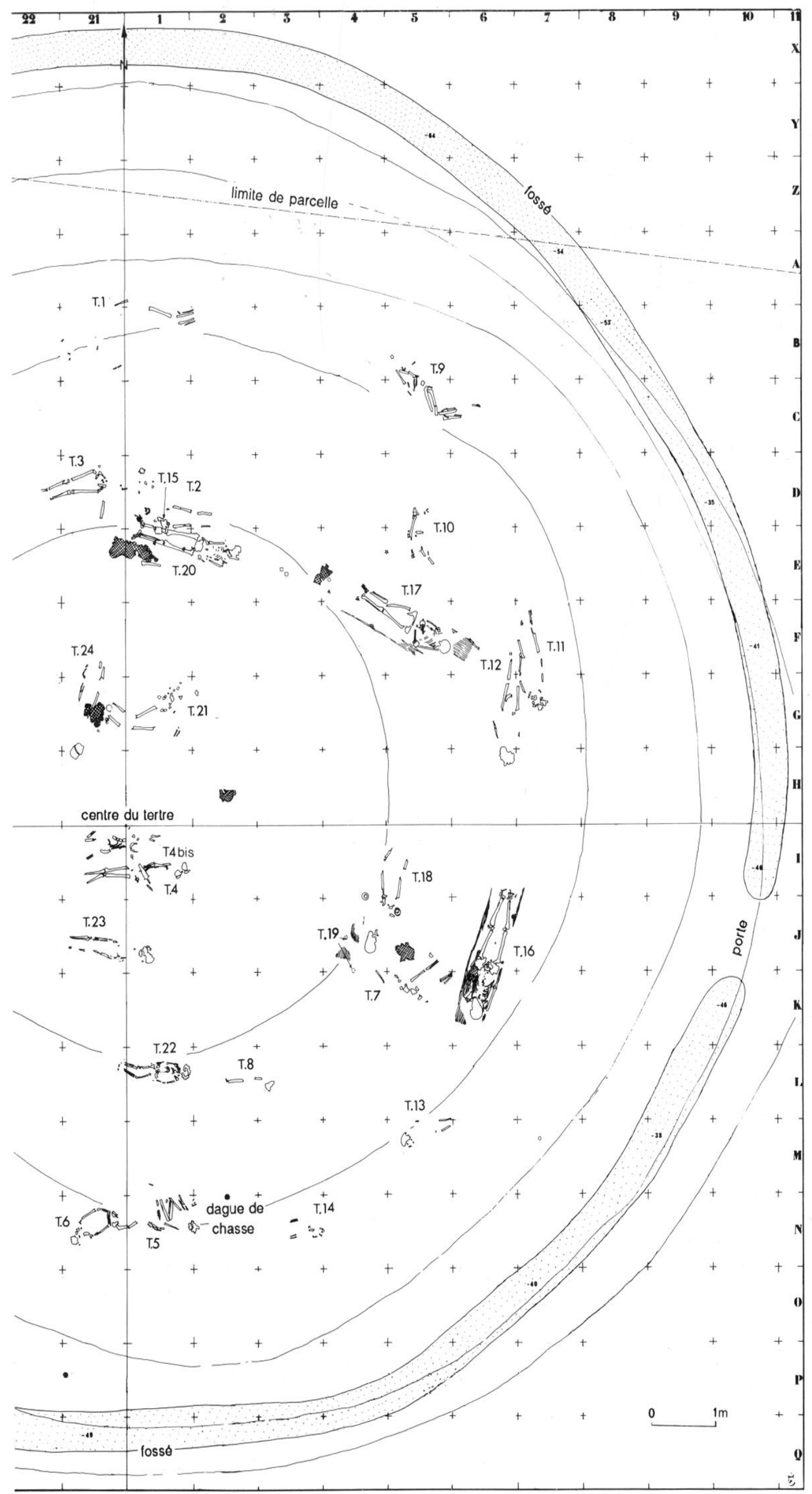




\section{Le' niveau horizontal $(-10 /-15 \mathrm{~cm})$}

Nous pensons que le remaniement des tombes du Bronze moyen pourraient s'expliquer par l'existence d'un niveau à peu près horizontal compris entre --10 et $-16 \mathrm{~cm}$, comme le confirment diverses constatations :

- à l'ou'est, les graviers extraits de la fosse sont étalés sur un terrain manifestement aplani, attesté par l'horizontalité de la nappe, au niveau -10 ;

- au nord, les restes humains bordant la tombe 20 et la grande urne de cette sépulture sont situés au niveau -15 . La fosse de la tombe 20 ne peut donc avoir été creusée qu'en terrain plat, avant édification du tertre dans ses dimensions actuelles;

- à l'est, les restes remainiés de la tombe 19 ont été retrouvés au niveau -16 , à côté de la tombe 18 . A proximité, la fosse de la tombe 16 et le substrat qui en a été extrait, sont apparents à partir du niveau -14 .

Seul un décapage circulaire au niveau $-10 /$ -16 , entamant largement le tertre primitif mais préservant son noyau central, permet d'expliquer à la fois la concordance des mesures précédentes et le remaniement des tombes "anciennes". Lors du décapage du tertre du Bronze moyen, les restes humains de ces sépultures auraient alors été partiellement récupérés et replacés dans certains cas autour des tombes hallstattiennes. Cette disposition intentionnelle est manifeste pour la tombe 26 et encore davantage pour la tombe 20 .

\section{La disposition générale des tombes hallstattiennes}

\section{Disposition des sépultures dans le tertre} (fig. 6 et 24)

Si toutes les sépultures sont situées à l'intérieur de l'aire délimitée par le fossé, leur emplacement paraît obéir à certaines règles.

On constate que les sépultures évitent le tiers ouest, qui est curieusement vide. En revanche, c'est là que se trouve le "puits", à peu près à égale distance du centre du tertre et du bord externe du fossé, à l'opposé de la porte. Le tiers ouest du tertre semble donc constituer une zone réservée

En outre, aucune tombe n'empiète sur le fossé ou n'est située à sa proximité immédiate. Cette disposition crée un espace vide d'au moins $2 \mathrm{~m}$ de large, concentrique au fossé et s'élargissant un peu du côté est, au voisinage de la "porte». Quelle est la signification de cet espace? Est-il lié à l'existence de quelque obstacle (fossé, palissade ...) que l'homogénéité du sol ne nous a pas permis de déceler? Marque-t-il peut- être l'existence d'un passage permettant une circulation et l'accès au "puits" depuis la "porte"?

\section{Relations entre la tombe centrale et les tombes profondes}

A partir du noyau préservé du tertre du Bronze moyen, certaines données stratigraphiques permettent d'enitrevoir la chronologie de l'occupation.

A l'évidence, les sépultures profondes dont le mobilier est contemporain de la tombe 4 ont été disposées concentriquement autour d'elle suivant deux arcs de cercle. Le premier (encore situé dans le tertre du Bronze moyen) pourrait être représenté par les tombes 18 et 26,21 et 22 dont la situation est rigoureusement symétrique par rapport à la tombe 4 ; le second, situé à l'extérieur du tertre primitif restant, correspondrait aux tombes les plus profondes $(16,17$ et 20). Mais l'absence de preuves ne permet pas d'exclure d'autres associations. La position de la tombe 23 (indatable faute de mobilier) est plus difficile à intégrer dans cette organisation, mais il n'est pas impossible que ce soit une tombe intacte du tertre du Bronze moyen.

\section{Les tombes superficielles}

Dans un second temps, d'autres tombes auraient été déposées dans le tertre agrandi. Ces tombes sont presque toutes superficielles, à l'exception des tombes 12 et 13 , et sont situées entre les niveaux +7 et +16 . Nous constatons qu'aucune d'entre elles n'empiète sur la zone ouest, ce qui signifierait que cette zone était encore réservée et que le "puits» était toujours accessible et fonctionnel. Elles sont disposées en deux couronnes à peu près concentriques et probablement successives; la première pourrait comprendre les tombes $2,3,7,8,10,12,25$, 27 , la seconde les tombes $1,5,6,9,11,13,14,28$.

Quelques rares données stratigraphiques permettent d'étayer certaines hypothèses : la tombe 2 recouvre partiellement la tombe 20 , qui est donc plus ancienne; la tombe 11 repose en partie sur la tombe 12 , militant pour l'antériorité de la première couronne. La rareté du mobilier ne fournit que peu d'arguments supplémentaires, car tout le mobilier appartient à la même phase chronologique ( $\mathrm{Ha}$ Dl), à l'exception du fragment de fibule à ressort bilatéral bien daté du Ha D2, mais dont l'appartenance à la tombe 2 n'est nullement assurée à cause des très nets remaniements du secteur où elle se trouve. Le gobelet caréné de la tombe 13 et le bracelet de la tombe 28 pourraient aussi appartenir au début de cette phase plus récente. 


\section{CONCLUSIONS}

\section{Les caractéristiques du tertre}

Le grand nombre de tombes contenues dans le tertre I de Riedwihr étonne de prime abord. La plupart des tertres d'Alsace paraissent beaucoup moins densément occupés, si l'on excepte celui de Hilsenheim, qui a livré une quarantaine de tombes (Heintz, 1949) et quelques rares tumulus de Haguenau (Königsbruck 14 et Ohlungen 3: Schaeffer, 1930). Mais ce constat doit être modulé, car les conditions pédologiques souvent défavorables à la conservation des ossements occultent généralement toutes les tombes dépourvues de mobilier. Or le tumulus I de Riedwihr, avec 15 tombes sans mobilier sur 28, prouve qu'elles peuvent être fort nombreuses.

L'homogénéité de la quasi-totalité du matériel archéologique du tertre est frappante. Le terminus post quem est fourni par la tombe centrale 4 dont le poignard est bien daté de la fin du Ha Dl (Sievers, 1982b : Egg, 1985̄b). D'après la sériation établie par H. Parzinger (1986b) à partir du matériel du Magdalenenberg, cette datation est cohérente avec celle de la fibule à navicelle (tombe 22); elle correspond aussi à celle des urnes basses des tombes 20 et 21 et à celle des bracelets en lignite de type haut des tombes 17 et 18 .

La tombe 12 (rasoir et pointes de flèches), qui semble appartenir à la première couronne périphérique, mais qui est plus profonde que les autres sépultures de cette couronne, est contemporaine des tombes de la première phase du tertre. La tombe 13 appartenant à la seconde couronne, a livré un gobelet proche d'un modèle du Magdalenenberg. Seule la tombe 2 , datée par le fragment de petit axe de ressort de fibule en bronze, appartient avec certitude au Ha D2. L'absence de mobilier dans toutes les autres tombes superficielles de la seconde couronne périphérique rend difficile tout essai de datation, mais rien ne permet d'affirmer que l'occupation se soit prolongée.

Si l'on ne tient compte que des tombes bien datées, la durée d'occupation du tertre hallstattien de Riedwihr est donc très réduite, car elle ne recouvre que la seconde phase du $\mathrm{Ha} \mathrm{Dl}$ et le début du Ha D2 (phases 2 et 3 de H. Parzinger, 1988). En chronologie absolue, elle débute vers la fin de la première moitié du $\mathrm{vI}^{e}$ s. et se termine avant 500 avant notre ère. Elle couvre donc deux générations seulement.

\section{La définition sociale du tertre}

Le sexe des défunts n’a pu être précisé que pour dix sépultures. Parmi elles, quatre sont sùrement masculines, deux autres probablement; deux tombes féminines seulement sont assurées et deux autres probables.

Parmi les sépultures en place, vingt et une appartiennent à des adultes, deux tombes sont peutêtre celles de grands adolescents. L'âge des défunts a pu être déterminé à sept reprises et toutes les classes d'âge adulte paraissent représentées. Aux trois tombes d'enfants $(13,14$ et 22$)$ il faut ajouter la sépulture 20 qui contenait les restes de deux enfants, ce qui donne un total de cinq enfants pour une population totale de 26 individus ( $20 \%$ ). Si l'on exclut d'éventuels problèmes de conservation différentielle et si l'on tient compte des données actuelles concernant la mortalité infantile des "populations anciennes", les enfants paraissent fortement sousreprésentés. Certaines classes d'âge font totalement défaut, les enfants décédés en période périnatale et les adolescents, le tertre n'ayant livré aucune sépulture de sujet âgé entre 10 et 18 ans. Au Magdalenenberg aussi, cette classe d'àge (entre 14 et 18 ans) est mal représentée : 4 tombes seulement sur 127 (Gallay, 1977, p. 106).

L'association de plusieurs hommes, femmes, enfants, la qualité du mobilier funéraire et la très brève durée d'occupation du tertre (deux à trois générations au maximum) permettent de tirer quelques conclusions sur la définition sociale du tertre.

Le poignard de la tombe centrale signale incontestablement une sépulture importante, occupée par un personnage dont le rôle de chef ne fait aucun doute. En revanche, il est paradoxal de constater la pauvreté des autres ensembles correspondants à cette première phase d'occupation : dans les tombes riches contemporaines (forêt de Haguenau, Magdalenenberg, etc.), il est fréquent de trouver au moins quatre à cinq catégories d'objets différents, parfois même sept à huit pour des tombes particulièrement bien dotées. Ici, aucune tombe ne possède plus de deux catégories d'objets différents. On peut néanmoins souligner la rareté régionale de la plupart des objets : fibule à navicelle, bracelets en lignite hauts et très hauts, pointes de flèche. Cette rareté pourrait être un témoignage de l'importance de ces tombes, au-delà de leur pauvreté apparente.

Liè à la tombe d'un chef symbolisé par le poignard, ce tertre aurait été réservé à un groupe social de rang élevé. Quant à la durée d'occupation très courte, on peut l'expliquer soit par une mobilité géographique, soit par le fait que la prééminence sociale de ce groupe n'ait été qu'éphémère.

Charles Bonnet, Suzanne Plocin, François LaMbach 
Tableau I - Fosses comparables à celles de Riedwihr (S. Plouin).

\begin{tabular}{|c|c|c|c|c|c|c|c|}
\hline Sites & $\begin{array}{c}\text { Diamètre } \\
(\text { en } \mathrm{cm})\end{array}$ & Profondeur & Contenu & $\begin{array}{l}\text { Structure } \\
\text { circulaire } \\
\text { associée }\end{array}$ & $\begin{array}{c}\text { Position } \\
\text { par rapport } \\
\text { à cette } \\
\text { structure }\end{array}$ & $\begin{array}{c}\text { Position } \\
\text { par rapport } \\
\text { au centre } \\
\text { du tertre }\end{array}$ & $\begin{array}{c}\text { Orientation } \\
\text { de la } \\
\text { tombe } \\
\text { centrale }\end{array}$ \\
\hline Huttenheim .... & $120 / 150$ & 80 & $\begin{array}{l}\text { bois, débris } \\
\text { organiques }\end{array}$ & palissade & dehors & sud & sud \\
\hline Grosseibstadt ... & 100 & 30 & $\begin{array}{l}\text { ossements } \\
\text { animaux }\end{array}$ & fossé & dedans & nord & \\
\hline Riedwihr ...... & $75 / 100$ & 123 & $\begin{array}{l}\text { bois, ossements } \\
\text { animaux, } \\
\text { restes végétaux }\end{array}$ & fossé & dedans & ouest & est \\
\hline
\end{tabular}

Tableau II - Tableau synthétique des sépultures et de leur mobilier.

$1: 0$ an $; 2: 1-4$ ans $; 3: 5-9$ ans $; 4: 10-14$ ans; $5: 15-19$ ans $; 6: 20-22$ ans; $7: 23-40$ ans $; 8: 40-59$ ans $; 9: 60$ ans et plus. $\mathrm{A}=$ adulte d'âge indéterminé $; \mathrm{Ad}-\mathrm{A}=$ adolescent ou adulte d'àge indéterminé.

\begin{tabular}{|c|c|c|c|c|c|c|c|c|c|c|c|c|c|c|c|c|c|c|c|c|c|c|c|c|c|c|c|c|c|}
\hline & & 1 & 2 & 3 & $4 \mathrm{a}$ & $4 \mathrm{~b}$ & 5 & 6 & 7 & 8 & 9 & 10 & 11 & 12 & 13 & 14 & 15 & 16 & 17 & 18 & 19 & 20 & 21 & 22 & 23 & 24 & 25 & 26 & 27 \\
\hline \multirow{5}{*}{ 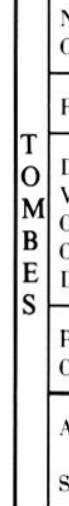 } & $\begin{array}{l}\text { Niveau } \ldots \ldots \ldots \ldots \ldots \\
\text { Orientation ............. }\end{array}$ & 7 & $\begin{array}{l}16 \\
0\end{array}$ & $\begin{array}{c}16 \\
\mathrm{E}\end{array}$ & $\begin{array}{c}19 \\
\mathrm{E}\end{array}$ & 19 & $\begin{array}{l}12 \\
\mathrm{SE}\end{array}$ & $\begin{array}{c}7 \\
\text { so }\end{array}$ & $\begin{array}{l}18 \\
\text { so }\end{array}$ & $\begin{array}{c}20 \\
0\end{array}$ & $\begin{array}{l}12 \\
\mathrm{NO}\end{array}$ & $\begin{array}{l}15 \\
\mathrm{~N}\end{array}$ & $\begin{array}{c}6 \\
\mathrm{SE}\end{array}$ & $\begin{array}{c}-3 \\
\mathrm{~s}\end{array}$ & $\begin{array}{l}-7 \\
\text { so }\end{array}$ & $\begin{array}{l}1 \\
\mathrm{E}\end{array}$ & 7 & $\begin{array}{l}-40 \\
\text { so }\end{array}$ & $\begin{array}{c}-32 \\
\mathrm{SE}\end{array}$ & $\begin{array}{c}-21 \\
\text { so }\end{array}$ & -16 & $\begin{array}{l}-30 \\
\mathrm{SE}\end{array}$ & $\begin{array}{c}-9 \\
\mathrm{E}\end{array}$ & $\begin{array}{c}-22 \\
\mathrm{E}\end{array}$ & $\begin{array}{c}-4 \\
\mathrm{E}\end{array}$ & $\begin{array}{c}3 \\
\text { so }\end{array}$ & $\begin{array}{l}11 \\
\text { so }\end{array}$ & $\begin{array}{c}-13 \\
\mathrm{NE}\end{array}$ & $\begin{array}{l}14 \\
\text { No }\end{array}$ \\
\hline & Remaniement ........ & + & + & + & & + & & + & + & + & & + & & & & + & + & & & & + & & + & & & & + & & \\
\hline & 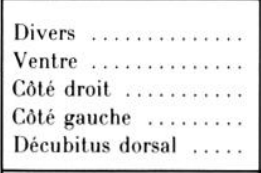 & + & + & & + & & + & + & & & + & & + & + & + & & & + & + & + & & + & + & + & + & & + & + & + \\
\hline & $\begin{array}{l}\text { Pleine terre } \ldots \ldots \ldots \ldots \\
\text { Cercueil } \ldots \ldots \ldots \ldots \ldots\end{array}$ & & & & $+?$ & & + & & + & & & & & & & & & + & + & + & & + & & + & & & & + & \\
\hline & $\begin{array}{l}\text { Age } \ldots \ldots \ldots \ldots \ldots \ldots \\
\text { Sexe } \ldots \ldots \ldots \ldots \ldots \ldots\end{array}$ & $\begin{array}{c}\text { Ad- } \\
\text { A }\end{array}$ & A & $\begin{array}{l}\mathrm{A} \\
\mathrm{H} ?\end{array}$ & A & A & A & A & $\begin{array}{l}\mathrm{A} \\
\mathrm{H} ?\end{array}$ & $\begin{array}{c}A d- \\
A\end{array}$ & A & A & A & $\begin{array}{l}9 \\
\mathrm{H}\end{array}$ & 3 & 3 & A & $\begin{array}{l}8 / 9 \\
\mathrm{H}\end{array}$ & $\begin{array}{l}7 \\
F\end{array}$ & $\begin{array}{l}\text { A } \\
\text { F? }\end{array}$ & 3 & $\begin{array}{c}6.3 .2 \\
\mathrm{H}\end{array}$ & A & 3 & $\begin{array}{c}8 / 9 \\
\mathrm{~F}\end{array}$ & $\begin{array}{l}\mathrm{A} \\
\mathrm{H}\end{array}$ & A & A & A \\
\hline & Datation $\ldots \ldots \ldots \ldots$ & & $\mathrm{D} 2 / 3$ & & D1 & & & & & & & & & DI & D & & & D1 & D1 & D1 & $\mathrm{Bm}$ & DI & D & DI & & & & & \\
\hline $\begin{array}{l}\mathrm{M} \\
\mathrm{O} \\
\mathrm{B} \\
\mathrm{I} \\
\mathrm{L} \\
\mathrm{I} \\
\mathrm{E} \\
\mathrm{R}\end{array}$ & 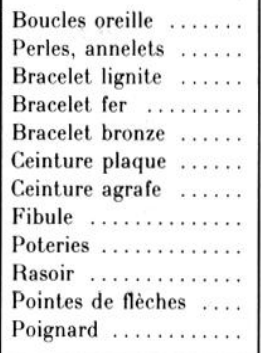 & & 1 & & 1 & & & & & & & & & $\begin{array}{c}1 \\
4 / 5\end{array}$ & 2 & & & 1 & $\begin{array}{l}2 \\
2\end{array}$ & 1 & 2 & 2 & 6 & 1 & & & & & \\
\hline
\end{tabular}


Tableau III - Inventaire des restes humains isolés (Fr. Lambach).

\begin{tabular}{|c|c|c|}
\hline CARRÉ & Niveau & IDENTIFICATION DES OS ISOLÉS \\
\hline D1 & -15 & 1 fémur gauche symétrique de celui du carré E1 (cf. T20) \\
\hline D5 & 0 & 1 diaphyse humérale gauche \\
\hline DE6 & +2 & 1 diaphyse fémorale (et 3 esquilles) \\
\hline D21 & -15 & 1 diaphyse tibiale droite (cf. T20) \\
\hline DE23 & +20 & 1 diaphyse fémorale droite grêle \\
\hline E1 & -30 & 1 fémur droit (cf. T20) \\
\hline E1 & -30 & 1 diaphyse de fibula (cf. T20) \\
\hline E2 & -30 & 1 patella gauche (cf. T20) \\
\hline E4 & 0 & 1 diaphyse tibiale gauche robuste \\
\hline $\mathrm{F} 6$ & +15 & radius et ulna droits (cf. T11) \\
\hline G2 & 0 & $\begin{array}{l}10 \text { fragments cràniens de petite taille dont: } \\
-2 \text { fragments du toit de l'orbite } \\
-2 \text { fragments d'occipital } \\
-1 \text { fragment de pariétal (gauche?) }\end{array}$ \\
\hline G2 & - & $\begin{array}{l}\text { - } 1 \text { fragment de mandibule portant les } 1^{\text {re }} \text { et } 2^{\text {e }} \text { molaires définitives droites } \\
\text { - } 1 \text { esquille crânienne }\end{array}$ \\
\hline G2 & +2 & 5 esquilles de diaphyse \\
\hline GH2 & +10 & 16 esquilles diaphysaires \\
\hline GH2 & +10 & $\begin{array}{l}\text { - } 4 \text { fragments de maxillaire dont un portant la seconde prémolaire et la } 1^{\text {re }} \text { molaire gauches } \\
\text { - os zygomatique gauche }\end{array}$ \\
\hline G21 & +15 & 1 fragment d'occipital \\
\hline $\mathrm{H} 4$ & - & 1 diaphyse humérale gauche \\
\hline $\mathrm{H} 24$ & +5 & 1 diaphyse humérale gauche \\
\hline H24 & -3 & 1 fémur gauche (cf. T26) \\
\hline HI1-21 & - & 1 crête tibiale \\
\hline I 2 & +35 & 1 fragment d'occipital \\
\hline I2 & 0 & 2 petits fragments de diaphyse \\
\hline I3 & +40 & $\begin{array}{l}\text { - } 1 \text { temporal gauche d'adulte (processus mastoïde) } \\
-2 \text { grands fragments de pariétal gauche }\end{array}$ \\
\hline I3-J3 & -5 & 1 petit fragment crânien (pariétal?) \\
\hline I6 & -20 & 1 diaphyse humérale droite \\
\hline $\mathrm{I} 23$ & +5 & 1 fragment d'occipital \\
\hline $\mathrm{I} 24$ & +15 & 1 diaphyse humérale droite vraisemblablement symétrique de celle de H24 \\
\hline $\mathrm{I} 25$ & +12 & 1 diaphyse tibiale gauche \\
\hline $\mathrm{J} 4$ & - & 1 petit fragment de diaphyse \\
\hline $\mathrm{J} 23$ & - & 1 fragment de diaphyse \\
\hline K22 & +20 & 1 diaphyse humérale droite \\
\hline L22 & +14 & 1 diaphyse tibiale gauche \\
\hline M1 & - & $\begin{array}{l}\text { dents isolées: } \\
\text { - } 1 \text { incisive inférieure, les molaires et la canine déciduales gauches } \\
\text { - la canine inférieure déciduale droite } \\
\text { - les germes des } 1{ }^{\text {res }} \text { molaires supérieure et inférieure et de la canine inférieure gauches ainsi que } \\
\text { celui d'une incisive centrale inférieure }\end{array}$ \\
\hline M7 & - & 3 petits fragments de diaphyse \\
\hline $\mathrm{N} 1$ & +15 & 1 fragment de diaphyse fémorale droite (et 3 esquilles) \\
\hline
\end{tabular}

Origine des illustrations :

C. Bonnet (fig. 1, 2, 3, 6, 18, 19, 21-24); Fr. Lambach (fig. 4, 5, 7-17, 24); S. Plouin (fig. 20); R.-M. Arbogast (fig. 25 et 26); A. Fontaine (fig. 19). 


\title{
ANNEXE I \\ La brebis du tumulus I de Riedwihr
}

\author{
par Rose-Marie ARBOGAST *
}

L'échantillon osseux relevé dans le tumulus I est constitué de 52 fragments. A une exception près, une canine inférieure de porc, ils sont tous attribuables au mouton (Ovis aries). Le contexte archéologique ainsi que les caratéristiques de cet échantillon, pourtant très faible numériquement, contribuent à l'intérêt de cette étude.

Les ossements ont bénéficié de bonnes conditions de conservation, ainsi que d'une fragmentation relativement restreinte. Des parties fragiles comme le corps d'une scapula (omoplate) n'ont pas été détruites par les agents physico-chimiques et certains ossements sont entiers.

La composition de l'échantillon est caractérisée par l'absence d'os des bas de pattes, d'éléments de la colonne vertébrale et du crâne. Seuls certains os longs et des fragments de côtes sont présents. L'étude de la distribution anatomique des parties présentes (fig. 25) permet d'y reconnaître les éléments des quatre pattes d'un seul individu. Aucune
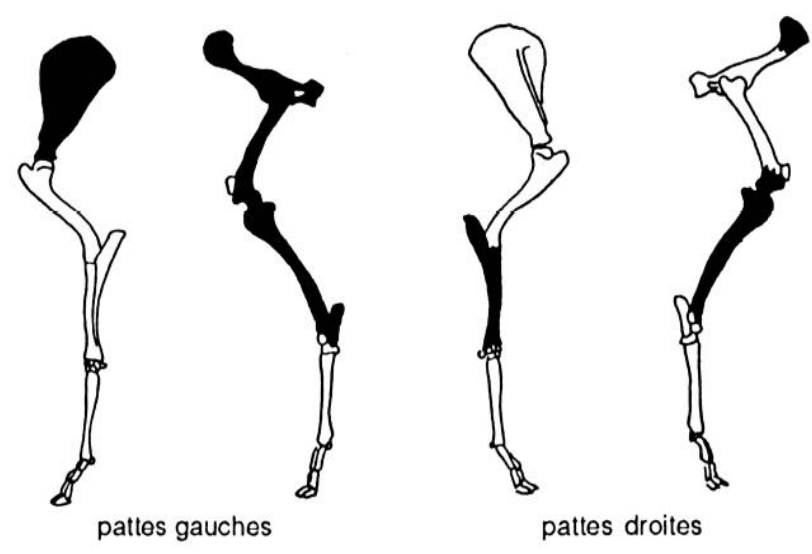

Fig. 25 - Schéma des parties présentes des ossements de la brebis. de ces pattes n'est complète. Des prélèvements d'os ont été effectués sur chacun des membres. Le radius et le talus droits (fig. 26) présentent des traces de découpe qu'il est possible d'attribuer au prélèvement des bas de pattes. La patte arrière droite est complète jusqu'au tarse (coxal, fémur, tibia, talus et calcanéum). L'absence de la rotule ainsi que des traces de découpe sur les os de la hanche (coxal et fémur) montrent que les os ont été désarticulés avant d'être déposés. La patte arrière gauche n'est représentée que par le tibia et des fragments de fémur et de coxal. La scapula gauche et le radio-ulna droit sont les seuls éléments du train antérieur. Sur la région proximale du radius, de fines incisions signalent la désarticulation du coude.

L'étude des parties permet d'effectuer des appariements entre pattes droite et gauche (tibia), de restituer la liaison articulaire entre tibia et une partie $\mathrm{du}$ tarse gauches, et d'effectuer des associations entre pattes antérieures et postérieures. Ces observations confirment que les vestiges osseux proviennent d'un seul et même individu. Ils ont été déposés simultanément après une désarticulation suivie d'une sélection des parties.

D'après les critères de diagnose sexuelle sur le bassin, il s'agit d'une brebis. L'état d'épiphysation des os longs indique un âge compris entre 36 et 42 mois. Les mesures sur les os longs (voir tabl. IV) permettent d'évaluer une hauteur au garrot de $58 \mathrm{~cm}$ environ (coefficients de Teichert).

\section{R.-M. A.}

* Centre régional d'archéologie du Val-d'Oise, 21, rue des Cordeliers, 60200 Compiègne. 

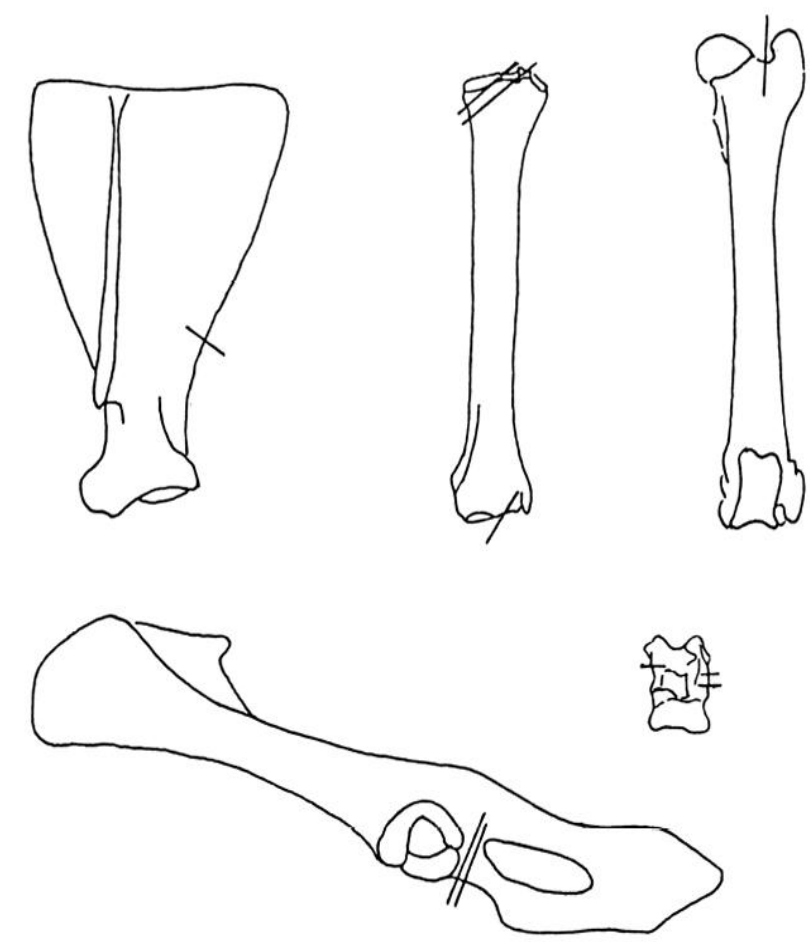

Fig. 26 - Localisation des traces de découpe.
Tableau IV - Mensurations des restes de mouton.

\begin{tabular}{|c|c|c|c|c|c|c|}
\hline & Dp & Dt & ColDP & ColDt & & \\
\hline \multirow[t]{2}{*}{ Scapula .... } & 31,2 & 21,4 & 16,5 & 9,5 & & \\
\hline & Lt & PDt & PDp & DiaDt & DDt & DDp \\
\hline Radius ...... & 144 & 27,2 & 13,5 & 14,0 & 25,5 & 18,0 \\
\hline Fémur ...... & & 39,7 & 17,0 & & & \\
\hline Tibia ....... & 192 & 36,0 & 35,5 & 12,5 & 23,0 & 17,0 \\
\hline Talus ....... & 25,5 & & & & 16,0 & \\
\hline Calcanéum .. & 49,0 & & & & & \\
\hline
\end{tabular}

\section{Inventaire des parties : mouton (poids des restes : $235 \mathrm{~g}$ )}

- 13 côtes et 25 éclats ;

- scapula gauche;

- radius droit, entier et épiphysé ;

- ulna droite, entière et épiphysée;

- coxal gauche de brebis, entier;

- illion droit;

- fémur gauche, manque le distum, proximum soudé ;

- fémur gauche, fragment d'articulation distale en cours de soudure;
- fémur droit, manque le proximum, distum en cours de soudure;

- un éclat de diaphyse de fémur;

- tibia droit, diaphyse cassée;

- tibia gauche, entier, distum soudé, proximum en cours de soudure;

- talus gauche;

- calcanéum gauche.

- une canine inférieure de truie. 


\section{ANNEXE II}

\section{Analyses palynologiques}

\section{par Hervé RICHARD*}

Tous les échantillons présentés ici ont été préparés grâce à une méthode physico-chimique faisant appel à une liqueur lourde : la solution de Thoulet, certains d'entre eux sont même passés deux fois sur cette solution. Malgré cela les résultats sont très décevants. Le matériel sporo-pollinique est mal conservé et le nombre de spores et de pollens comp- tés est trop faible pour proposer des conclusions sérieuses (tabl. V).

H. R.

* Laboratoire de chronoécologie de l'Est de la France, ERA 35, UPR 7557, Université de Besançon.

Tableau V - Analyses palynologiques (les résultats sont exprimés en nombre de pollens).

\begin{tabular}{|c|c|c|c|c|c|c|c|c|c|c|c|}
\hline & \multicolumn{4}{|c|}{$\mathrm{H} 26$} & \multirow{2}{*}{ P2 } & \multirow{2}{*}{ P3 } & \multirow{2}{*}{ P4 } & \multicolumn{4}{|c|}{ Strati B } \\
\hline & 10 & 20 & 30 & 40 & & & & 1 & 2 & 3 & 4 \\
\hline Abies $\ldots \ldots \ldots \ldots \ldots \ldots \ldots \ldots$ & - & - & 1 & - & 1 & 1 & 2 & - & 1 & 2 & - \\
\hline Alnus $\ldots \ldots \ldots \ldots \ldots \ldots \ldots$ & 1 & 3 & 8 & 4 & 3 & 1 & 4 & 2 & 12 & 8 & 11 \\
\hline Betula $\ldots \ldots \ldots \ldots \ldots \ldots \ldots$ & - & - & 1 & - & - & - & 1 & 1 & 1 & 1 & - \\
\hline Corylus ................... & 2 & 4 & - & 18 & 14 & 6 & 11 & 2 & 18 & 11 & 11 \\
\hline Fagus $\ldots \ldots \ldots \ldots \ldots \ldots \ldots$ & 1 & - & - & - & - & - & - & - & 2 & 1 & 3 \\
\hline Picea $\ldots \ldots \ldots \ldots \ldots \ldots \ldots$ & - & - & - & 1 & - & - & 1 & - & - & - & 1 \\
\hline Pinus $\ldots \ldots \ldots \ldots \ldots \ldots \ldots$ & 10 & 3 & 8 & 21 & 8 & 12 & 6 & 4 & 21 & 14 & 8 \\
\hline Quercus ................... & 1 & - & 3 & - & - & - & - & - & 1 & - & 2 \\
\hline Salix $\ldots \ldots \ldots \ldots \ldots \ldots$ & 1 & - & - & 一 & - & 1 & - & - & 1 & 1 & 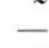 \\
\hline Tilia $\ldots \ldots \ldots \ldots \ldots \ldots$ & - & 1 & - & 2 & 1 & - & - & 1 & - & 1 & 1 \\
\hline Ulmus ................... & - & - & 1 & - & - & - & 一 & - & 1 & 一 & - \\
\hline A.P. $\ldots \ldots \ldots \ldots \ldots \ldots \ldots \ldots$ & 16 & 11 & 22 & 46 & 27 & 21 & 25 & 10 & 58 & 39 & 37 \\
\hline Graminées $\ldots \ldots \ldots \ldots \ldots \ldots$ & 4 & 2 & 4 & 14 & 1 & 3 & 2 & 2 & 4 & 14 & 18 \\
\hline Cypéracées $\ldots \ldots \ldots \ldots \ldots \ldots$ & 1 & 一 & 1 & 3 & 1 & 1 & 1 & 1 & 1 & 3 & 1 \\
\hline Céréales $\ldots \ldots \ldots \ldots \ldots \ldots$ & 1 & - & - & - & - & - & - & - & 1 & 2 & - \\
\hline Cichoriées $\ldots \ldots \ldots \ldots \ldots \ldots$ & 12 & 3 & 5 & 18 & 4 & 2 & 7 & 5 & 10 & 2 & 10 \\
\hline Chénopodiacées $\ldots \ldots \ldots \ldots \ldots$. & 8 & 1 & 2 & 9 & - & - & 3 & 2 & 4 & - & 1 \\
\hline Plantago lanc. $\ldots \ldots \ldots \ldots \ldots$ & - & 1 & - & 1 & - & 1 & - & - & 1 & 1 & 3 \\
\hline Artemisia $\ldots \ldots \ldots \ldots \ldots \ldots$ & 2 & - & 1 & 3 & - & - & - & - & 1 & 2 & 2 \\
\hline Anthémidées $\ldots \ldots \ldots \ldots \ldots$ & 1 & - & & - & 2 & 3 & 6 & 一 & - & 5 & 2 \\
\hline Géraniacées $\ldots \ldots \ldots \ldots \ldots \ldots$ & - & - & 1 & - & - & - & 5 & - & - & 2 & - \\
\hline Caryophyllacées $\ldots \ldots \ldots \ldots$ & - & 1 & - & 2 & 1 & - & - & - & - & - & 一 \\
\hline N.A.P. $\ldots \ldots \ldots \ldots \ldots \ldots \ldots$ & 29 & 8 & 14 & 50 & 9 & 10 & 24 & 10 & 22 & 31 & 37 \\
\hline Total $\ldots \ldots \ldots \ldots \ldots \ldots$ & 45 & 19 & 36 & 96 & 36 & 31 & 49 & 20 & 80 & 70 & 74 \\
\hline Monolètes $\ldots \ldots \ldots \ldots \ldots \ldots$. & 3 & - & 3 & 12 & 3 & - & 4 & 4 & 10 & 4 & 1 \\
\hline Polypodium vulg. ............ & - & - & 1 & 2 & - & - & 3 & - & 1 & - & 1 \\
\hline Indéterminés $\ldots \ldots \ldots \ldots \ldots$ & - & 4 & - & 3 & 5 & - & - & 3 & 1 & 2 & 6 \\
\hline
\end{tabular}




\section{BIBLIOGRAPHIE}

\section{Aufdermauer $\mathrm{J}$.}

1963: Ein Grabhügelfeld der Hallstattzeit bei Mauenheim, Badische Fundberichte, sonderheft 3, 45 p., $17 \mathrm{pl}$.

\section{Bonnet Ch.}

1972 : Compléments à la carte archéologique de la région de Colmar, Cahiers Alsaciens d'Archéologie, d'Art et d'Ilistoire, XVI, p. 57-74, 15 fig.

Bonnet Ch., Plouin S.

1979: Compléments à la carte archéologique du Haut-Rhin (région colmarienne), Cahiers Alsaciens d'Archéologie, d'Art el d'llistoire, XXII, p. 5-21.

Bonnet Ch., Lambach F., Plouin S.

1983 : De quelques sites gallo-romains haut-rhinois, Cahiers Alsaciens d'Archéologie, d'Art et d'Ilistoire, XXVI, p. 55-66, 6 fig.

Bonnet Ch., Plouin S., Lambach F.

1981 : Les tertres du Bronze Moyen d'Appenwihr, forêt de Kastenwald (Haut-Rhin), BSPF, 78, 10-12, p. 432-471, 10 fig., tabl.

Déchelette J.

1927: Manuel d'archéologie préhistorique, celtique et galloromaine, III, Premier âge du Fer ou époque de Hallstatt, Paris, 416 p., 384 fig., 8 pl., 1 carte.

Dehn R.

1985 : Ein Gräberfeld der Hallstattzeit von Dattingen, Stadt Müllheim, Kreis Breisgau-Hochschwartzwald, Archäologische Ausgrabungen in Baden-Württemberg, p. 96-98, 3 fig.

Der Keltenfürst von Hochdorf

1985 : Der Keltenfürst von Hochdorf, Katalog zur Austellung, Stuttgart, 512 p., ill.

\section{Drack W.}

1968-1969 : Die Gürtelhaken und Gürtelbleche der Hallstattzeit aus dem schweizerischen Mitteland und Jura, Jahrbuch der schweizerischen Gesellschaft für Ur- und Frühgeschichle, 54, p. 13-59, 22 fig., 10 pl., 4 cartes.

Duval A., Eluère C., Mohen J.-P.

1974 : Les fibules antérieures au $\mathrm{vI}^{\mathrm{e}}$ siècle avant notre ère trouvées en France, Gallia, 32, 1, p. 1-61, 29 fig.

\section{Egg M.}

1985a : Die hallstattzeitlichen Grabhügel vom Siedelberg in Oberösterreich, Jahrbuch des römisch-germanischen Zentralmuseums Mainz, 32, p. 265-322, 34 fig.

1985b: Die hallstattzeitlichen Hügelgräber bei HelpfauUttendorf in Oberösterreich, Jahrbuch des römisch-germanischen Zentralmuseums Mainz, 32, p. 323-393, 49 fig.

Engels H.-J.

1967: Die Hallstalt und Latènekultur in der Pfalz, Speyer, 122 p., 43 pl., 9 cartes.

Gallay G.

1977 : Die Körpergräber aus dem Magdalenenberg bei Villingen, in: Spindler K. (dir.), Magdalenenberg $V$, p. 79-112, 5 tabl.
Giffen E. van

1930 : Die Bauart der Einzelgräber, Leipzig, Mannus-Bibliothek, 44, vol. 1 : texte, 208 p.; vol. $2: 119$ pl.

Haffner A.

1986 : Buchbesprechungen, S. Sievers, Die Kleifunde der Heuneburg, Fundberichle aus Baden-Würllemberg, 11, p. 395-398.

Hatt J.-J.

1940-1946 : Une sépulture à inhumation du Hallstatt tardif dans un tumulus à Mussig, près Sèlestat, Cahiers d'Archéologie et d'Histoire d'Alsace, 121-127, p. 161-165, 2 pl.

Heintz G. F.

1949 : Les tertres funéraires celtiques de la "Willermatt" près IIilsenheim (Bas-Rhin), Cahiers d'Archéologie el d'IIistoire d'Alsace, 130, p. 53-66, 4 fig.

Hoffmann $\mathbf{H}$.

1940a: Die Stellung des Gräberfeldes von Datteln, Kr. Recklinghausen, im Rahmen der Kreisgrabenfriedhöfe, Germania, 24, p. 179-194, 5 fig., 2 cartes.

1940b : Vier Karten zur Kreisgrabenfrage, Westfälische Forschungen, 3, 2-3, p. 183-192, 4 cartes.

Jehl M., Bonnet Ch.

1954: Fouilles et découvertes faites dans les environs de Colmar, I, Le tumulus de Sundhoffen, Cahiers d'Archéologie et IIistoire d'Alsace, 134, p. 25-32, 3 fig., 1 pl.

1958 : Nouvelles trouvailles faites dans la région de Colmar, III, Les tertres du Kastenwald, Cahiers Alsaciens d'Archéologie, d'Art et d'Hisloire, II, p. 14-20, 7 fig.

Jockenhövel A.

1971: Die Rassiermesser in Mitteleuropa (Süddeutschland, Tchecoslovakei, Österreich, Schweiz), Prähistorische Bronzefunde, VIII, 1, Munich, 282 p., $82 \mathrm{pl}$.

Kilian-Dirlmeier I.

1970: Bemerkungen zur jüngeren Hallstattzeit im Elsass, Jahrbuch des römisch-germanischen Zentralmuseums Mainz,17, p. 84-93, 4 fig., 1 tabl.

1972: Die hallstattzeitlichen Gürtelbeche und Blechgürtel in Mitteleuropas, Prähistorische Bronzefunde, XII, 1, Munich, 147 p., $122 \mathrm{pl}$.

Kimmig W.

1965 : Zur Interpretation der Opferszene auf dem GundestrupKessel, Fundberichte aus Schwaben, 17, p. 135-143.

Kœnig M.-P., Legendre J.-P.

1989 : Le site de Geispolsheim "Bruechel " (Bas-Rhin), rapport de fouille, inédit.

Kossack G.

1970 : Gräberfeld der Hallstattzeit am Main und fränkischen Saale, Materialhefte zur Bayerische Urgeschichte, 24, Kallmünz,180 p., $138 \mathrm{pl}$.

Kubach W.

1977 : Die Nadeln in Hessen und Rheinhessen, Prähistorische Bronzefunde, XIII, 3, Munich, 636 p., $130 \mathrm{pl}$. 
Lagrand Ch., Thalmann J.-P.

1973 : Les habitats protohistoriques du Pègue (Drôme), Centre de documentation de la préhistoire alpine, 2, Grenoble, 159 p., 23 fig., $39 \mathrm{pl}$.

Lassère M., Legendre J.-P.

1987 : Les nécropoles de tumulus protohistoriques de la région d'Erstein (Bas-Rhin). Etude topographique et directions de recherches, Cahiers Alsaciens d'Archéologie, d'Art et d'Histoire, $\mathrm{XXX}$, p. 75-79, 2 fig.

Mansfeld G.

1973 : Die Fibeln der Heuneburg 1950-1970. Ein Beitrag zur Geschichte der Späthallstattfibel, Berlin, W. de Gruyter, 299 p., 33 fig., 21 pl., 13 cartes.

Masurel $\mathrm{H}$.

1984: Un problème de stratigraphie inhabituel : les couches de tissus enveloppant les éléments métalliques du char hallstattien d'Apremont (Haute-Saône), BSPF, 81, 9, p. 281-288, 13 fig.

\section{Naue A.W.}

1905 : Die Denkmäler der vorrömischen Metallzeit im Elsass, Strasbourg, R. Schultz, 529 p., $32 \mathrm{pl}$.

Nellissen H. E.

1975 : Hallstattzeilliche Funde aus Nord-Baden, Bonn, thèse dactyl.

1984 : $\mathrm{Zu}$ hallstattzeitlichen Befunden aus Huttenheim und Rheinsheim, Kreis Bruchsal, Fundberichte aus Baden-Württemberg, 1, p. 313-320, 2 fig.

Oeftiger C.

1984a: Mehrfachbestattungen im Westhallstattkreis. Zum Probleme der Totenfolge, Antiquitas Reihe, 3, 26, Bonn, 223 p., 10 fig., 2 cartes.

1984b : Hallstattzeitliche Grabhügel bei Deisslingen, $\mathrm{Kr}$. Rottweil, Fundberichte aus Baden-Württemberg, 9 p. 41-79, 30 fig.

\section{Parzinger $\mathrm{H}$.}

1986a : Zur Späthallstatt- und Frühlatènezeit in Nordwürttemberg, Fundberichte aus Baden-Würltemberg, 11, p. 231-258, 16 fig., 3 tabl., 1 annexe.

1986b : Zur Belegungsabfolge auf dem Magdalenenberg bei Villingen, Germania, 64, 2, p. 390-407, 8 fig., 1 tabl.

1988 : Chronologie der Späthallstatt- und Frühlatène-Zeit. Studien zu Fundgruppen zwischen Mosel und Save, Quellen und Forschungen zur prähistorischen und provinzialrömischen Archäologie, 4, Weinheim, 354 p., 174 pl.

Pauli L.

1975 : Kellischer Volksglaube. - Amulette und Sonderbestattungen am Dürrnberg bei Hallein und im eisenzeitlichen Mitteleuropa, Münchner Beitrage zur Vor- und Frühgeschichte, 28, Munich, $231 \mathrm{p}$.

Pétry F.

1984 : Informations archéologiques : Obenheim, Gallia, 42, 2, p. 261.

Plouin S.

1987 : Le tertre de Colmar-Nord. - A propos de la restauration d'une épingle en fer, Cahiers Alsaciens d'Archéologie, d'Art et Histoire, XXX, p. 81-89. 6 fig., 1 tabl.

Plouin S., Kœnig M.-P.

1990 : Les bracelets hallstattiens à cannelures longitudinales Témoignage d'une production artisanale originaire de la région de Colmar?, Annuaire de la Socièté d'histoire et d'archéologie de Colmar, p. 7-32, 9 fig.

Plouin S., Lambach F., Piningre J.-F., Bonnet Ch.

1986 : Un tertre à palissade : le tumulus 21 de Mussig (BasRhin), Revue Archéologique de l'Est el du Centre-Est, XXXVII, 1-2, p. 3-39, 21 fig.

Plouin S., Lambach F., Kœnig M.-P., Piningre J.-F.

1989: La nécropole tumulaire de Nordhouse, in: L'Alsace celtique. 20 ans de recherches, catalogue d'exposition, Musée d'Unterlinden, Colmar, p. 74-75, 2 fig.

Polenz H.

1973: Zu den Grabfunden der späthallstattzeit im RheinMain-Gebiet, Bericht des Römisch-Germanische Kommission, 54, p. 107-202, $70 \mathrm{pl}$.

Ratel R.

1977 : Un tumulus de l'Age de Fer à Bressey-sur-Tille (Côted'Or), $2^{\mathrm{e}}$ supplément à la Revue Archéologique de l'Est et du Centre-Est, 11-115 p., 47 pl.

Rehmet J.

1987 : Neues zur Kreisgrabenfrage, Opuscula, Festschrift Franz Fischer. Tübingen, p. 71-87, 3 fig.

Riek G., Hundt H. J.

1962 : Der Hohmichele, Ein Fürstengrabhügel der späten Hallstattzeit bei der Heuneburg, Heuneburgstudien I, RömischGermanische Forschungen, 25, 214 p., fig., $44 \mathrm{pl}$.

Rochna $\mathrm{O}$.

1962 : Hallstattzeitlichen Lignit und Gagat-Schmuck, Fundberichte aus Schwaben, NF 16, p. 44-83, 4 fig.

1977 : Die Sapropelit- und Gagatfunde vom Magdalenenberg, in: Spindler K. (dir.), Magdalenenberg VI, p. 11-26, 6 pl., 2 tabl.

Röder J.

1941 : Grabhügel der späten Urnenfelderkultur im Bendorfer Wald (Ldkr. Koblenz), Germania, 25, 4, p. 219-232, 4 fig., $1 \mathrm{dplt}, 1 \mathrm{pl}$.

Schaeffer C. F. A.

1930 : Les terires funéraires préhistoriques de la forêt de Haguenau, 2, Haguenau, 332 p., 30 pl., 191 fig.

Schermer $\mathrm{H}$.

1952 : Ein Beitrag zur Kreisgrabenfrage in Süd- und Südwestdeutschland, p. 139-146, 1 fig.

Schneider $\mathbf{M}$.

1981: Tumuli de l'âge du bronze et du Hallstatt entre Hatten et Seltz, Cahiers Alsaciens d'Archéologie, d'Art et d'Histoire, XXIV, p. 15-24, 6 fig.

\section{Schumacher A.}

1972, 1974: Die Hallstattzeil im südlichen IIessen, Bonner Hefte zur Vorgeschichte, Bonn, $n^{\circ} 5$ : texte et planches, 179 p., 35 pl., 5 cartes; n* 6 : catalogue, 200 p.

\section{Schwab H.}

1984 : Ein Späthallstatt- bis Frühlatènezeitlicher Bestattungsplatz in Murten-Löwenberg (Kt. Freiburg), Archäologisches Korrespondenzblatt, 14, 1, p. 71-79, 10 fig., 2 pl.

\section{Sievers S.}

1982a : Die Kleinfunde der Heuneburg. Die Funde aus den Grabungen von 1950-1979, Heuneburgstudien V, Mayence, $\mathrm{Ph}$. von Zabern, 2 vol., 256 p., 18 fig., 1 tabl., 250 pl.

1982b : Die mitteleuropäischen Hallstattdolche, Prähistorische Bronzefunde, VI, 6, Munich, 160 p., 49 pl. 
Spindler K.

1971-1980: Magdalenenberg. Der hallstattzeitliche Fürstengrabhügel bei Villingen im Schwarzwald, Villingen, 6 vol.

\section{Stieren A.}

1935 : Der Kreisgrabenfriedhof von Sölten, Kr. Recklinghausen, Bodenaltertümer Westfalen, 20, p. 247-266, 5 fig.

\section{Torbrugge W.}

1979 : Die Hallstattzeil in der Oberpfalz, Bayerische Landesamt für Denkmalpflege, Abteilung für Vor- und Frühgeschichte, 29.2 vol., 422 p., $186 \mathrm{pl}$.

\section{Wehrberger $\mathrm{K}$.}

1984 : Das hallstattzeitliche Gräberfeld von Werbach, Fundberichte aus Baden-Württemberg, 9, p. 81-221, 70 fig.

\section{Zumstein $\mathrm{H}$.}

1966: L'Age du Bronze dans le département du Haut-Rhin, Bonn, 172 p., 65 fig.

\section{Zürn H.}

1943 : Zur Keramik der späten Hallstattzeit, Germania, 27, 1, p. 20-35, 2 pl.

1970 : Hallstattforschungen in Nordwürttemberg. Die Grabhügel von Asperg, Ilirschlanden und Mühlacker, Veröffentlichungen des Staatlichen Amtes für Denkmalpflege, Stuttgart, Reihe A, 16, 128 p., 78 fig., 112 pl.

1979: Grabhügel bei Böblingen, Fundberichte aus BadenWürttemberg, 4, p. 54-117, 71 fig.

1987 : Hallstattzeitliche Grabfunde in Württemberg und Hohenzollern, Forschungen und Berichte zur vor und frühgeschichte in Baden-Württemberg, 25/1 et 25/2, Stuttgart, 1987, 2 vol., vol I : 247 p., 99 fig.; vol II : 505 pl. 